\title{
Temporary Losses of Highway Capacity and Impacts on Performance
}

May 2002

Prepared by

S. M. Chin

O. Franzese

D. L. Greene

H. L. Hwang

Oak Ridge National Laboratory

Oak Ridge, Tennessee

R. C. Gibson

The University of Tennessee

Knoxville, Tennessee 


\section{DOCUMENT AVAILABILITY}

Reports produced after January 1, 1996, are generally available free via the U.S. Department of Energy (DOE) Information Bridge:

Web site: http://www.osti.gov/bridge

Reports produced before January 1, 1996, may be purchased by members of the public from the following source:

National Technical Information Service

5285 Port Royal Road

Springfield, VA 22161

Telephone: 703-605-6000 (1-800-553-6847)

TDD: 703-487-4639

Fax: 703-605-6900

E-mail: info@ntis.fedworld.gov

Web site: http://www.ntis.gov/support/ordernowabout.htm

Reports are available to DOE employees, DOE contractors, Energy Technology Data Exchange (ETDE)

representatives, and International Nuclear Information System (INIS) representatives from the following source:

Office of Scientific and Technical Information

P.O. Box 62

Oak Ridge, TN 37831

Telephone: 865-576-8401

Fax: 865-576-5728

E-mail: reports@adonis.osti.gov

Web site: http://www.osti.gov/contact.html

This report was prepared as an account of work sponsored by an agency of the United States Government. Neither the United States government nor any agency thereof, nor any of their employees, makes any warranty, express or implied, or assumes any legal liability or responsibility for the accuracy, completeness, or usefulness of any information, apparatus, product, or process disclosed, or represents that its use would not infringe privately owned rights. Reference herein to any specific commercial product, process, or service by trade name, trademark, manufacturer, or otherwise, does not necessarily constitute or imply its endorsement, recommendation, or favoring by the United States Government or any agency thereof. The views and opinions of authors expressed herein do not necessarily state or reflect those of the United States Government or any agency thereof. 


\title{
TEMPORARY LOSSES OF HIGHWAY CAPACITY AND IMPACTS ON PERFORMANCE
}

\author{
S.M. Chin \\ O. Franzese \\ D.L. Greene \\ H.L. Hwang \\ Oak Ridge National Laboratory \\ R.C. Gibson \\ The University of Tennessee \\ National Transportation Research Center \\ 2360 Cherahala Boulevard \\ Knoxville, Tennessee 37932
}

May 2002

\author{
Prepared by \\ OAK RIDGE NATIONAL LABORATORY \\ P.O. Box 2008 \\ Oak Ridge, Tennessee 37831-6285 \\ managed by \\ UT-Battelle, LLC \\ for the \\ U.S. DEPARTMENT OF ENERGY \\ under contract DE-AC05-00OR22725
}




\section{TABLE OF CONTENTS}

Page

LIST OF FIGURES

V

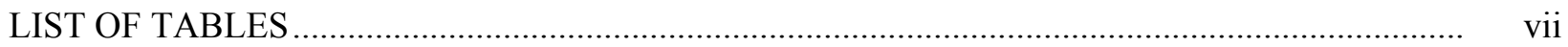

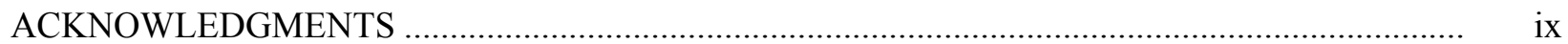

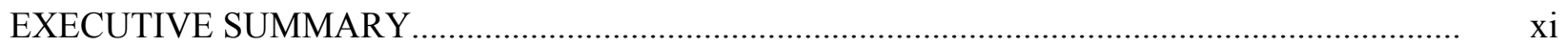

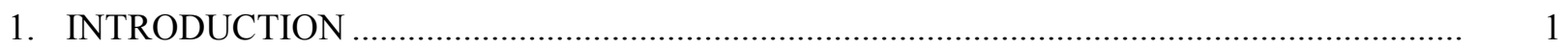

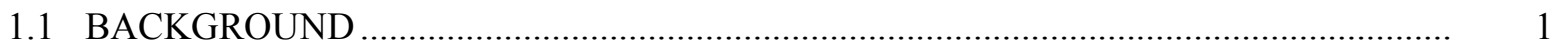

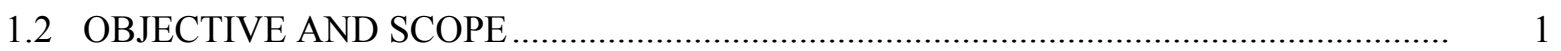

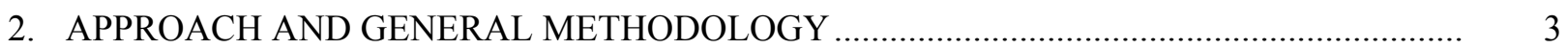

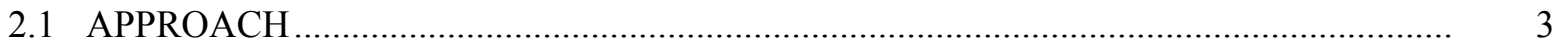

2.2 BASIC CONCEPTS OF CAPACITY, CAPACITY REDUCTION, AND DELAY .......... 4

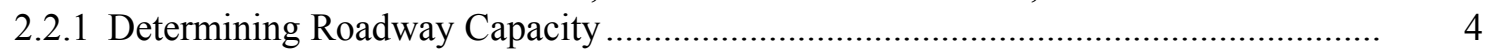

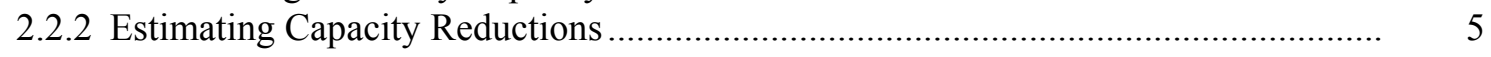

2.2.3 Estimating Delays for Localized Events ............................................................... 9

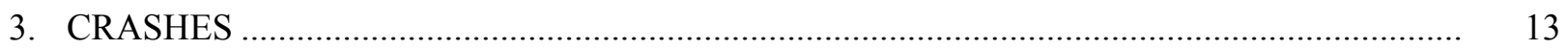

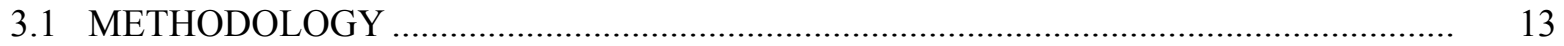

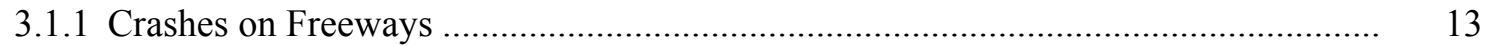

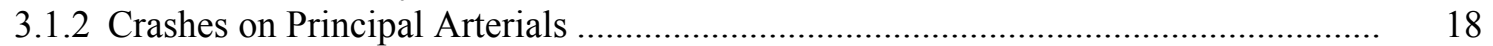

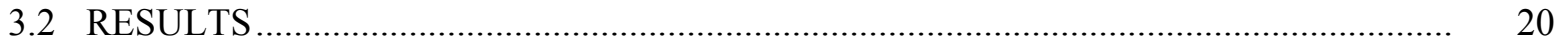

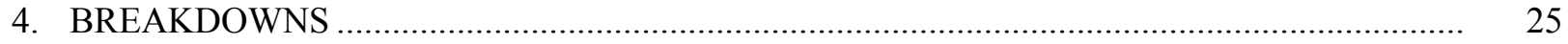

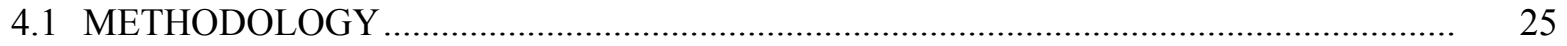

4.1.1 Estimating the Total Number of Breakdowns...................................................... 25

4.1.2 Assigning Each Breakdown to a Location in the Highway Network ....................... 26

4.1.3 Assigning Temporal Characteristics to Each Breakdown........................................ 26

4.1.4 Assigning Each Breakdown a Location within the Selected Link ............................. 26

4.1.5 Estimating Capacity Reduction....................................................................... 26

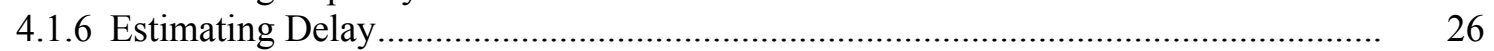

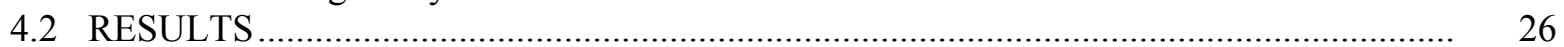

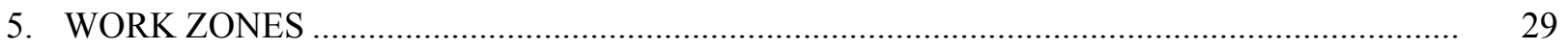

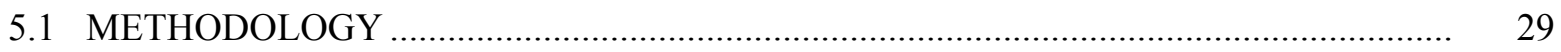

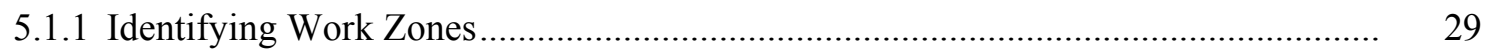

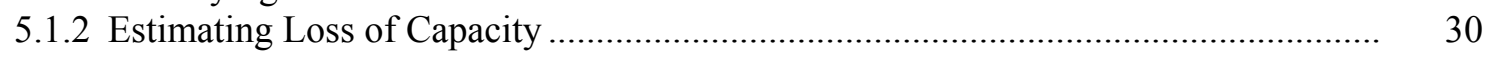

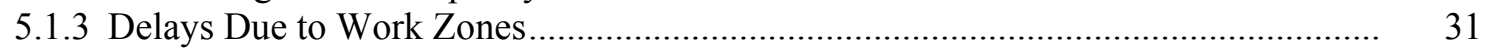

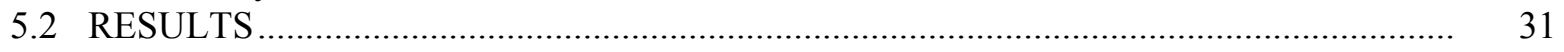

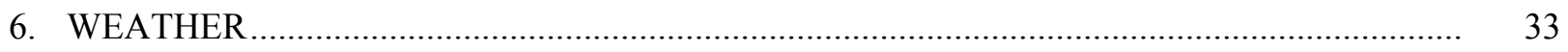

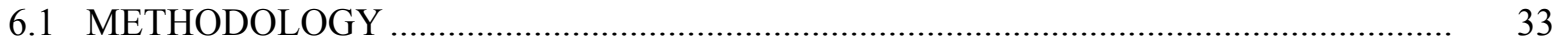

6.1.1 Identifying Adverse Weather Conditions .............................................................. 33

6.1.2 Mapping Adverse Weather Conditions to Highway Segments ................................ 35 


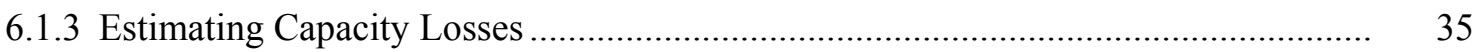

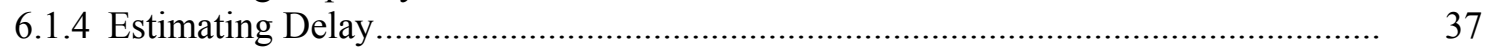

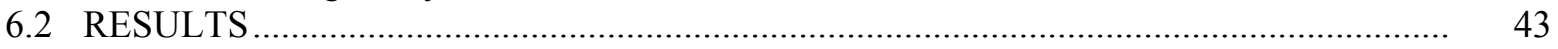

6.2.1 Capacity Losses \& Delay Due to Fog..................................................................... 44

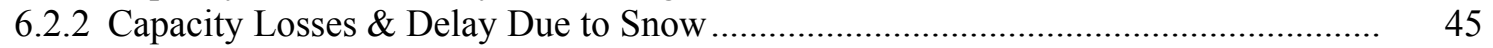

6.2.3 Capacity Losses \& Delay Due to Ice .................................................................. 45

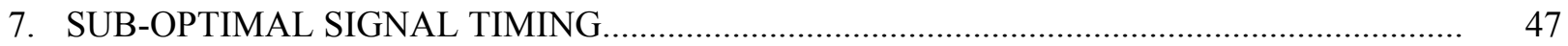

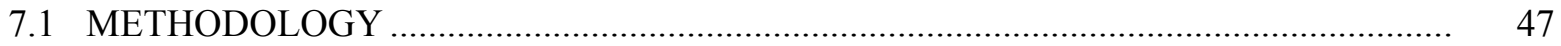

7.1.1 Identifying Signal-Controlled Intersections on Principal Arterials ........................... 47

7.1.2 Estimating Total Delay for Signal-Controlled Intersections....................................... 47

7.1.3 Typical Delay Associated with Inadequate Signal Timing ......................................... 49

7.1.4 Typical Capacity Loss Associated with Inadequate Signal Timing......................... 50

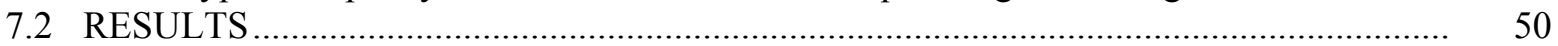

7.2.1 Delay Due to Sub-optimal Signal Control ........................................................ 50

7.2.2 Capacity Losses Due to Sub-optimal Signal Control.............................................. 50

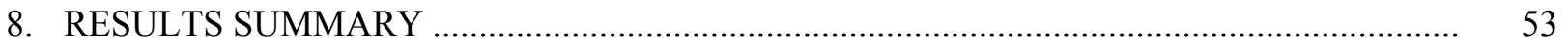

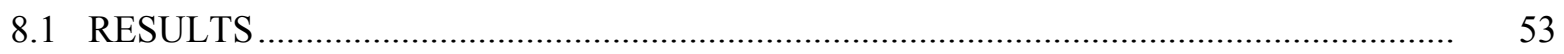

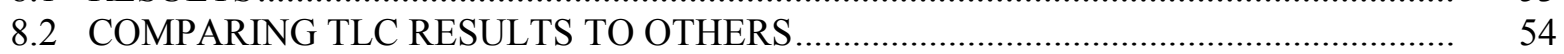

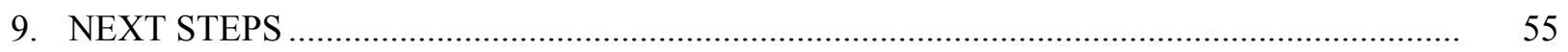

9.1 IMPROVE WORK ZONE ESTIMATES......................................................... 55

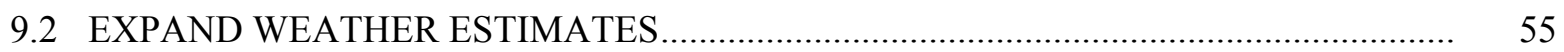

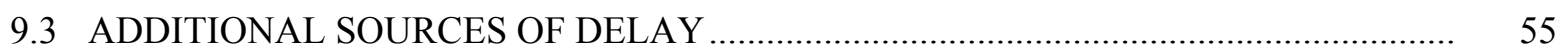

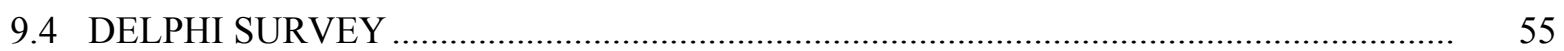

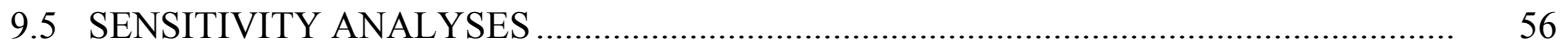

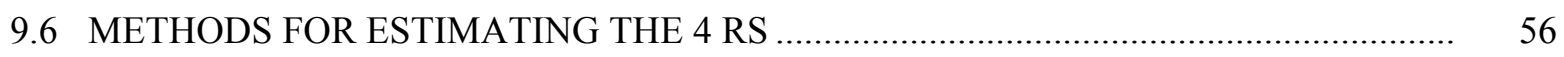

9.7 ASSESS POLICY AND TECHNOLOGY IMPACTS................................................. 56

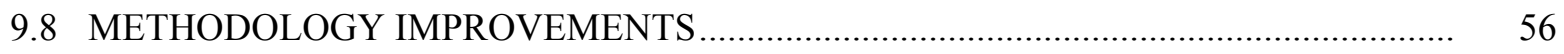

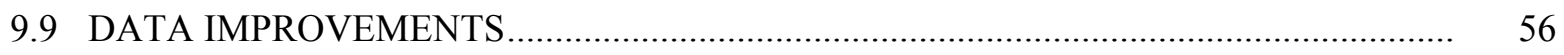

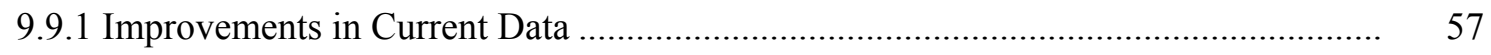

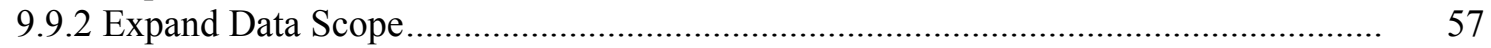

9.10 CONSIDER PUBLISHING TLC STUDY AS AN ANNUAL REPORT .......................... 57

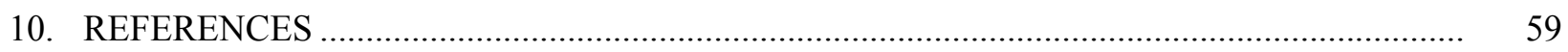




\section{LIST OF FIGURES}

Figure

Page

ES-1 Comparison of TLC and TTI delay estimates ......................................................... $\mathrm{x}$

ES-2 TLC Estimates of delay per licensed driver compared to TTI estimates ................... xi

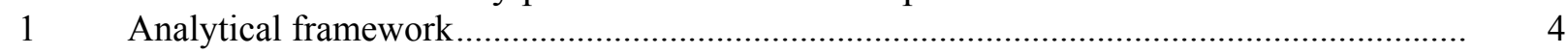

2 Flow rate vs. density for a highway segment with capacity $\mathrm{C}$ and a highway segment

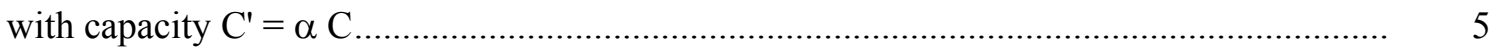

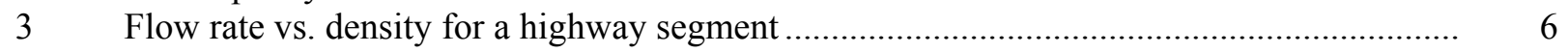

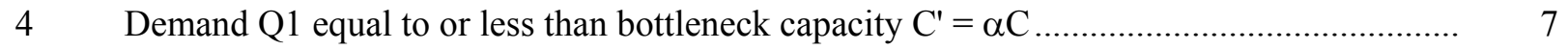

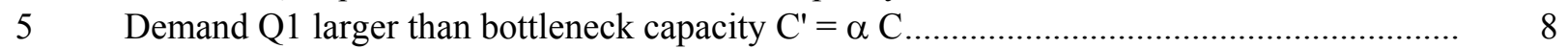

$6 \quad$ Cumulative flow vs. time for a highway bottleneck......................................................... 9

7 Cumulative flow vs. time for a highway bottleneck with demand and capacity varying

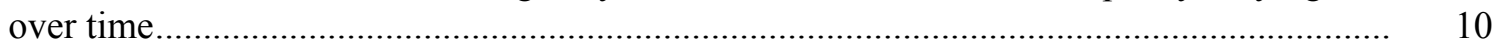

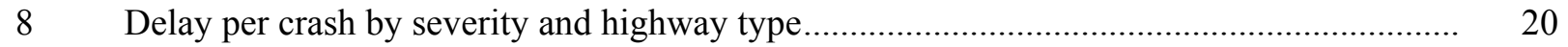

$9 \quad$ Crashes on principal arterials were more likely to cause bottleneck delays ....................... 21

10 Speed-flow relationships for various adverse weather conditions .................................... 37

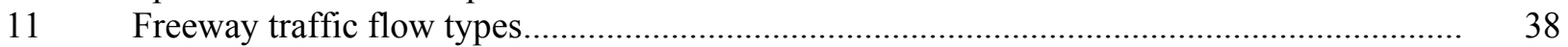

12 Speed-flow relationships for a typical basic freeway segment ......................................... 39

13 Speed relationship to volume/capacity ratio for basic freeway segment......................... 40

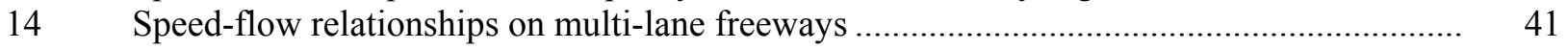

15 Speed relationship to volume/capacity ratio for multi-lane freeways ............................... 42

16 Most delay from adverse weather conditions was experienced in urban areas ................... 44

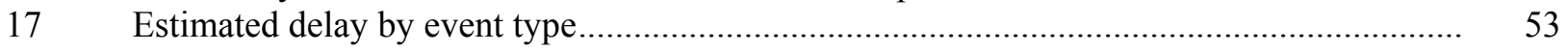

18 Comparison of TLC and TTI delay estimates …......................................................... 54 



\section{LIST OF TABLES}

ES-1 Summary of capacity loss and delay estimates for freeways and principal arterials............. $\mathrm{x}$

$1 \quad$ Capacity reduction due to freeway incidents ............................................................. 5

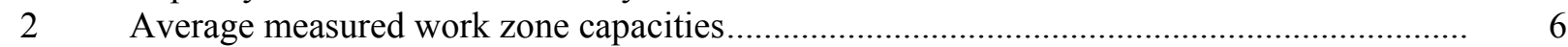

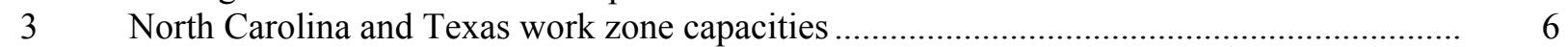

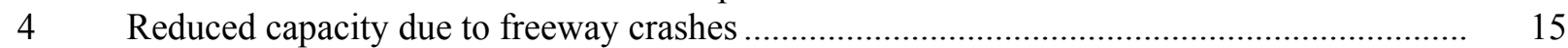

$5 \quad$ Probability of lane closures due to crashes and breakdowns ........................................... 16

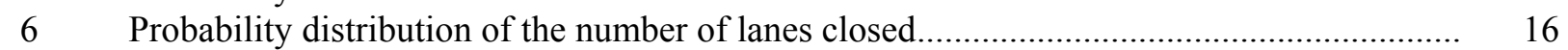

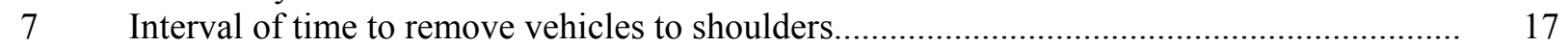

$8 \quad$ Estimated crash duration (in minutes): mean and standard deviation (SD) ....................... 18

$9 \quad$ Estimated crash duration (in minutes) ....................................................................... 18

10 Total estimated capacity reductions and delay due to fatal and non-fatal crashes on

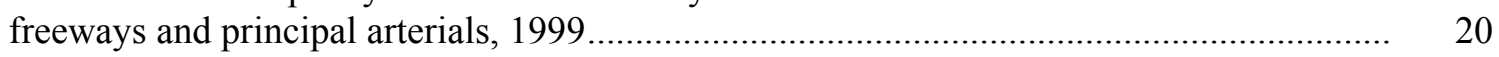

11 Total estimated capacity reductions and delay due to fatal and non-fatal crashes on freeways and principal arterials by time of day and whether or not the crash resulted in bottleneck delay, 1999

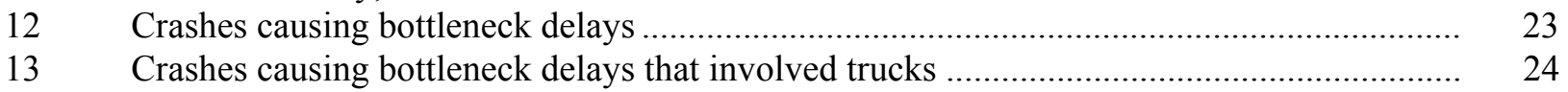

14 Total estimated capacity reductions and delay due to breakdowns on freeways and

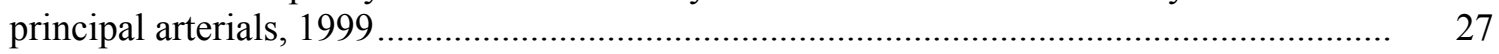

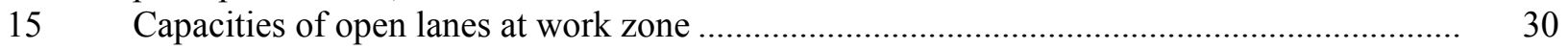

16 Probability distribution of the number of lanes closed in work zone area .......................... 31

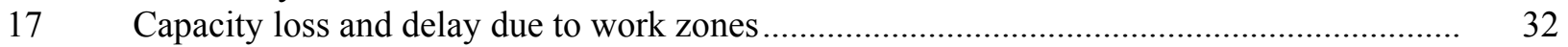

$18 \quad$ Comparison of work zone and fatal crash impacts........................................................ 32

$19 \quad$ Work zone mileage and bridgework by highway type.................................................... 32

$20 \quad$ National weather service weather event categories used in the study ............................... 34

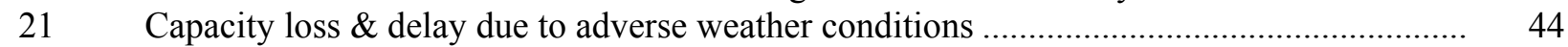

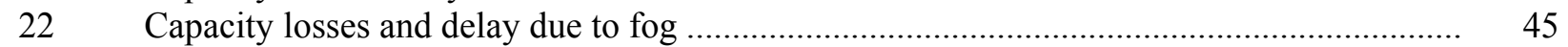

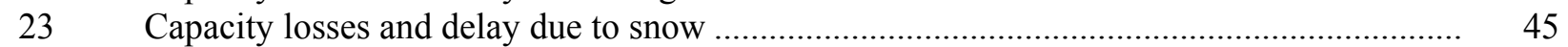

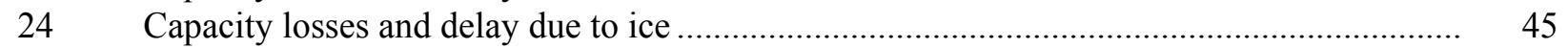

$25 \quad$ Number of signals on principal arterials nation-wide, 1999 ........................................... 50

26 Delay associated with sub-optimal signal control, 1999 _................................................. 50

27 Capacity loss on principal arterials due to sub-optimal signal control, 1999...................... 51

28 Summary of capacity loss and delay estimates for freeways and principal arterials............. 53 


\section{ACKNOWLEDGMENTS}

The authors gratefully acknowledge the support of the Operations Core Business Unit of the Federal Highway Administration, U.S. Department of Transportation. They also thank Dr. Rolf R. Schmitt, Mr. Vincent Pearce and Mr. Jeffrey Lindley for their guidance in the course of this work and review of

early drafts of this report. The authors, however, are solely responsible for any remaining deficiencies or errors. 


\section{EXECUTIVE SUMMARY}

\section{ES-1. BACKGROUND}

Traffic congestion and its impacts significantly affect the nation's economic performance and the public's quality of life. In most urban areas, travel demand routinely exceeds highway capacity during peak periods. In addition, events such as crashes, vehicle breakdowns, work zones, adverse weather, and suboptimal signal timing cause temporary capacity losses, often worsening the conditions on already congested highway networks. The impacts of these temporary capacity losses include delay, reduced mobility, and reduced reliability of the highway system. They can also cause drivers to re-route or reschedule trips.

Prior to this study, no nationwide estimates of temporary losses of highway capacity had been made by type of capacity-reducing event. Such information is vital to formulating sound public policies for the highway infrastructure and its operation. This study is an initial attempt to provide nationwide estimates of the capacity losses and delay caused by temporary capacity-reducing events.

\section{ES-2. OBJECTIVE AND SCOPE}

The Temporary Loss of Capacity (TLC) study develops estimates of highway capacity losses and delay caused by transitory events, such as construction work zones, crashes, breakdowns, extreme weather conditions, and sub-optimal traffic controls. The scope of the study includes all urban and rural freeways and principal arterials in the nation's highway system. Impacts other than capacity losses and delay, such as re-routing, re-scheduling, reduced mobility, and reduced reliability, are not covered in this phase of research.

\section{ES-3. APPROACH}

The study uses traffic engineering modeling methods, the best available data, and engineering judgment to derive estimates of capacity losses and delays. Because direct measurements are scarce and available data are generally incomplete, the validity of the estimates is dependent on the reasonableness of a number of critical assumptions. The philosophy followed is to rely on published peer-reviewed studies whenever possible and, when assumptions must be made solely on the basis of the researchers' judgment, to err on the side of underestimating losses of capacity and delay. There is one general exception to this rule, which is discussed below.

A critical distinction is made between the loss of capacity and its impacts. Capacity is a measure of potential: it describes the maximum sustainable throughput at a point on a highway. As such, it is independent of the highway's actual use. Impacts, however, depend not only on the loss of capacity, but on the volume of traffic on the highway at the time the loss of capacity occurs. The same type of crash occurring on an interstate highway in the middle of the night will cause far less delay, but possibly the same loss of capacity as the same crash occurring during rush hour. Delay is measured in vehicle-hours, which can be converted to person-hours by multiplying by suitable vehicle occupancy. Capacity loss, on the other hand, is a loss of throughput (measured in vehicles per lane per hour), integrated over time and a length of roadway. In this study, capacity loss is measured in vehicles.

In the course of this study, methods were developed for estimating the impacts of temporary events on the loss of capacity and delay, but not for estimating the impacts of TLCs on re-scheduling, re-routing, reduced mobility, and reliability (the four Rs). Thus, the impacts of events on traffic volumes were not 
predicted. For example, a heavy snowstorm might reduce traffic volumes drastically due to travelers rescheduling or canceling planned travel. On the other hand, because normal traffic volumes are assumed, delay will be overestimated. Thus, in general, the delay estimates presented here reflect, to an unknown degree, the other negative impacts of TLCs on the four Rs. A high priority for future analysis should be to develop methods for analyzing all five types of impacts.

\section{ES-4. RESULTS}

\section{Total Effects}

Temporary capacity losses due to work zones, crashes, breakdowns, adverse weather, and sub-optimal signal timing resulted in an estimated 2.3 billion vehicle-hours of delay on U.S. freeways and principal arterials in 1999 (Table ES-1). Assuming an average vehicle occupancy of 1.6 persons, this translates into 3.7 billion person-hours of delay. Assuming an average value of time of $\$ 15$ per hour for each person impacted, temporary capacity losses produced $\$ 55$ billion in lost time alone in 1999 . Because conservative assumptions have been used throughout this analysis, and because several significant sources of delay have not been included, these estimates are believed to be a lower bound on the actual impacts of TLC.

Table ES-1. Summary of capacity loss and delay estimates for freeways and principal arterials*

\begin{tabular}{lccrr}
\hline Event & $\begin{array}{c}\text { Total capacity loss } \\
\text { (billion vehicles) }\end{array}$ & $\begin{array}{c}\text { Total delay } \\
\text { (million veh-hours) }\end{array}$ & $\begin{array}{c}\text { Delay/driver } \\
\text { (hours) }\end{array}$ & $\begin{array}{c}\text { Delay/event } \\
\text { (hours) }\end{array}$ \\
\hline Crashes & 1.9 & 772.6 & 4.1 & 289.5 \\
Breakdowns & 5.9 & 217.1 & 1.2 & 10.2 \\
Work zones * & 3.1 & 482.1 & 2.6 & $824,023.2$ \\
Adverse weather & 24.0 & 543.9 & 2.9 & $362,117.2$ \\
Signal timing & 172.9 & 296.4 & 1.6 & $2,773.7$ \\
Total & 207.8 & $2,312.1$ & 12.4 & 95.8 \\
Non-recurring delay & 34.9 & $2,015.7$ & 10.8 & 83.9 \\
\hline
\end{tabular}

* Work zone estimates only include capacity loss and delay on freeways; they do not include delay on principal arterials.

The estimates of total delay produced in this study compare reasonably well with non-recurrent traffic delay estimated by Texas Transportation Institute (TTI) in the most recent edition of its annual Mobility Study. TTI estimated incident-based non-recurring delay for its 68 cities, which include the largest cities in the country and a selection of smaller cities in sponsoring states.

Neither TTI nor the present study covers all sources of non-recurring delay. TTI considers 68 congested cities while the TLC study is nationwide, and the methods are different. If the TTI method reflects disruption from all factors in the present study except signal timing, the TTI estimate of 2.4 billion hours of total delay is remarkably close to the TLC estimate of 2.3 billion hours (Fig. ES-1). The delay per driver is much different since the TLC numbers average congested urban settings with uncongested rural environments (Fig. ES-2). Both estimates are probably low because several sources of delay are not included directly in the TLC study and indirectly by TTI, and because delay in smaller cities and rural areas (especially on rural portions of high-volume intercity highways and in popular recreational areas) is not covered by TTI. 


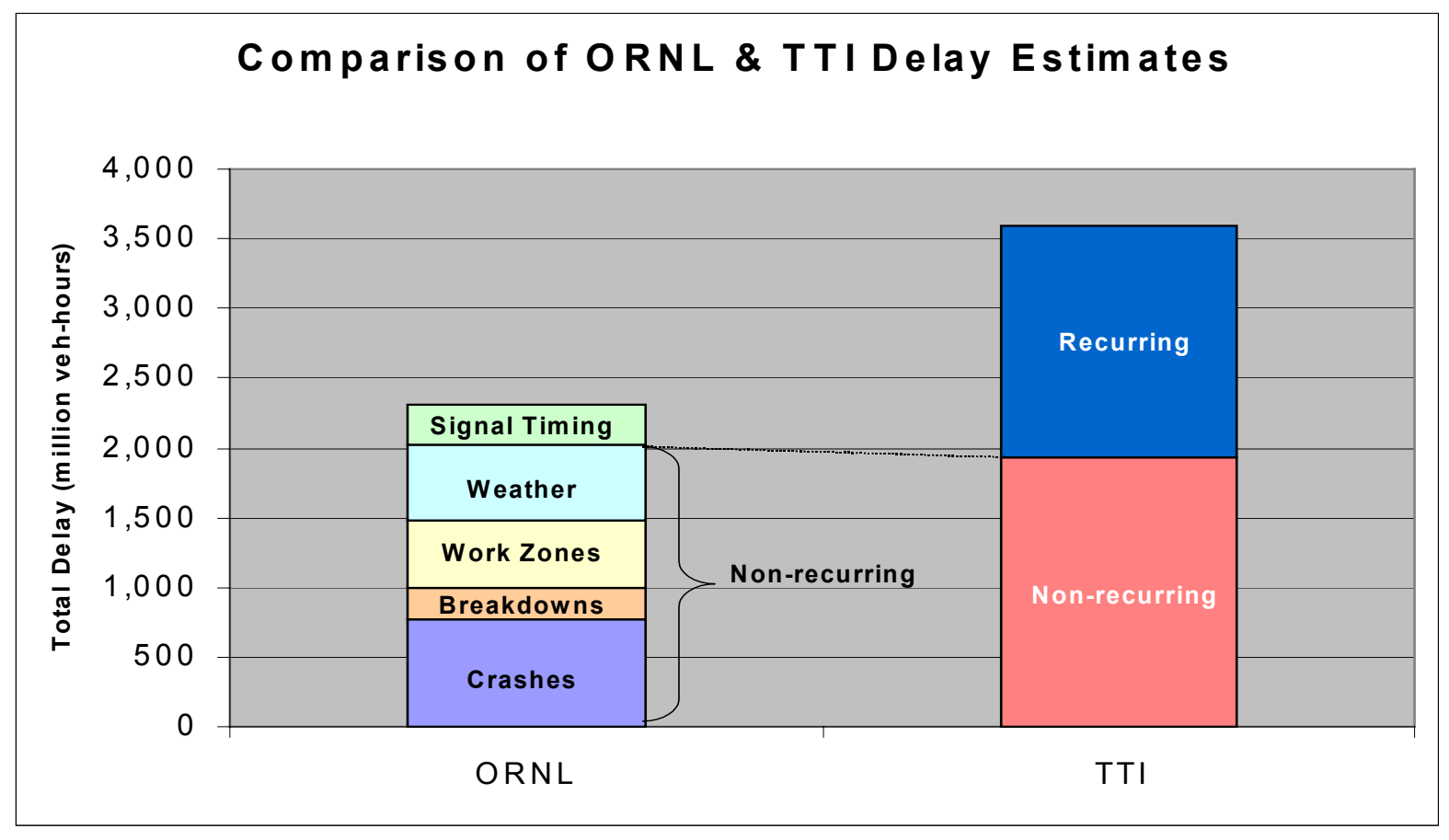

Fig. ES-1. Comparison of TLC and TTI delay estimates

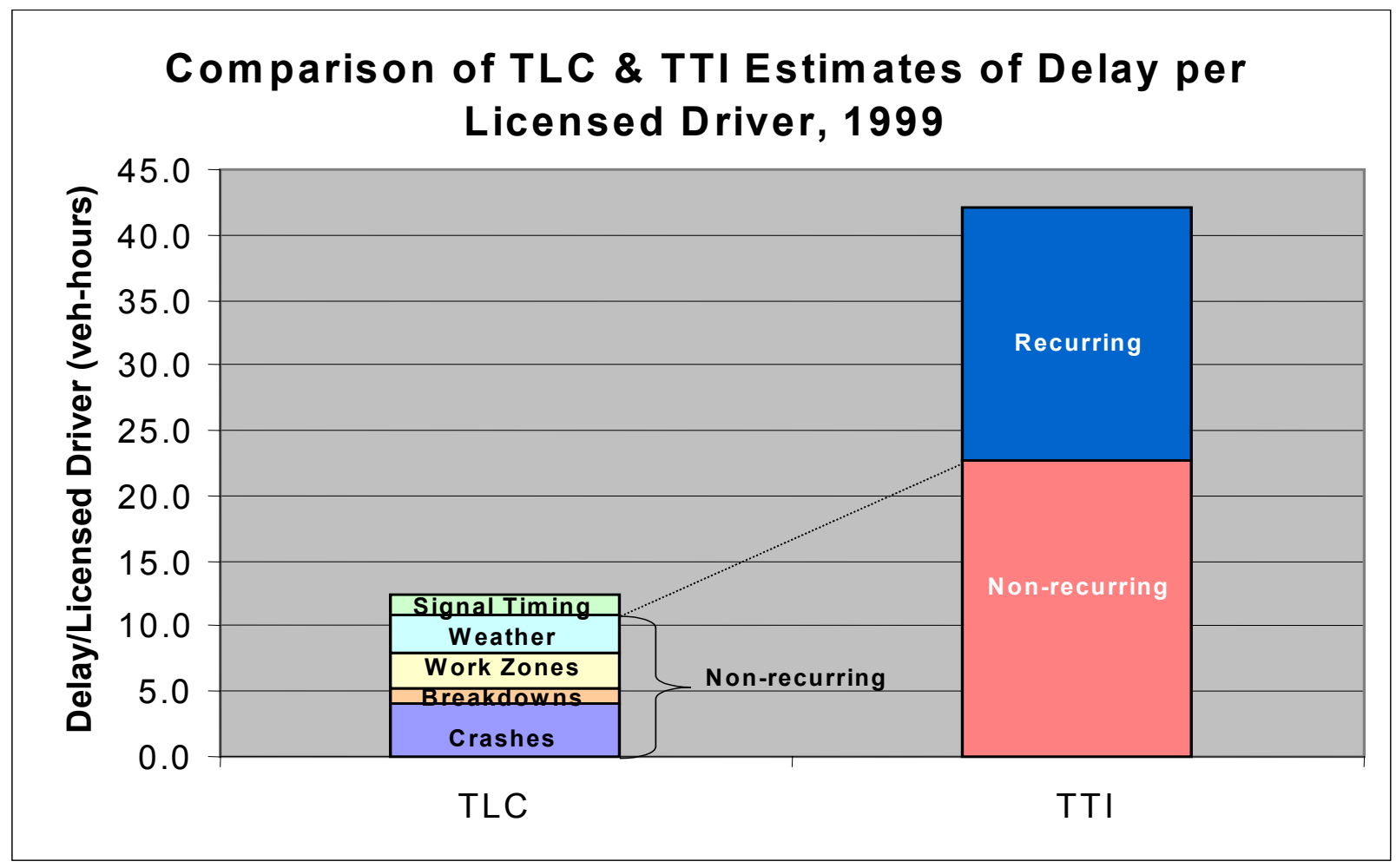

Fig. ES-2. TLC Estimates of delay per licensed driver compared to TTI estimates 


\section{Work Zones}

Work zones on freeways caused an estimated 0.5 billion vehicle-hours ( 0.8 billion person-hours) of delay in 1999. No estimates were made for principal arterials. The majority of delay ( 90 percent) is associated with the transition area of the work zone rather than the activity area.

Work zone impact estimates are believed to be low for two principal reasons. First, the estimates presented in this report are based on interstate and freeway construction only. Capacity losses and delays on principal arterials have not been estimated. Second, the research team believes the Rand McNally database under-represents construction projects scheduled for more than four months in the future. It is highly likely that these two defects could be corrected by using FHWA's Fiscal Management Information System (FMIS) database, but this was beyond the scope of this study.

\section{Crashes}

Crashes on freeways and principle arterials caused an estimated 0.8 billion vehicle-hours (approximately 1.2 person-hours) of delay in 1999. Estimated delays on freeways amounted to 0.5 billion vehicle-hours, almost twice the delays on principal arterials. Non-fatal crashes were the primary source of delay due to their greater occurrence rate.

Several areas for improving crash impact estimates have been identified: (1) developing methods to estimate delays on transverse arterials (neglected here), (2) developing improved methods for geolocating non-fatal accidents, and (3) developing means of validating the Monte Carlo methods used in conjunction with the GES crash data.

\section{Breakdowns}

Vehicle breakdowns caused an estimated 0.2 billion vehicle-hours ( 0.3 billion person-hours) of delay in 1999. Nearly all of the delay is from breakdowns that occurred on congested roadways and caused bottleneck delays. Delays appear to be roughly equally divided between freeways and principal arterials.

Information about breakdowns is scarce, making the associated capacity loss and delay estimates likely the weakest of all impacts estimated. Better data are needed on virtually all aspects of breakdowns. In particular, information regarding the total number of breakdowns or vehicle breakdown rates would improve estimates greatly, as would case studies of the impacts of breakdowns under a variety of circumstances.

\section{Weather}

Major events of fog, snow and ice combined to cause an estimated 0.5 billion vehicle-hours ( 0.9 billion person-hours) of delay on freeways and principal arterials in 1999. Snow was by far the most significant weather factor, accounting for 90 percent of the estimated delay. However, the methods used do not estimate the impacts of the weather event on traffic volumes. Thus, the impacts of major snowstorms are estimated assuming normal traffic volumes. In reality, a substantial fraction of the impacts of such storms is likely to be in re-scheduled or reduced travel, and these impacts were not estimated. As a result, the delay impacts, per se, have likely been overestimated, while the total impacts may be underestimated.

No estimates have been made of the impacts rain or catastrophic events such as hurricanes and other natural disasters. 


\section{Traffic Controls}

It is estimated that sub-optimal traffic controls caused an estimated 0.3 billion vehicle-hours $(0.5$ billion person-hours) of delay on principal arterials in 1999. These estimates differ from the other delay estimates in that they represent the potential for benefits due to improved operations. Delays caused by fixed-time and actuated signals appear to be roughly proportional to the number of signals of each type.

These impact estimates are believed to be among the most reliable, although a number of areas for refinement have been identified.

\section{ES-5. NEXT STEPS}

This study has broken new ground in developing the first "bottom-up," nationwide estimates of temporary losses of highway capacity and resulting delay. In the course of the research, much has been learned about both data sources and methodologies that can be applied to improve and expand information about TLC impacts.

The next phase of research will estimate additional sources of delay that time and resources precluded from this first phase of research. These sources include highway work zones not included in the first phase, tollbooth operations, at-grade railroad crossings, weather events such as rain and flooding, nearroad utility work zones, and trucks loading/unloading in commercial districts. Also, for crashes at intersections, delay on transversal roadway segments will be estimated.

In the future, the research should be extended to quantify and separate the re-routing, re-scheduling, reduced mobility, and reduced reliability (4-R) impacts from delay. This will not only improve estimates of delay, but also give a more accurate and complete picture of the wider range of impacts of temporary capacity losses.

Furthermore, methods should be developed for estimating the degree to which impacts can be reduced by various mitigation strategies. Perhaps more useful for public policymaking than the total impacts of TLCs are the total benefits that can be obtained by mitigating them.

Finally, a number of specific methodological and data improvements are identified that can increase the accuracy and credibility of the TLC estimates. These include conducting a Delphi survey of transportation experts to obtain both a consensus and range of variability on key assumptions and parameter values. The variability would then be directly useful for sensitivity analysis. Estimates based on the judgment of the community of traffic engineers and reflecting uncertainty would undoubtedly have greater credibility than those based on the judgment of a few researchers. 


\section{INTRODUCTION}

\subsection{BACKGROUND}

Traffic congestion and its impacts significantly affect the nation's economic performance and the public's quality of life. In most urban areas, travel demand routinely exceeds highway capacity during peak periods. In addition, events such as crashes, vehicle breakdowns, work zones, adverse weather, and suboptimal signal timing cause temporary capacity losses, often worsening the conditions on already congested highway networks. The impacts of these temporary capacity losses include delay, reduced mobility, and reduced reliability of the highway system. They can also cause drivers to re-route or reschedule trips.

Prior to this study, no nationwide estimates of temporary losses of highway capacity had been made by type of capacity-reducing event. Such information is vital to formulating sound public policies for the highway infrastructure and its operation. This study is an initial attempt to provide nationwide estimates of the capacity losses and delay caused by temporary capacity-reducing events.

\subsection{OBJECTIVE AND SCOPE}

The objective of this study was to develop and implement methods for producing national-level estimates of the loss of capacity on the nation's highway facilities due to temporary phenomena as well as estimates of the impacts of such losses. The estimates produced by this study roughly indicate the magnitude of problems that are likely be addressed by the Congress during the next re-authorization of the Surface Transportation Programs.

The scope of the study includes all urban and rural freeways and principal arterials in the nation's highway system for 1999. Specifically, this study attempts to quantify the extent of temporary capacity losses due to crashes, breakdowns, work zones, weather, and sub-optimal signal timing. These events can cause impacts such as capacity reduction, delays, trip rescheduling, rerouting, reduced mobility, and reduced reliability. This study focuses on the reduction of capacity and resulting delays caused by the temporary events mentioned above. Impacts other than capacity losses and delay, such as re-routing, rescheduling, reduced mobility, and reduced reliability, are not covered in this phase of research. 


\section{APPROACH AND GENERAL METHODOLOGY}

\subsection{APPROACH}

The study uses traffic engineering modeling methods, the best available data, and engineering judgment to derive estimates of capacity losses and delays. Because direct measurements are scarce and available data are generally incomplete, the validity of the estimates is dependent on the reasonableness of a number of critical assumptions. The study used rigorous procedures and methodologies firmly grounded in traffic theory and practice, but attempted to keep the methods as straightforward and transparent as possible. Existing data from a variety of sources was used, as well as results from evaluation studies sponsored by the Intelligent Transportation System (ITS) Joint Program Office. Real data was used where possible. For areas that are not covered by existing data, data or findings from literature sources, reasonable assumptions, and Monte Carlo simulations were used. The philosophy followed throughout the study was to rely on published peer-reviewed studies whenever possible and, when assumptions must be made solely on the basis of the researchers' judgment, to err on the side of underestimating losses of capacity and delay. There is one general exception to this rule: the assumption that traffic volumes are not changed by the occurrence of a TLC event. This issue is discussed below.

The study's analytical framework is portrayed in Fig.1. Events causing temporary capacity losses occur in an environment comprised of roadway characteristics, location, time, and ambient (e.g., weather) conditions. The characteristics of the event and its environment provide the information based on which traffic impact models can predict impacts. These travel impacts include delay and the four Rs: (1) rerouting, (2) re-scheduling, (3) reduced mobility (foregone travel), and (4) reduced reliability. In general, delay is probably the more useful, and certainly the more intuitive, measure of loss of functionality. In general, an event will generate all five types of impacts, with the relative importance of each depending on the nature of the event and its context. For example, an unexpected event such as a crash is likely to produce relatively less re-routing and re-scheduling than a work zone whose existence can be known in advance and which may persist for days, weeks or even longer.

A critical distinction is made between the loss of capacity and its impacts. Capacity is a measure of potential: it describes the maximum sustainable throughput of a highway. As such, it is independent of the highway's actual use. Impacts, however, depend not only on the loss of capacity, but on the volume of traffic on the highway at the time the loss of capacity occurs. The same type of crash occurring on an interstate highway in the middle of the night will cause far less delay, but possibly the same loss of capacity as the same crash occurring during rush hour. Delay is measured in vehicle-hours, which can be converted to person-hours by multiplying by suitable vehicle occupancy. Capacity loss, on the other hand, is a loss of throughput (measured in vehicles per lane per hour), integrated over time and a length of roadway. In this study, capacity is measured in vehicles.

In the course of this study, methods were developed for estimating the impacts of temporary events on the loss of capacity and delay, but not for estimating the impacts of TLCs on the four Rs. Thus, the impacts of events on traffic volumes were not predicted. For example, a heavy snowstorm might reduce traffic volumes drastically due to travelers re-scheduling or canceling planned travel. Such impacts have not been estimated. On the other hand, because normal traffic volumes are assumed, delay will be overestimated. Thus, in general, the delay estimates presented here reflect, to an unknown degree, the other negative impacts of TLCs on re-scheduling, re-routing, reduced mobility, and reliability (the four Rs). A high priority for future analysis should be to develop methods for analyzing all five types of impacts. 


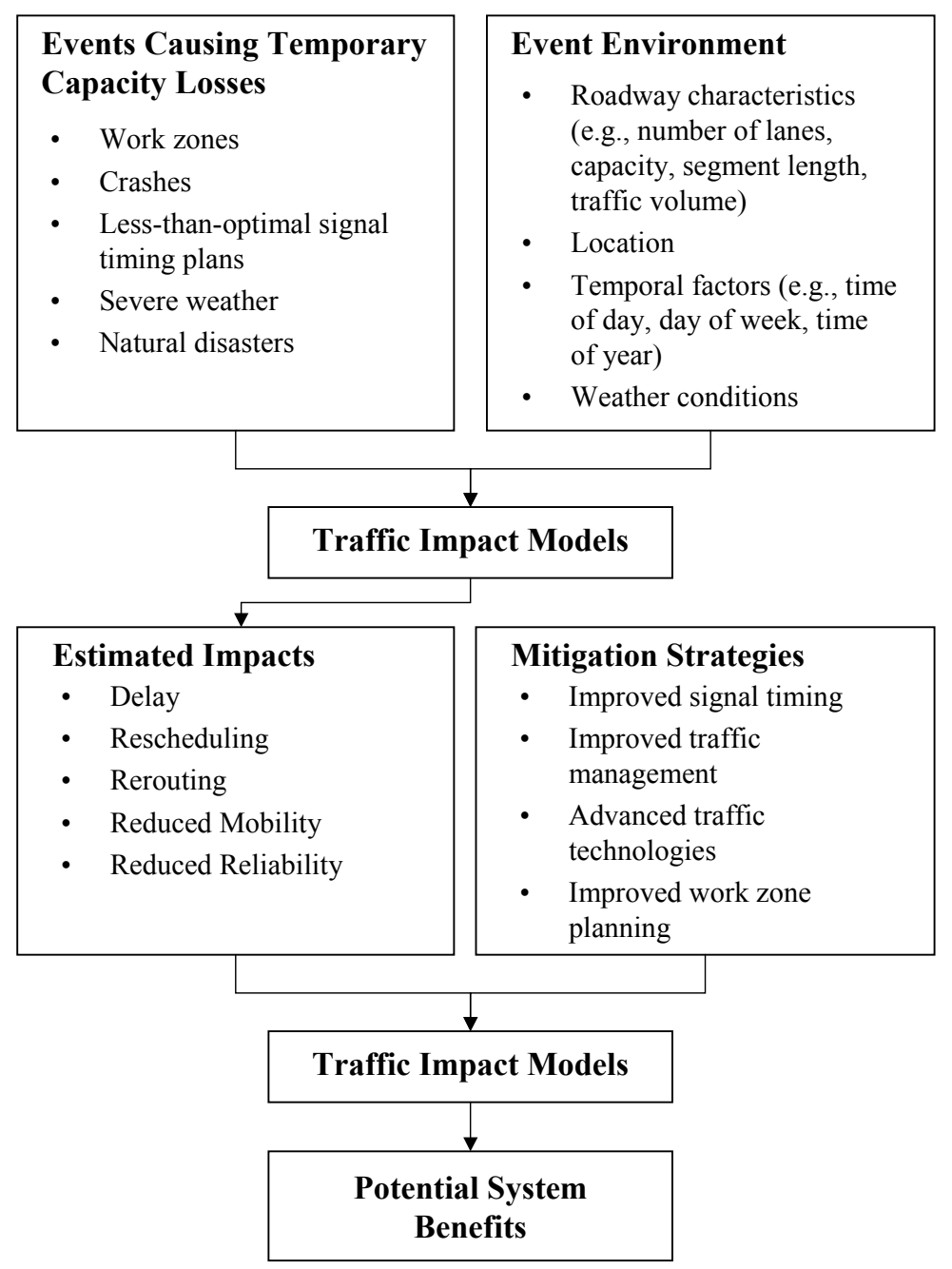

Fig. 1. Analytical Framework

\subsection{BASIC CONCEPTS OF CAPACITY, CAPACITY REDUCTION, AND DELAY}

This section describes the general concepts and methods used in this study to calculate the impacts of temporary capacity loss events on freeways and major highways. Methodologies to measure other adverse consequences, such as trip re-scheduling, trip re-routing, reduced mobility (i.e., trip cancellation), and to describe the impacts on reliability, should be considered candidates for further research.

\subsubsection{Determining Roadway Capacity}

Roadway capacity is the maximum vehicular flow rate at a point on a segment of the roadway. The capacity of a roadway segment with relatively homogeneous physical and operational characteristics is the maximum number of vehicles the segment can accommodate within a unit of time. In cases where the capacity is different at different points on the segment, the point with the least capacity is considered to represent the capacity for the entire segment. For example, for a roadway segment with a narrow bridge, the capacity of the narrow bridge is assumed to represent the capacity of the roadway segment. Usually, an access-controlled, divided, multi-lane highway can carry approximately 2,000 vehicles per hour per 
lane (vphpl). This results in a total of approximately 48-thousand vehicles per day per lane or over 17.5million vehicles per year per lane.

\subsubsection{Estimating Capacity Reductions}

Traffic flow theory asserts that, in a steady state, the flow-density curve of a roadway has a shape similar to the one shown in Fig. 2. For a given demand Q1, the segment of freeway that is represented by the density-flow curve operates at a density D1 and at a speed S1, represented by the slope of the line from the origin to point P1. The segment can also operate at higher densities and slower speeds (point P2), but with unstable flow. The maximum of the flow-density curve is the segment's capacity C.

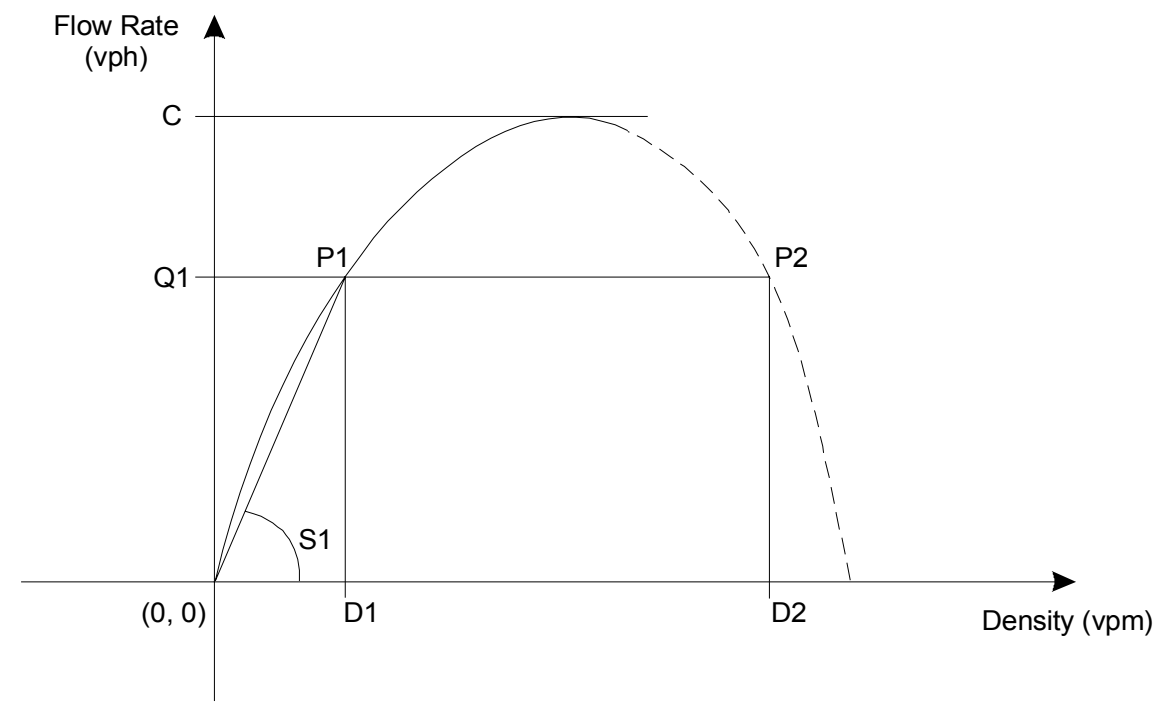

Fig. 2. Flow rate vs. density for a highway segment with capacity $C$ and a highway segment with capacity $\mathbf{C}^{\prime}=\alpha \mathbf{C}$

Assuming a segment of freeway, with a given capacity $\mathrm{C}$, and a section within that segment with a reduced capacity $C^{\prime}=\alpha C$, where $\alpha<1$, capacity $C^{\prime}$ was computed using the capacity reduction factor $\alpha$ for incidents obtained from Blumentritt et al. (1981) (Table 1). For work zones, the entire term $\mathrm{C}^{\prime}$ was obtained from the Highway Capacity Manual, Special Report 209 (Table 2).

Table 1. Capacity reduction due to freeway incidents

\begin{tabular}{lrrrr}
\hline & \multicolumn{4}{c}{ Highway with } \\
Incident type & 2 lanes & 3 lanes & 4 lanes & 5 lanes \\
\hline Vehicle moved to shoulder & $25 \%$ & $16 \%$ & $11 \%$ & - \\
1 lane blocked & $68 \%$ & $47 \%$ & $44 \%$ & $25 \%$ \\
2 lanes blocked & $100 \%$ & $78 \%$ & $66 \%$ & $50 \%$ \\
\hline
\end{tabular}

Confidence: $+/-5 \%$ for small numbers; $+/-10 \%$ for large numbers

Table 2 shows the freeway capacity at work zones as a function of the total number of lanes and the number of lanes open. More recently, Dixon et al. (1996) analyzed speed-flow behavior in work zones in North Carolina. The study also presents a comparison with an earlier research conducted in Texas (see Table 3). The differences in the results from those two states are less than 10 percent. 
Table 2. Average measured work zone capacities

\begin{tabular}{|c|c|c|}
\hline \multicolumn{2}{|c|}{ Number of lanes } & \multirow{2}{*}{$\begin{array}{l}\text { Average capacity } \\
\quad(\mathrm{vphpl})\end{array}$} \\
\hline Normal & Open & \\
\hline 3 & 1 & 1,170 \\
\hline 2 & 1 & 1,340 \\
\hline 5 & 2 & 1,370 \\
\hline 4 & 2 & 1,480 \\
\hline 3 & 2 & 1,490 \\
\hline 4 & 3 & 1,520 \\
\hline
\end{tabular}

Caveat: Data has high variation from site to site.

Table 3. North Carolina and Texas work zone capacities

\begin{tabular}{|c|c|c|c|c|c|}
\hline \multicolumn{2}{|c|}{ No. of lanes } & \multirow[b]{2}{*}{$\begin{array}{l}\text { Rural or } \\
\text { urban }\end{array}$} & \multicolumn{2}{|c|}{ North Carolina* } & \multirow{2}{*}{$\begin{array}{c}\text { Texas** } \\
\text { End of transition } \\
\text { (veh/hr/lane) }\end{array}$} \\
\hline Normal & Open & & $\begin{array}{l}\text { End of transition } \\
\text { (veh/hr/lane) }\end{array}$ & $\begin{array}{l}\text { Activity area } \\
\text { (veh/hr/lane) }\end{array}$ & \\
\hline 2 & 1 & Rural & 1,300 & 1,210 & --- \\
\hline 2 & 1 & Urban & 1,690 & $1,515 * * *$ & 1,575 \\
\hline 3 & 1 & Urban & 1,640 & 1,440 & 1,460 \\
\hline
\end{tabular}

* Capacities

** Queue discharge

*** Two values reported 1,560 and 1,490 for moderate and heavy work activity, respectively

Fig. 3 shows the flow-density curves for the freeway segment with capacity $\mathrm{C}$ (curve fd) and for the section with reduced capacity $\mathrm{C}^{\prime}$ (curve $f d^{\prime}$ ).

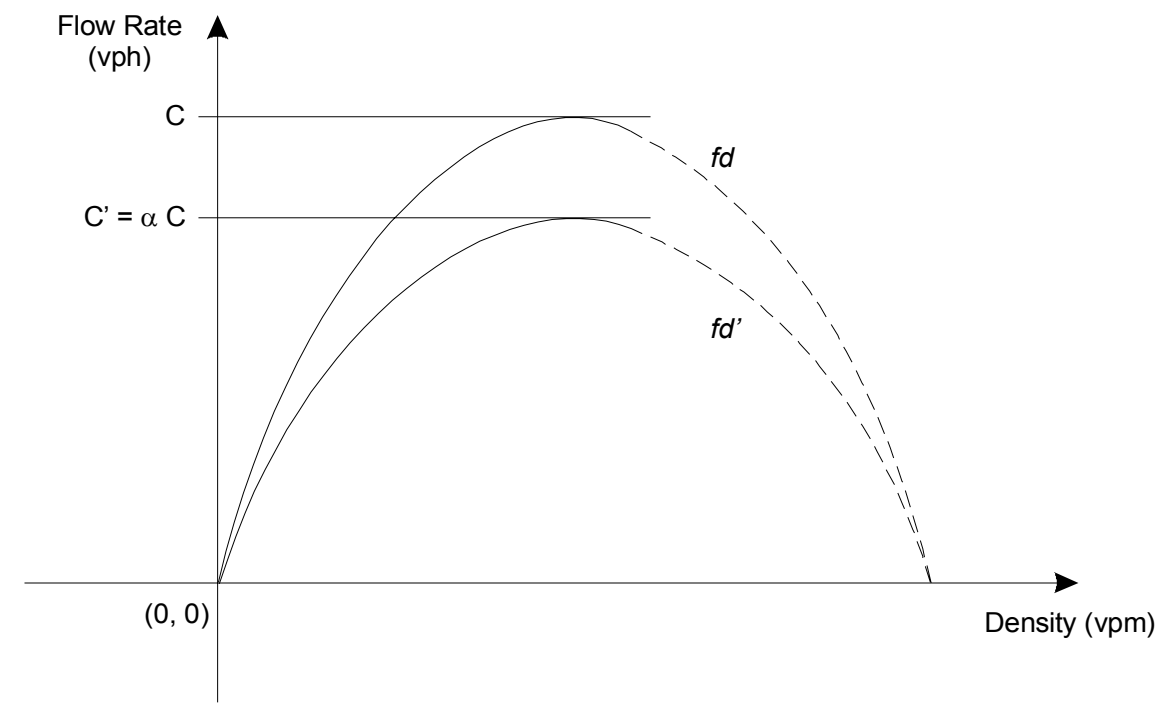

Fig. 3. Flow rate vs. density for a highway segment

Two cases must be analyzed: one in which the demand on the highway segment is less or equal to the reduced capacity $\mathrm{C}^{\prime}$, and one in which the demand is larger than $\mathrm{C}^{\prime}$. 


\section{Case 1: Demand Less Than or Equal to the Reduced Capacity}

The first case examined is where the demand is equal to or less than the reduced capacity (Fig. 4). Upstream of the bottleneck (i.e., the freeway section with capacity $\mathrm{C}^{\prime}$ ), the highway is operating at a density D1 for the current demand Q1, with an average speed of S1 $\mathrm{mph}$ as described above (curve $f d$ ). Within the reduced capacity section, the flow-density curve is $f d^{\prime}$ and, at demand Q1, that section is operating at a density D2 ( $>$ D1) with average speeds of S2 mph $(<\mathrm{S} 1)$. Downstream of the bottleneck, the highway has capacity $\mathrm{C}$, the density (with demand Q1) decreases again to D1, and the average speed increases from S2 to S1. Thus, demand Q1 is served within the three sections (i.e., upstream of bottleneck, bottleneck, and downstream of bottleneck), with average delays resulting from the difference between speeds S1 and S2.

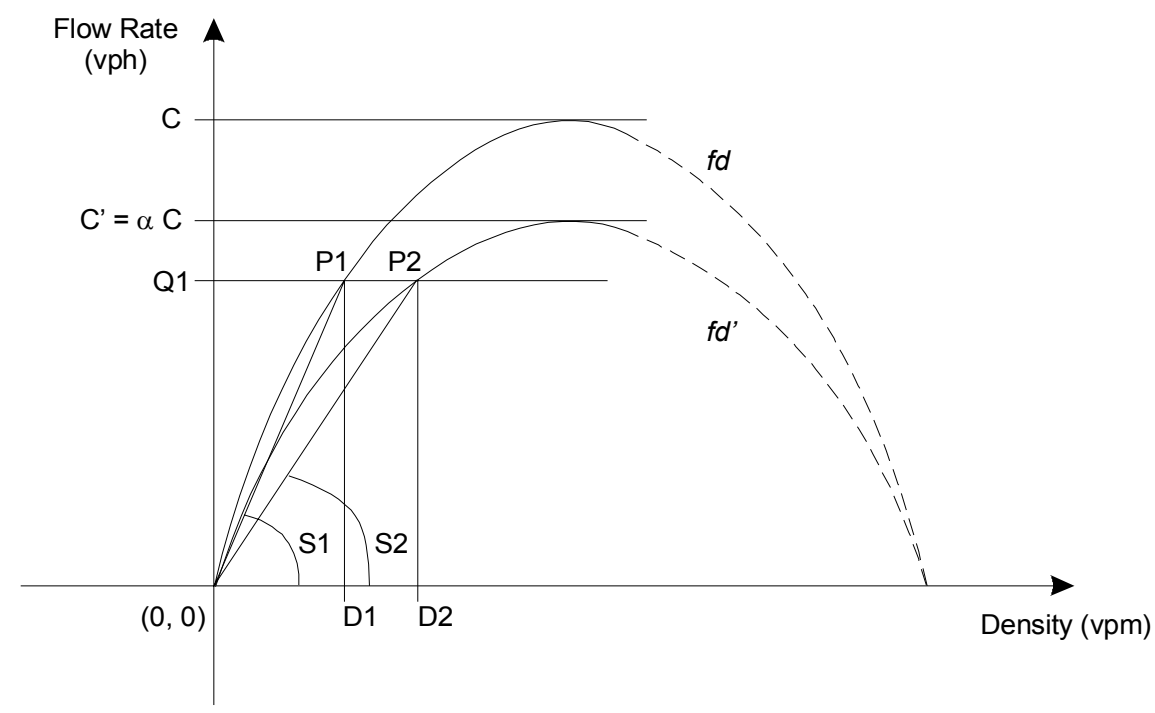

Fig. 4. Demand $Q 1$ equal to or less than bottleneck capacity $C^{\prime}=\alpha C$

Assuming the bottleneck section is L' miles long, the average delay can be computed as follows. The travel time (TT) in seconds for the bottleneck section under normal conditions (i.e., no incident) is

$$
T T=\frac{L^{\prime}}{S_{1}} \times 3600
$$

where $\mathrm{S} 1$ is the speed in mph obtained from curve $f d$ for demand Q1, and 3600 is merely a factor for converting hours to seconds. Under reduced capacity conditions, the travel time (in seconds) within the bottleneck section (TT") becomes

$$
T T^{\prime}=\frac{L^{\prime}}{S_{2}} \times 3600
$$

where $\mathrm{S} 2$ is the speed in mph obtained from curve $f d^{\prime}$ for demand Q1. The average delay each vehicle experiences $\left(\mathrm{AD}_{1}\right)$ is calculated as the difference between these average travel times:

$$
A D_{1}=T T^{\prime}-T T=\frac{S_{1}-S_{2}}{S_{1} \times S_{2}} \times L^{\prime} \times 3600
$$

where $\mathrm{AD}_{1}$ is given in seconds per vehicle. 
This statistic may be consequential for work zones where L' could be significant. For incidents, it may be irrelevant (i.e., $L^{\prime}$ is almost 0 ), but it could be used as a proxy for the rubbernecking delays at the incident location. To account for this effect, this study assumes a length of $L^{\prime}=1 / 2$ mile for incidents and computes the travel time delays on this segment.

\section{Case 2: Demand Greater than the Reduced Capacity}

The next case examined is where demand Q1 is larger than the capacity $\mathrm{C}^{\prime}$ of the bottleneck section (Fig. 5). If there were no loss of capacity, the highway would operate at point P1 with a density D1 and an average speed of $\mathrm{S} 1 \mathrm{mph}$. However, because of the bottleneck, only a demand equal to $\mathrm{C}^{\prime}$ can be passed through the reduced capacity section, which will operate at density D2 and speed S2 (point P2). Downstream of the bottleneck, the freeway has a normal capacity $\mathrm{C}$, and, with a demand $\mathrm{C}^{\prime}$ (i.e., the demand that the bottleneck section can handle), it operates at point P3 with density D3 and speed S3 > S1.

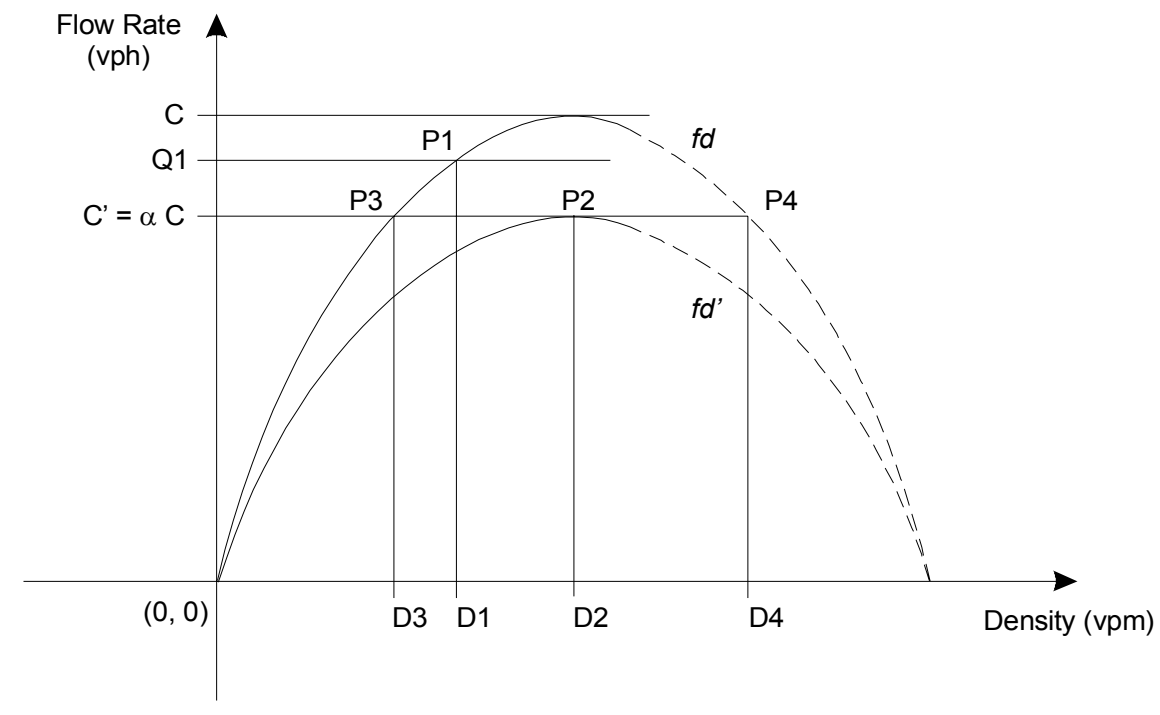

Fig. 5. Demand $Q 1$ larger than bottleneck capacity $C^{\prime}=\alpha C$

Upstream of the bottleneck, the freeway also has capacity $\mathrm{C}$ and operates as described by flow-density curve $f d$. However, because only demand $\mathrm{C}^{\prime}$ can pass through the bottleneck section, vehicles begin to accumulate upstream of the bottleneck, increasing the density. Thus, this section of the freeway operates at point $\mathrm{P} 4$ along line $f d$ with a density D4 which is greater than D1 (the density of the areas upstream of the bottleneck not yet affected by it) and greater than D2 (the density at which the bottleneck section is operating).

Due to the difference between Q1 and $\mathrm{C}^{\prime}$, a queue builds up upstream of the bottleneck section at a rate indicated by $\left(\mathrm{Q} 1-\mathrm{C}^{\prime}\right)$. Calling SW the speed at which this queue grows (also known as the "shock wave" speed), it is possible to write the following equation:

$$
Q_{1}-C^{\prime}=S W \times\left(D_{4}-D_{1}\right)
$$

where

$$
S W=\frac{Q_{1}-C^{\prime}}{D_{4}-D_{1}}
$$




\subsubsection{Estimating Delays for Localized Events}

Fig. 6 shows the effect over time that a loss of capacity can have on a section of freeway. This can also be used to compute several statistics, such as total duration of the congestion produced by the incident, total number of cars affected, the maximum individual delay, and the average delay per vehicle.

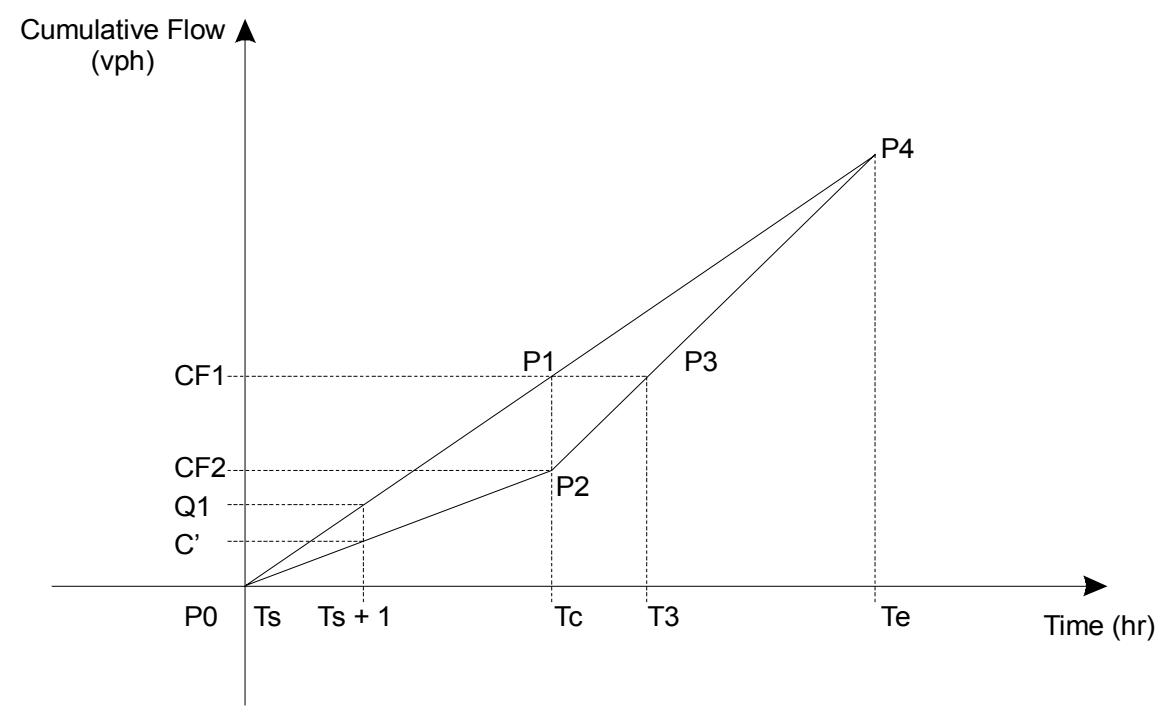

Fig. 6. Cumulative flow vs. time for a highway bottleneck

In Fig. 8, it is assumed that, on a freeway with constant demand Q1, an event occurs at time Ts, reducing the capacity of a section of that freeway from $\mathrm{C}$ to $\mathrm{C}^{\prime}$. Line P0-P4 represents the cumulative demand over the entire period from $\mathrm{Ts}$ to $\mathrm{Te}$ in which there is congestion on the freeway due to an event (the slope of this line is Q1). The event ends at time Tc (i.e., the duration of the event is Tc - Ts), and during this period this section of freeway is operating at reduced capacity $\mathrm{C}^{\prime}$. Line P0-P2 represents the cumulative capacity of the bottleneck (the slope of this line is $\mathrm{C}^{\prime}<\mathrm{Q} 1$ ). Once the event ends (time Tc), the freeway returns to its normal capacity $\mathrm{C}$ (line $\mathrm{P} 2-\mathrm{P} 4$ represents the cumulative capacity under normal conditions; the slope of this line is $\mathrm{C}>\mathrm{Q} 1)$.

During the period Ts to Tc, the demand exceeds capacity, causing an accumulation of vehicles upstream of the bottleneck as discussed before. When the capacity of the freeway is restored (time Tc), there is a queue with a length given by the difference in the ordinates of points P1 and P2 (i.e., CF1 - CF2). It takes $\mathrm{Te}-\mathrm{Tc}$ hrs to dissipate this queue once capacity is restored to $\mathrm{C} v \mathrm{vph}$. Therefore, the total duration of the event and its effects are calculated as $\mathrm{Te}-\mathrm{Ts}$, and the maximum individual delay is given by the difference of the abscissas of points P3 and P1 (i.e., T3 - Tc). It can also be shown that the area enclosed between the cumulative demand line and the cumulative capacity lines gives the total delay. Equations 6 and 7 show the areas of triangles P1-P0-P2 and P1-P4-P2, respectively, and equation 8 shows the total delay.

$$
\begin{aligned}
& A T_{1}=\frac{\left(Q_{1}-C^{\prime}\right) \times(T c-T s)^{2}}{2} \\
& A T_{2}=\frac{\left(Q_{1}-C^{\prime}\right) \times(T c-T s) \times(T e-T c)}{2} \\
& T D=\frac{\left(Q_{1}-C^{\prime}\right) \times(T c-T s) \times(T e-T s)}{2}
\end{aligned}
$$


Note: The average delay per vehicle can be computed by dividing TD by the total number of vehicles involved (i.e., Q1 × (Te-Ts)).

If the event is a crash, several actions may be taken to safeguard public safety while the incident is being cleared. This produces a situation in which the reduced capacity of the roadway changes over time. Also, the demand may not be constant during the duration of the incident and its effects. In Fig. 6 and equation 8, it is assumed that both demand Q1 and capacity $\mathrm{C}^{\prime}$ are constant over time. Fig. 7 shows a more general case where this assumption has been relaxed.

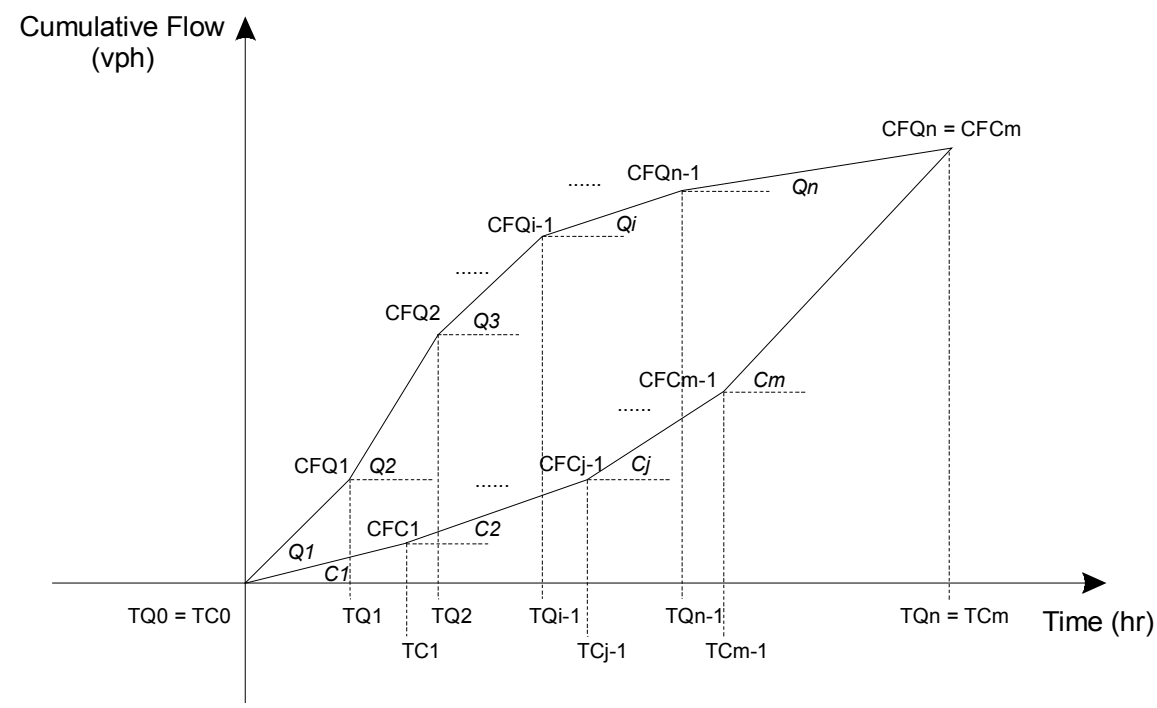

Fig. 7. Cumulative flow vs. time for a highway bottleneck with demand and capacity varying over time

For example, given an incident that occurs at time TC0 and is cleared at time TCm-1, events occur during the interval (e.g., arrival of personnel from emergency agencies, removal of affected vehicles to the shoulder, etc.) that affects the capacity of the roadway. In this case, those $\mathrm{m}-1$ events are represented by a starting time $\mathrm{TCj}-1$, an ending time $\mathrm{TC}$, and a capacity level $\mathrm{Cj}$ that is assumed constant during that interval (i.e., the slope of the Cumulative Capacity Flow line in the interval [TCj-1, TCj]). At time TCm1 , the capacity of the road is restored to normal (i.e., $\mathrm{Cm}=\mathrm{C}$ ).

Thus, during and event and after its clearance, the demand may not be constant. Fig. 7 shows a case where the demand has been divided into intervals [TQi-1, TQi] within which it has a constant value of Qi (i.e., the slope of the Cumulative Demand Flow line in the interval [TQi-1, TQi]). As opposed to the capacity side, it is not known beforehand how many intervals need to be considered for the demand. All of the intervals with constant demand that have starting and ending times within the interval $[\mathrm{TC} 0=\mathrm{TQ} 0$, TCm-1] must be included. A simple iterative process must be used to determine which constant demand intervals having initial times later than TCm-1 are to be considered. This is because point (TQn, CFQn) $\equiv(\mathrm{TCm}, \mathrm{CFCm})$ is not known beforehand. ${ }^{1}$

The cumulative demand and capacity at the end of each respective constant interval can be found from equations 9 and 10 .

\footnotetext{
${ }^{1}$ For each interval $\mathrm{k}$ with constant demand that starts after time $\mathrm{TCm}-1$, find the intersection with the line defined by point (TCm-1, CFCm-1) and slope $\mathrm{Cm}$. If the intersection is outside the interval $\mathrm{k}$, then go to the next interval with constant demand. If it is inside, then stop.
} 


$$
\begin{gathered}
C F Q_{i}=\sum_{s=1}^{i-1} Q_{s}\left(T Q_{s}-T Q_{s-1}\right) \\
C F C_{j}=\sum_{s=1}^{j-1} C_{s}\left(T C_{s}-T C_{s-1}\right)
\end{gathered}
$$

Assuming that there are $\mathrm{n}$ intervals with constant demand and $\mathrm{m}$ intervals with constant capacity, and considering that $\mathrm{Cm}=\mathrm{C}$ then

$$
T Q_{n}=T C_{m}=\frac{C F C_{m-1}-C F Q_{n-1}+Q_{n} \times T Q_{n-1}-C \times T C_{m-1}+T C_{0} \times\left(Q_{n}-C\right)}{\left(Q_{n}-C\right)}
$$

and the total delay

$$
T D=\frac{1}{2}\left[\sum_{i=1}^{n}\left(C F Q_{i-1} \times T Q_{i}-C F Q_{i} \times T Q_{i-1}\right)-\sum_{j=1}^{m}\left(C F C_{j-1} \times T C_{j}-C F C_{j} \times T C_{j-1}\right)\right]
$$

Note: Another way of computing the delay would be to calculate $S$ from equation 4 as a function of time, given $\mathrm{Q}(\mathrm{t})$ and $\mathrm{C}(\mathrm{t})$ and using the following equation to determine $\mathrm{D}(\mathrm{t})$.

$$
Q(t)=\frac{4 \times C}{J d^{2}} \times D(t) \times[J d-D(t)]
$$

where $\mathrm{Jd}$ is the "jam density" and $\mathrm{C}$ is the capacity of the roadway.

$\mathrm{S}(\mathrm{t})$ would provide the speed at which the queue is growing upstream of the bottleneck. Furthermore, since the density in that area is $\mathrm{D} 4(\mathrm{t})$, it is possible to know the queue length QL(t) by multiplying $\mathrm{S}(\mathrm{t}) \times$ $\mathrm{D} 4(\mathrm{t})$. The summation of $\mathrm{QL}(\mathrm{t}) \times \mathrm{dt}$ (where $\mathrm{dt}$ is a small discrete interval of time) would give the total delay. 


\section{CRASHES}

\subsection{METHODOLOGY}

The concepts described in Section 2 are used to estimate capacity reductions and resulting delays due to vehicle crashes. As discussed before, crashes are defined by the following variables: crash type (fatal, injury, property-damage-only [PDO]), number and type of vehicles involved, the location of the crash, the time of the day and day of the week the crash occurs, and the crash duration. A three-step process was used for estimating delay from vehicle crashes:

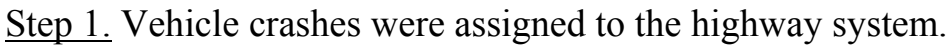

Step 2. Capacity reductions were estimated based on crash type (fatal, injury, or PDO crash), number and type of vehicles involved, the location of the crash, the time of the day the crash occurs, and the crash duration.

Step 3. Delay was estimated based on capacity reduction, vehicle demand, the time of the day and day of the week the crash occurs, and the duration of the capacity reduction.

Due to differences in the characteristics of freeways and principal arterials, as well as data quality issues, capacity reductions and delays for these two highway groups were calculated using slightly different data and methods.

\subsubsection{Crashes on Freeways}

\section{Assigning Crashes to Freeways}

The first step in estimating capacity loss was to assign crashes to a time and location within the national highway network. Three primary data source were used: the Fatality Analysis Reporting System (FARS) and the General Estimates System (GES), both compiled by the National Highway Traffic Safety Administration (NHTSA), and the Highway Performance Monitoring System (HPMS) maintained by the Federal Highway Administration (FHWA). These data sources are described in the paragraphs below.

Fatality Analysis Reporting System (FARS): The FARS is a collection of data files documenting all qualifying fatal crashes that have occurred in the United States since 1975 (U.S. DOT/NHTSA). FARS is compiled by the National Center for Statistics and Analysis (NCSA) of the NHTSA. Information provided in FARS allows analysts to form an overall measure of highway safety. It also provides an objective basis for decision-makers to evaluate the effectiveness of motor vehicle safety standards and highway safety programs.

FARS contains data on a census of fatal traffic crashes within the 50 States, the District of Columbia, and Puerto Rico. To be included in FARS, a crash must involve a motor vehicle traveling on a highway customarily open to the public and must result in the death of a person (occupant of a vehicle or a non-occupant) within 30 days of the crash. Since 1975, FARS has collected information for over 989,451 motor vehicle fatalities and on over 100 different coded data elements that characterize the crash, the vehicle, and the people involved. The latest available FARS data is for 1999.

General Estimates System (GES): The GES is also compiled by the NCSA in NHTSA. GES data are used in traffic safety analyses by NHTSA as well as other DOT agencies. GES data are also used to answer motor vehicle safety questions from the Congress, lawyers, doctors, students, researchers, and the public. 
GES data are collected from a nationally representative sample of police-reported crashes. The system began its operation in 1988. The latest available GES data is for 1999- the year used for this study. To be eligible for the GES sample selection, a police accident report (PAR) must be completed for the crash, and the crash must have involved at least one motor vehicle traveling on a highway, and the incident must have resulted in property damage, injury, or death.

Data collectors for the GES make weekly visits to approximately 400 police jurisdictions in 60 sites across the United States. They randomly sample about 50,000 PARs every year from these police jurisdictions. These collectors obtain copies of the PARs and send them to a central contractor for coding. No other data is collected beyond the selected PARs. That is, no driver license, vehicle registration, or medical information is obtained.

Highway Performance Monitoring Systems (HPMS): The HPMS, maintained by the FHWA, provides data that reflects the extent, condition, performance, use, and operating characteristics of the nation's highways (U.S. DOT/FHWA, a). Data collected for 1999 was used for this study. The provision of HPMS data is a cooperative effort between FHWA and state highway agencies, local governments, and metropolitan planning organizations (MPOs) working in partnership to collect, assemble, and report necessary information. The physical and operational characteristics of highway facilities on which temporary capacity loss events occurred were drawn from information contained in the HPMS.

FARS was used to assign fatal crashes to freeways. FARS contains information on all fatal crashes reported in the United States. For each crash, the data specifies the type of vehicles involved, location (i.e., county, route number/name, mile point), facility type (same classification as HPMS), date, and duration. Thus, for fatal crashes on freeways, the crash location within FARS was mapped to a location within the HPMS with reasonable certainty.

The GES data set was used to assign non-fatal crashes to the freeway system. Unfortunately, GES data is not as detailed as the data in FARS. GES does not specify the exact location of the crash: it merely specifies the region (Northeast, Mid-West, South, and West), land use type (large central city, suburb, other), general facility type (Interstate or non-Interstate), and number of lanes. Therefore, a Monte Carlo simulation was used to place the crash on a surrogate freeway location that would be similar to the environment under which the crash occurred, as described in the GES.

For crashes on Interstates, the region data was used to narrow down the possible states in which the crash may have taken place. Then, the land use type and number of lanes from GES and the annual average daily traffic (AADT) from HPMS were used in the Monte Carlo simulation to place the crash on the freeway system. ${ }^{2}$ The process for facilities classified as Other Freeways and Expressways was similar. However, since crashes on these roadways are included in the GES "non-Interstate" category with all other non-Interstate highway crashes, a method was used to disaggregate these crashes to more-specific facility types. In this study, crashes were "shared" to different non-Interstate highway types based on vehicle-miles of travel (VMT) by highway class as estimated in the VM-2 table in Highway Statistics (U.S. DOT/FHWA, b). The crashes shared to the Other Freeway and Expressway class were then assigned to the highway network using the same method as for Interstates.

\footnotetext{
${ }^{2}$ The average of the AADT for the freeways was taken for the freeways matching the land use and number of lanes. The Monte Carlo simulation places the incident on a freeway segment that has an ADT close to the average.
} 


\section{Estimating Capacity Loss for Freeway Crashes}

Crashes typically produce a loss of capacity on a freeway. This capacity loss depends on the total number of lanes available and the number of lanes affected by the crash. Table 4, adapted from Table 1, was used to determine such capacity losses. For example, a crash causing the closure of one lane on a two-lane highway would reduce the total capacity available (i.e., 2 lanes $\times 2000 \mathrm{pcphpl}$ ) to approximately one-third of its normal value (i.e., $0.320 \times 2$ lanes $\times 2000 \mathrm{pcphpl}$ ) as opposed to one-half (i.e., $0.5 \times 2$ lanes $\times 2000$ pcphpl) as a naive model would predict. $^{3}$

Table 4. Reduced capacity due to freeway crashes (normal capacity $=\mathbf{1 . 0 0 0})$

\begin{tabular}{llllrl}
\hline \multirow{2}{*}{ Effect of crash } & \multicolumn{5}{c}{ Number of freeway lanes } \\
\cline { 2 - 6 } & 1 & 2 & 3 & 4 & $5+$ \\
\hline Vehicle on shoulder & $0.450^{*}$ & 0.750 & 0.840 & 0.890 & $0.930^{*}$ \\
1 lane blocked & 0.000 & 0.320 & 0.530 & 0.560 & 0.750 \\
2 lanes blocked & N/A & 0.000 & 0.220 & 0.340 & 0.500 \\
3 lanes blocked & N/A & N/A & 0.000 & $0.150^{*}$ & $0.200^{*}$ \\
4 lanes blocked & N/A & N/A & N/A & 0.000 & $0.100^{*}$ \\
\hline
\end{tabular}

*Assumed

The total number of lanes at the location where the crash occurred was obtained from the FARS database and other sources of information. However, data on the number of blocked lanes was not generally available. Lane blockage depends on the type of crash and the number and type of vehicles involved. It was assumed that a fatal or injury crash involving more than one vehicle always result in lane closures (i.e., probability of lane closures $=100$ percent for injury crashes).

To estimate the probability of lane closures when only one vehicle was involved, the study proceeded as follows. First, the probability of fatal crashes not causing lane closures was estimated. From the FARS database for 1998, the total number of fatal crashes that were either located outside of the facility right of way or classified as off-road crashes (1,786 crashes) was estimated. This number was then divided by the total number of fatal crashes in the database for which the location of the crash was known $(16,542$ crashes out of 16,605). This resulted in a probability of 0.108 (i.e., $1,786 / 16,546=0.108$ ) that no lanes would be closed due to the crash. The probability of lane closures was then computed as $1-0.108=$ 0.892. For injury crashes (i.e., crashes resulting in non-fatal injuries), the same probability of lane closure as for fatal crashes was adopted.

Crash frequency information derived from Giuliano (1989) was used to determine the remaining probabilities of lane closures. Utilizing these frequencies, non-injury crashes had a probability of 0.6 that lanes would be closed (and a complementary probability of 0.4 that no lanes would be closed), while breakdowns were less likely to close lanes (i.e., the probability was 0.154 that a lane would be closed due to a disablement). For property-damage-only (PDO) crashes, these probabilities were overridden if more than three cars or more than one truck was involved in a crash. This study assumed those crashes resulted in lane closures. All fatal crashes involving multiple vehicles were assumed to close lanes. The probability of a fatal crash involving a single vehicle closing a lane was assumed the same as for injury crashes closing a lane. Table 5 summarizes lane closure probabilities.

\footnotetext{
${ }^{3} \mathrm{pcphpl}=$ passenger car equivalent $(\mathrm{PCE})$ vehicles per hour per lane. Passenger car equivalent is a measure used to account for the different size and performance of most multi-axle vehicles.
} 
Table 5. Probability of lane closures due to crashes and breakdowns

\begin{tabular}{llcc}
\hline Type of crash & Number of vehicles involved & $\begin{array}{c}\text { Lanes } \\
\text { closed }\end{array}$ & $\begin{array}{c}\text { No lanes } \\
\text { closed }\end{array}$ \\
\hline Fatal rash & 1 vehicle & 0.892 & 0.108 \\
& More than 1 vehicle & 1.000 & 0.000 \\
Injury crash & 1 vehicle & 0.892 & 0.108 \\
& More than 1 vehicle & 1.000 & 0.000 \\
Property damage only & Less than 3 cars and at most 1 truck & 0.600 & 0.400 \\
& 3 or more cars and/or 2 or more trucks & 1.000 & 0.000 \\
Breakdowns & N/A & 0.154 & 0.846 \\
\hline
\end{tabular}

Table 6 shows the number of lanes closed due to the crash as a function of the number and type of vehicles involved, which are used as a proxy to describe the severity of the crash. It is assumed that, at most, four lanes could be closed due to the crash. This assumption was made since extending the information on capacity losses to cases with more than four lanes closed (see Table 4) could be highly unreliable without further studies (using simulation, for example).

Table 6. Probability distribution of the number of lanes closed

\begin{tabular}{|c|c|c|c|c|c|}
\hline \multirow{2}{*}{$\begin{array}{l}\text { Number of } \\
\text { vehicles involved }\end{array}$} & \multirow{2}{*}{ Type of vehicles involved } & \multicolumn{4}{|c|}{ Lanes closed } \\
\hline & & 1 & 2 & 3 & $4+$ \\
\hline 1 Vehicle & Any type & 0.997 & 0.001 & 0.001 & 0.001 \\
\hline \multirow[t]{2}{*}{2 Vehicles } & 2 cars, or 1 car and 1 truck & 0.950 & 0.048 & 0.001 & 0.001 \\
\hline & 2 trucks & 0.001 & 0.997 & 0.001 & 0.001 \\
\hline \multirow[t]{2}{*}{3 Vehicles } & 3 cars, or 2 cars and 1 truck & 0.500 & 0.450 & 0.049 & 0.001 \\
\hline & 1 car and 2 trucks or 3 trucks & 0.001 & 0.600 & 0.300 & 0.099 \\
\hline More than 3 vehicles & Any type & 0.001 & 0.099 & 0.800 & 0.100 \\
\hline
\end{tabular}

For crashes involving a large number of vehicles (more than 3 ) and occurring on facilities with more than 4 lanes, this assumption may underestimate the delay caused by the crash since more than four lanes could actually be closed. Moreover, the number of lanes closed presented in Table 6 should be a function of the type of crash, since even those crashes involving only one vehicle may result in the closure of all lanes (e.g., a hazardous material spill). In an attempt to capture these types of occurrences, a probability larger than zero (0.001) was given to the closure of any number of lanes for any number and type of vehicles involved.

\section{Estimating Delays Due to Freeway Crashes}

The main effects of crashes are the congestion and delay that they generate, especially if they occur on freeways with high demand. Delays were calculated as described in Section 2, "Approach and General Methodology." Three important variables were involved in this computation: (1) the time of the day and day of the week when the crash occurred, (2) its location, and (3) its duration.

Location (rural or urban) together with time of day and day of week were used to determine the demand on the freeway during the interval of time the roadway was affected by the crash. This is done by adjusting the AADT for that location through multipliers obtained from the appropriate demand distribution curve. For this study, demand distributions were used by day of the week and time of the day derived from information collected for four cities: San Antonio, Texas; Milwaukee, Wisconsin; San 
Diego, California; and Seattle, Washington. ${ }^{4}$ For rural areas, information collected for the state of Tennessee was used.

The first step in determining the demand was to adjust the AADT for heavy vehicles. Due to lack of better information, it was assumed that each crash happened on a segment of freeway 0.5 to 1 mile long with a grade of 1 percent. This assumption resulted in a passenger car equivalent (PCE) of 3 for any one percent of trucks in the traffic stream. Information about annual average daily truck volumes (AADTT) on the facility where the crash occurred was obtained from HPMS. To obtain the PCE demand (call it AADT'), the AADT was adjusted by multiplying the estimated number of trucks by three and treating them as passenger vehicles. AADT already contains AADTT, and since the PCE for heavy vehicles was determined to be 3 , then AADT' $=$ AADT $+2 *$ AADTT. The AADT' was then multiplied by 7 to obtain the total volume for the week. The result was then multiplied by the factors (obtained from the urban or rural demand distributions) corresponding to the day of the week and hour of the day when the crash occurred.

Crashes were assumed composed of three intervals: (1) the crash detection/arrival-to-scene interval, (2) the remove-to-shoulder interval, and (3) the clearance interval. The crash detection/arrival-to-scene interval is the time that elapses between the actual occurrence of the crash and the time at which the corresponding emergency management (EM) personnel arrive at the location of the crash. During this interval, it was assumed that the vehicles involved were blocking a number of lanes determined using the procedure explained above. For a large percentage of the fatal crashes, the database contained information on the time at which a crash occurred and the time at which the police (or other EM personnel) arrived to the scene. For those cases, the crash detection/arrival-to-scene time was computed as the difference (in minutes) between these two time points. If any or both of these times were not known, a detection/arrival-to-scene time of 10 minutes was assumed, which is slightly larger than the one reported by Skabardonis et al. (1998).

The remove-to-shoulder interval (RSI) represents the time required to move the vehicles from the roadway to the shoulder. Table 7 shows the remove-to-shoulder duration times as a function of the number and type of vehicles involved in the crash. During this interval, it was assumed that the vehicles involved were blocking a number of lanes determined using the procedure explained above.

Table 7. Interval of time to remove vehicles to shoulders

\begin{tabular}{llcccc}
\hline \multirow{2}{*}{$\begin{array}{l}\text { Number of vehicles } \\
\text { involved }\end{array}$} & Types of vehicles involved & \multicolumn{4}{c}{ Time (minutes) } \\
\cline { 3 - 6 } & Any type & 0 & 10 & $\infty^{*}$ & $\infty^{*}$ \\
\hline 1 Vehicle & closed & $\begin{array}{c}\text { 1 Lane } \\
\text { closed }\end{array}$ & $\begin{array}{c}2 \text { Lanes } \\
\text { closed }\end{array}$ & $\begin{array}{c}\text { 3+ Lanes } \\
\text { closed }\end{array}$ \\
2 Vehicles & 2 cars, or 1 car and 1 truck & 0 & 10 & 15 & $\infty^{*}$ \\
& 2 trucks & 0 & $\infty^{*}$ & $\infty^{*}$ & $\infty^{*}$ \\
3 Vehicles & 3 cars, or 2 cars and 1 truck & 0 & 10 & 15 & $\infty^{*}$ \\
& 1 car and 2 trucks or 3 trucks & 0 & $\infty^{*}$ & $\infty^{*}$ & $\infty^{*}$ \\
More than 3 vehicles & Any type & 0 & $\infty^{*}$ & $\infty^{*}$ & $\infty^{*}$ \\
\hline
\end{tabular}

*Indicates that vehicles are not moved to the shoulder

The crash duration (CD) time represents the time elapsed between the arrival of emergency management personnel to the scene and the time at which the crash was totally cleared (this comprises both the

\footnotetext{
${ }^{4}$ Data compiled by Oak Ridge National Laboratory (ORNL) from real-time traffic count data from San Antonio, Texas; Milwaukee, Wisconsin; San Diego, California; and Seattle, Washington. For more information see Chin et al., 2000; Chin et al., 1999 .
} 
remove-to-shoulder time and the clearance time). This study used information derived from Giuliano (Table 8).

Table 8. Estimated crash duration (minutes): mean and standard deviation (SD)

\begin{tabular}{l|cccc|cccc}
\hline \multirow{2}{*}{ Incident type } & \multicolumn{3}{|c|}{ No lanes closed } & \multicolumn{4}{c}{ Lanes closed } \\
& May & SD & Mean & SD & Mean & SD & Mean & SD \\
\hline Injury crash & 47 & 29 & 62 & 40 & 54 & 28 & 66 & 58 \\
Non-injury crash & 41 & 24 & 47 & 24 & 38 & 22 & 66 & 41 \\
Breakdown & 29 & 22 & 30 & 24 & 14 & 11 & 18 & 22 \\
\hline
\end{tabular}

Knowing the type of crash and whether or not the crash resulted in lane closure (which was previously determined to assess the loss of capacity), the table gives the mean of the crash duration and its standard deviation. Table 9 below, derived from Table 8, shows these mean duration times. (Note: only the means are used in this version of this study.)

Table 9. Estimated crash duration (in minutes)

\begin{tabular}{l|cc|cc}
\hline \multirow{2}{*}{ Crash type } & \multicolumn{2}{|c|}{$\begin{array}{c}\text { Daytime } \\
(6 \text { am }-6 \text { pm })\end{array}$} & \multicolumn{2}{c}{$\begin{array}{c}\text { Nighttime } \\
(6 \mathrm{pm}-6 \text { am })\end{array}$} \\
\cline { 2 - 5 } & $\begin{array}{c}\text { No lanes } \\
\text { closed }\end{array}$ & $\begin{array}{c}\text { Lanes } \\
\text { closed }\end{array}$ & $\begin{array}{c}\text { No lanes } \\
\text { closed }\end{array}$ & $\begin{array}{c}\text { Lanes } \\
\text { closed }\end{array}$ \\
\hline Injury crash & 47 & 62 & 54 & 66 \\
Non-injury crash & 41 & 47 & 38 & 66 \\
Breakdown & 29 & 30 & 14 & 18 \\
\hline
\end{tabular}

The remove-to-shoulder interval (RSI) is assumed part of the CD interval. That is, for those cases where RSI $<=15$ minutes, it was assumed that, during the interval CD - RSI, the vehicles involved in the crash where located on the shoulder of the freeway, producing a capacity loss obtained from the first row of Table 4. Otherwise, it was assumed that, during the entire interval CD, the vehicles were blocking 1 or 2 lanes, as determined above, producing the corresponding capacity loss from Table 4.

\subsubsection{Crashes On Principal Arterials}

\section{Assigning Crashes To Principal Arterials}

Crashes were assigned to principal arterials in the same way they were assigned to freeways. However, for arterials, the GES data and associated methodology were used for both fatal and non-fatal crashes. FARS does contain data on fatal crashes on arterials. However, the conventions for identifying roadway names in FARS varies by state, making the process of matching these locations to locations in HPMS time-consuming. Therefore, due to time and resource limitations, the GES data was used along with the described Monte Carlo simulation method. A more accurate mapping of fatal accidents to principal arterials is, however, possible.

\section{Estimating Capacity Loss for Arterial Crashes}

The procedure used for predicting capacity losses on arterials due to crashes was different from the one described above for freeways, although some elements remain the same. Due to a lack of better information, it was assumed that the capacity losses on principal arterials were the same as for crashes on freeways. Thus, it was assumed that Table 4 was also valid for principal arterials. 
As explained before, the next step was to determine whether or not there were lane closures due to the crash. Again, the location distribution for freeways was used as a surrogate for principal arterials.

However, since most arterials do not have a shoulder, it was assumed that any crash would produce a lane closure, independent of the type of crash and the number and type of vehicles involved.

Due to a lack of information, it was assumed that the number of lanes closed was the same as for freeways (see Table 6). It was also assumed, however, that a severe crash on a principal arterial would likely close lanes in both directions of traffic. To account for this, the total number of lanes in both directions was considered when assigning the number of lanes closed. For example, if the model indicated that a crash under consideration closed four lanes on a principal arterial comprised of three lanes in each direction, it was assumed that one direction would be completely closed to traffic, and one lane in the opposite direction would be closed.

\section{Delays Due to Principal Arterial Crashes}

Delay on principal arterials was estimated using the same method used for freeways, although additional assumptions were necessary. Principal arterial traffic demand was adjusted using the multipliers for time of day and day of the week, just as it was for freeways. Due to the lack of better information, the same multipliers used for freeway demand were used for principal arterials.

Since it was assumed that principal arterials do not have shoulders, crashes on those types of facilities were composed of just one interval, rather than the three intervals used for crashes on freeways. In most cases, the length of this interval was assumed equal to the duration of the crash (see Table 9) plus another 10 minutes to account for the detection of the crash. However, there is one exception to this rule. As previously stated, the freeway lane-location distribution was used to locate non-fatal crashes on principal arterials. However, for "property damage only" (PDO) crashes (i.e., non-fatal, non-injury) involving less than four vehicles and assumed to end up on the shoulder in the location distribution were assigned a much smaller duration. A duration of 15 minutes was assumed for this kind of crash (10 minutes for the arrival of police to the scene and another 5 minutes to move the vehicles out of the way).

The delays were calculated using essentially the same approach used for freeways, with the following differences: First, an ideal capacity of 1,600 vphpl was assumed. Second, the green time percentage for the principal arterial was generated from a uniform distribution with lower and upper bounds of 50 and 70 percent, respectively. ${ }^{5}$ Since a principal arterial should get a green light at least half of the time, the lower bound of 50 percent was assumed. The upper bound of 70 percent green time was also based on assumption. Third, it was assumed that the principal arterials form a grid with separation $L$ uniformly distributed in the interval $[0.5,3.0]$ miles. It was further assumed that the crash had the same probability of being located anywhere along the arterial under consideration. Calling $d$ the distance from the immediate upstream transversal arterial to the location at which the crash occurred $(d<=L)$, it was assumed that the queue due to the crash could not be longer than $d$, since traffic would likely divert at the transversal arterial upstream of the crash. In effect, the size of each queue on an arterial was limited by truncating it at a length equal to $d$. This represents traffic diversion in an arterial network grid. Although the traffic diverting would not experience any delay due to the crash, the vehicles would incur a longer trip and, in consequence, longer travel times. However, since the effects of re-routing were beyond the scope of the present study, those longer travel times were not computed as part of the delays due to crashes on principal arterials.

\footnotetext{
${ }^{5}$ Since the ideal capacity represents the flow on uncontrolled links, the green time percentage is used to adjust the capacity to account for the fact that traffic is stopped part of the time.
} 


\subsection{RESULTS}

The TLC study estimates that, in 1999, approximately 2.1 million crashes on freeways and principal arterials caused temporary capacity reductions of 1.9 billion vehicles and over 773 million vehicle-hours of delay (Fig. 8, Table 10). ${ }^{6}$ Crashes on freeways caused slightly more delay than those on principal arterials. Freeway crashes produced around 508 million vehicle-hours of delay ( 66 percent), while crashes on principal arterials accounted for around 264 million (34 percent). However, the average delay caused by each freeway crash ( 573 vehicle-hours) was more than double the average for each principal arterial crash (220 vehicle-hours). Non-fatal crashes accounted for 99.1 percent of delay from all crashes.

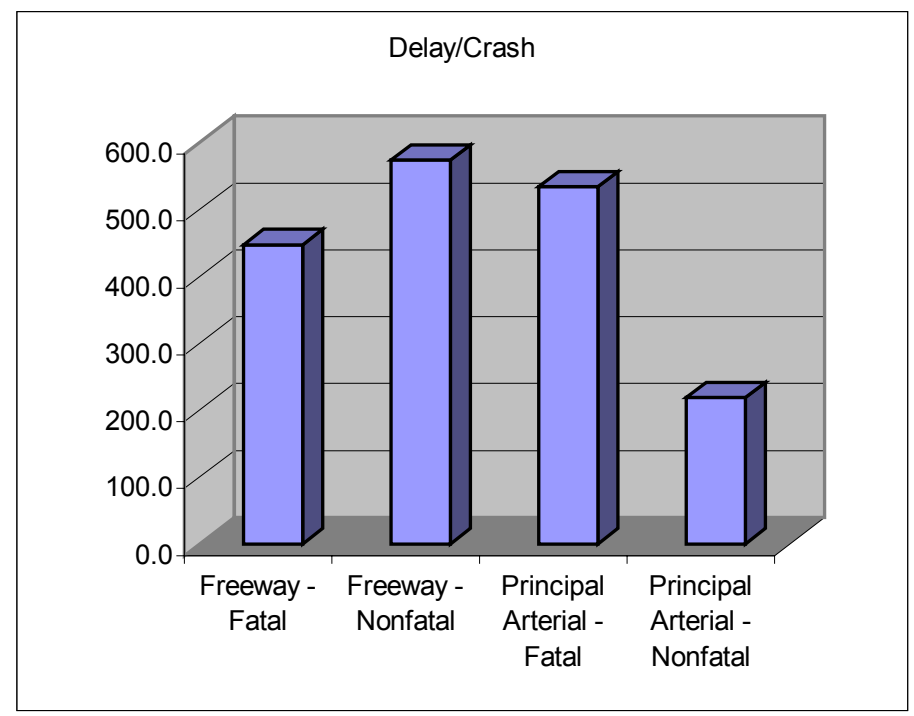

Fig. 8. Delay per crash by severity and highway type

Table 10. Total estimated capacity reductions and delay due to fatal and non-fatal crashes on freeways and principal arterials, 1999

\begin{tabular}{|c|c|c|c|c|c|}
\hline Highway type & Fatal/non-fatal & Crashes & $\begin{array}{c}\text { Capacity lost } \\
\text { (million vehicles) }\end{array}$ & $\begin{array}{c}\text { Delay } \\
\text { (million veh- } \\
\text { hours) }\end{array}$ & $\begin{array}{l}\text { Delay/crash } \\
\text { (veh-hours) }\end{array}$ \\
\hline \multirow[t]{3}{*}{ Freeways } & Fatal & 5,944 & 12.7 & 2.7 & 447.6 \\
\hline & Non-fatal & 880,624 & $1,042.5$ & 505.5 & 574.0 \\
\hline & All & 886,568 & $1,055.2$ & 508.2 & 573.2 \\
\hline \multirow[t]{3}{*}{ Principal arterials } & Fatal & 7,781 & 9.3 & 4.2 & 534.1 \\
\hline & Non-fatal & $1,194,604$ & 813.7 & 260.3 & 217.9 \\
\hline & All & $1,202,385$ & 823.0 & 264.4 & 219.9 \\
\hline $\begin{array}{l}\text { Freeways \& principal } \\
\text { arterials }\end{array}$ & & $2,088,953$ & $1,878.2$ & 772.6 & 369.8 \\
\hline
\end{tabular}

\footnotetext{
${ }^{6}$ Capacity is a measure of vehicle throughput at a given point along a roadway segment and is typically measured in vehicles per hour per lane (vphpl). However, since the methodology used in this study attempts to estimate capacity reductions along a finite length of roadway with a given number of lanes affected, the algorithm produces an estimate of vehicles not serviced through those lanes during the given amount of time.
} 
Principal arterial crashes were more likely to cause bottleneck delay, with fatal crashes on these roadways causing bottlenecks 82.4 percent of the time and non-fatal crashes causing bottleneck delay 76 percent of the time (Fig. 9). Freeway crashes were much less likely to result in bottleneck delay. It is estimated that fatal freeway crashes caused bottleneck delay 25.6 percent of the time and non-fatal crashes caused bottleneck delay 35.6 percent of the time. 7

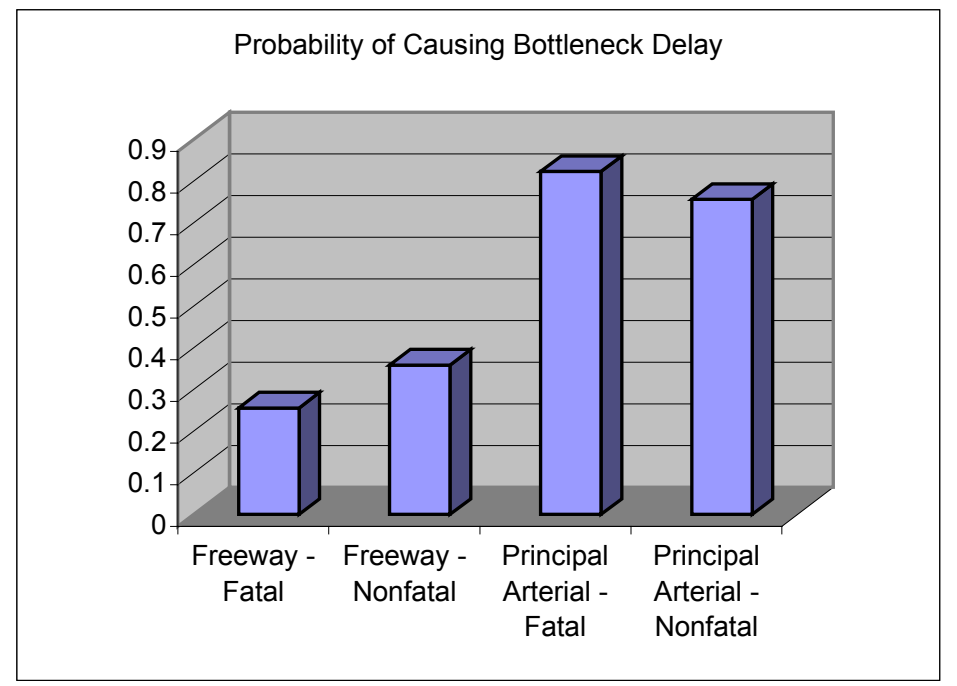

Fig. 9. Crashes on principal arterials were more likely to cause bottleneck delays

\footnotetext{
${ }^{7}$ Although any reduction in capacity may cause traffic to slow down, a bottleneck occurs when demand upstream of a capacity-reducing event exceeds the capacity, forming a queue upstream of the event.
} 
Table 11. Total estimated capacity reductions and delay due to fatal and non-fatal crashes on freeways and principal arterials by time of day and whether or not the crash

resulted in bottleneck delay, 1999

\begin{tabular}{|c|c|c|c|c|c|c|c|c|c|c|}
\hline \multirow{2}{*}{$\begin{array}{l}\text { Crash type } \\
\text { Freeway fatal }\end{array}$} & \multicolumn{6}{|c|}{ No. of crashes } & \multirow{2}{*}{\multicolumn{2}{|c|}{$\begin{array}{c}\text { Delay } \\
\text { (million vehicle- } \\
\text { hours) }\end{array}$}} & \multirow{2}{*}{\multicolumn{2}{|c|}{$\begin{array}{c}\text { Capacity Lost } \\
\text { (million vehicles) }\end{array}$}} \\
\hline & \multicolumn{2}{|c|}{ All times } & \multicolumn{2}{|c|}{$\begin{array}{c}\text { Daytime } \\
(6 \mathrm{am}-6 \mathrm{pm})\end{array}$} & \multicolumn{2}{|c|}{$\begin{array}{c}\text { Nighttime } \\
(6 \mathrm{pm}-6 \mathrm{am})\end{array}$} & & & & \\
\hline $\mathrm{W} / \mathrm{O}$ bottleneck delay & 4,422 & $74.4 \%$ & 1,940 & $62.5 \%$ & 2,481 & $87.4 \%$ & 0.01 & $0.5 \%$ & 8.5 & $66.8 \%$ \\
\hline W/ bottleneck delay & 1,522 & $25.6 \%$ & 1,164 & $37.5 \%$ & 358 & $12.6 \%$ & 2.6 & $99.5 \%$ & 4.2 & $33.3 \%$ \\
\hline Total crashes & 5,944 & $100.0 \%$ & 3,105 & $100.0 \%$ & 2,839 & $100.0 \%$ & 2.7 & $100.0 \%$ & 12.7 & $100.0 \%$ \\
\hline Freeway non-fatal & & & & & & & & & & \\
\hline W/O bottleneck delay & 566,742 & $64.4 \%$ & 380,890 & $57.2 \%$ & 185,853 & $86.4 \%$ & 1.7 & $0.3 \%$ & 606.2 & $58.2 \%$ \\
\hline W/ bottleneck delay & 313,882 & $35.6 \%$ & 284,678 & $42.8 \%$ & 29,204 & $13.6 \%$ & 503.8 & $99.7 \%$ & 436.3 & $41.9 \%$ \\
\hline Total crashes & 880,624 & $100.0 \%$ & 665,567 & $100.0 \%$ & 215,057 & $100.0 \%$ & 505.5 & $100.0 \%$ & $1,042.5$ & $100.0 \%$ \\
\hline Principal arterial fat & & & & & & & & & & \\
\hline W/O bottleneck delay & 1,370 & $17.6 \%$ & 896 & $17.4 \%$ & 474 & $18.1 \%$ & 0.002 & $0.1 \%$ & 2.2 & $23.9 \%$ \\
\hline $\mathrm{W} /$ bottleneck delay & 6,411 & $82.4 \%$ & 4,264 & $82.6 \%$ & 2,147 & $81.9 \%$ & 4.2 & $99.9 \%$ & 7.1 & $76.1 \%$ \\
\hline TotalcCrashes & 7,781 & $100.0 \%$ & 5,160 & $100.0 \%$ & 2,622 & $100.0 \%$ & 4.2 & $100.0 \%$ & 9.3 & $100.0 \%$ \\
\hline Principal arterial nor & fatal & & & & & & & & & \\
\hline W/O bottleneck delay & 286,743 & $24.0 \%$ & 210,278 & $22.4 \%$ & 76,465 & $29.9 \%$ & 0.3 & $0.1 \%$ & 236.3 & $29.0 \%$ \\
\hline W/ bottleneck delay & 907,861 & $76.0 \%$ & 728,852 & $77.6 \%$ & 179,008 & $70.1 \%$ & 260.0 & $99.9 \%$ & 577.4 & $71.0 \%$ \\
\hline Total crashes & $1,194,604$ & $100.0 \%$ & 939,131 & $100.0 \%$ & 255,473 & $100.0 \%$ & 260.3 & $100.0 \%$ & 813.8 & $100.0 \%$ \\
\hline
\end{tabular}


Table 12. Crashes causing bottleneck delays

\begin{tabular}{|c|c|c|c|c|c|}
\hline \multirow{2}{*}{ Fatal freeway crashes } & \multirow[t]{2}{*}{ All times } & \multicolumn{2}{|c|}{$\begin{array}{c}\text { Daytime } \\
(6 \mathrm{am}-6 \mathrm{pm}) \\
\end{array}$} & \multicolumn{2}{|c|}{$\begin{array}{c}\text { Nighttime } \\
(6 \mathrm{pm}-6 \mathrm{am})\end{array}$} \\
\hline & & & & & \\
\hline Total crashes & 1,522 & 1,164 & $76.5 \%$ & 358 & $23.5 \%$ \\
\hline Total delay (million vehicle-hours) & 2.6 & 2.3 & $86.9 \%$ & 0.3 & $13.1 \%$ \\
\hline Capacity lost (million vehicles) & 4.2 & 2.9 & $68.4 \%$ & 1.3 & $31.6 \%$ \\
\hline Delay per crash (vehicle-hours) & 1,739 & 1,977 & & 966 & \\
\hline Capacity lost per crash (vehicles) & 2,767 & 2,475 & & 3,715 & \\
\hline Bottleneck delay per unit of capacity lost & 0.63 & 0.80 & & 0.26 & \\
\hline \multicolumn{6}{|l|}{ Non-fatal freeway crashes } \\
\hline Total crashes & 313,882 & 284,678 & $90.7 \%$ & 29,204 & $9.3 \%$ \\
\hline Total delay (million vehicle-hours) & 503.9 & 494.2 & $98.1 \%$ & 9.7 & $1.9 \%$ \\
\hline Capacity lost (million vehicles) & 436.3 & 388.3 & $89.0 \%$ & 48.0 & $11.0 \%$ \\
\hline Delay per crash (vehicle-hours) & 1,605 & 1,736 & & 330 & \\
\hline Capacity lost per crash (vehicles) & 1,390 & 1,364 & & 1,643 & \\
\hline Bottleneck delay per unit of capacity lost & 1.15 & 1.27 & & 0.20 & \\
\hline \multicolumn{6}{|l|}{ Fatal principal arterial crashes } \\
\hline Total crashes & 6,411 & 4,264 & $66.5 \%$ & 2,147 & $33.5 \%$ \\
\hline Total delay (million vehicle-hours) & 4.2 & 3.3 & $80.5 \%$ & 0.8 & $19.5 \%$ \\
\hline Capacity lost (million vehicles) & 7.1 & 4.5 & $63.2 \%$ & 2.6 & $36.8 \%$ \\
\hline Delay per crash (vehicle-hours) & 648 & 784 & & 378 & \\
\hline Capacity lost per crash (vehicles) & 1,102 & 1,047 & & 1,211 & \\
\hline Bottleneck delay per unit of capacity lost & 0.59 & 0.75 & & 0.31 & \\
\hline \multicolumn{6}{|l|}{ Non-fatal principal arterial crashes } \\
\hline Total crashes & $1,194,604$ & 939,131 & $78.7 \%$ & 255,473 & $21.4 \%$ \\
\hline Total delay (million vehicle-hours) & 260.3 & 235.4 & $90.5 \%$ & 24.8 & $9.5 \%$ \\
\hline Capacity lost (vehicles) & 813.7 & 588.0 & $75.4 \%$ & 225.7 & $24.5 \%$ \\
\hline Delay per crash (vehicle-hours) & 218 & 251 & & 97 & \\
\hline Capacity lost per crash (vehicles) & 681 & 626 & & 884 & \\
\hline Bottleneck delay per unit of capacity lost & 0.32 & 0.40 & & 0.11 & \\
\hline
\end{tabular}


Table 13. Crashes causing bottleneck delays that involved trucks

\begin{tabular}{|c|c|c|c|c|c|}
\hline \multirow[b]{2}{*}{ Fatal freeway crashes } & \multirow[t]{2}{*}{ All Times } & \multicolumn{2}{|c|}{$\begin{array}{c}\text { Daytime } \\
(6 \mathrm{am}-6 \mathrm{pm}) \\
\end{array}$} & \multicolumn{2}{|c|}{$\begin{array}{c}\text { Nighttime } \\
(6 \mathrm{pm}-6 \mathrm{am})\end{array}$} \\
\hline & & & & & \\
\hline Total crashes & 475 & 356 & $75 \%$ & 119 & $25 \%$ \\
\hline Total delay (million vehicle-hours) & 1.0 & 0.9 & $90 \%$ & 0.1 & $10 \%$ \\
\hline Capacity lost (million vehicles) & 1.7 & 1.1 & $65 \%$ & 0.6 & $35 \%$ \\
\hline Delay per crash (vehicle-hours) & 2,069 & 2,463 & & 890 & \\
\hline Capacity lost per crash (vehicles) & 3,635 & 3,224 & & 4,862 & \\
\hline Bottleneck delay per unit of capacity lost & 0.57 & 0.76 & & 0.18 & \\
\hline \multicolumn{6}{|l|}{ Non-fatal freeway crashes } \\
\hline Total crashes & 39,003 & 35,317 & $91 \%$ & 3,686 & $9 \%$ \\
\hline Total delay (million vehicle-hours) & 36.6 & 35.2 & $96 \%$ & 1.4 & $4 \%$ \\
\hline Capacity lost (million vehicles) & 68.7 & 59.2 & $86 \%$ & 9.4 & $14 \%$ \\
\hline Delay per crash (vehicle-hours) & 938 & 997 & & 375 & \\
\hline Capacity lost per crash (vehicles) & 1,759 & 1,678 & & 2,540 & \\
\hline Bottleneck Delay per Unit of Capacity Lost & 0.53 & 0.59 & & 0.15 & \\
\hline \multicolumn{6}{|l|}{ Fatal principal arterial crashes } \\
\hline Total crashes & 498 & 487 & $98 \%$ & 10 & $2 \%$ \\
\hline Total delay (million vehicle-hours) & 0.6 & 0.6 & $99.9 \%$ & .0007 & $0.1 \%$ \\
\hline Capacity lost (million vehicles) & 0.5 & 0.5 & $96 \%$ & 0.02 & $4 \%$ \\
\hline Delay per crash (vehicle-hours) & 1,151 & 1,174 & & 64.2 & \\
\hline Capacity lost per crash (vehicles) & 1,041 & 1,026 & & 1,724 & \\
\hline Bottleneck delay per unit of capacity lost & 1.11 & 1.14 & & 0.04 & \\
\hline \multicolumn{6}{|l|}{ Non-fatal principal arterial crashes } \\
\hline Total crashes & 43,382 & 40,555 & $93 \%$ & 2,826 & $7 \%$ \\
\hline Total delay (million vehicle-hours) & 14.0 & 13.4 & $96 \%$ & 0.5 & $4 \%$ \\
\hline Capacity lost (million vehicles) & 25.1 & 22.7 & $90 \%$ & 2.4 & $10 \%$ \\
\hline Delay per crash (vehicle-hours) & 321 & 330 & & 190 & \\
\hline Capacity lost per crash (vehicles) & 579 & 560 & & 849 & \\
\hline Bottleneck delay per unit of capacity lost & 0.56 & 0.59 & & 0.22 & \\
\hline
\end{tabular}




\section{BREAKDOWNS}

\subsection{METHODOLOGY}

Capacity reductions and delays due to vehicle breakdowns were estimated using a method that is similar to the one used for crashes. However, since national-level data on breakdowns was not available, additional assumptions were necessary to estimate the annual number of breakdowns, the time they occurred, and their location on the national highway network. The methodology can be summarized into the following steps:

Step 1. The total number of vehicle breakdowns was estimated.

Step 2. The location of each breakdown on the highway network was simulated using a Monte Carlo simulation method based on the VMT on each segment.

Step 3. The time of day each breakdown occurred was simulated using a Monte Carlo simulation method based on hourly vehicle counts.

Step 4. The location of the vehicle on each selected segment was simulated (e.g., right-hand shoulder, left-hand shoulder, right-most lane, etc.).

Step 5. The capacity reduction due to each breakdown is based on the characteristics of the selected highway segment and the location of the vehicle on the segment (e.g., right-hand shoulder, left-hand shoulder, right-most lane, etc.).

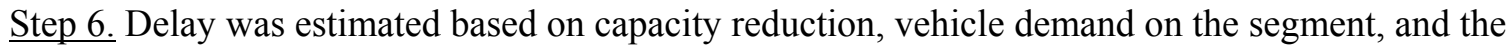
duration of the capacity reduction.

These steps are described in more detail in the paragraphs below.

\subsubsection{Estimating the Total Number of Breakdowns}

The total number of breakdowns was estimated based on the number of crashes on the highway system. Studies in the literature and data collected from cities with freeway service patrols showed that the ratio of breakdowns to crashes on freeways was roughly eight breakdowns per every crash. Thus, it was assumed that the total number of breakdowns in the nation would be equal to eight times the number of crashes. As described in the sections that follow, temporal and location characteristics were assigned to breakdowns based on traffic volume and VMT.

The ratio of breakdowns to crashes was based on a study by the American Trucking Association (ATA) and Cambridge Systematics, Inc. (1991). In this study, ATA and Cambridge Systematics collected data from Freeway Service Patrols and other agencies that collected crash and breakdown data. They analyzed this data and produced estimates of the percentage of incidents classified as disablements, crashes, and other events (e.g., clearing debris). These shares were further broken down by whether or not they blocked lanes. The study also estimated the average incident duration and the vehicle-hours of delay caused by each type. The ratio of crashes to breakdowns given in the Cambridge Systematics study was comparable to the ratios observed in both the Giuliano (1989) and Skabardonis et al. (1998) studies. 


\subsubsection{Assigning Each Breakdown to a Location in the Highway Network}

Breakdowns were assigned a location within the highway network using a Monte Carlo simulation method. The probability of a breakdown being assigned to a given segment in the HPMS was dependent upon the VMT for that segment. VMT was calculated as the product of the segment's length and its AADT volume.

\subsubsection{Assigning Temporal Characteristics to Each Breakdown}

A Monte Carlo simulation was used to assign a day of the week and time of the day to each breakdown. Each hour of the week was assigned a separate bin whose size was dependent upon the traffic volume for that time based on hourly traffic volumes. For breakdowns assigned to urban highways, hourly traffic volume distributions taken from four cities (San Antonio, Texas; Milwaukee, Wisconsin; San Diego, California; and Seattle, Washington) were used in the Monte Carlo simulation (see footnote 4 on page 17). For breakdowns assigned to rural areas, hourly traffic volume distributions taken from the state of Tennessee (T. DOT) were used.

\subsubsection{Assigning Each Breakdown a Location within the Selected Link}

Each breakdown was assigned a location along the link on which it was placed. This includes the lane, shoulder, or other location at which the vehicle came to rest. Locations on freeways were based on statistics in the literature and from data provided by a few highway service patrols. Principal arterial breakdowns were assumed to have characteristics similar to breakdowns on freeways, except it was assumed that they either came to rest in a lane or were able to get the vehicle to a parking area or side street. It was also assumed that most vehicles breaking down on principal arterials were able to get off the principal arterial ( 85 percent) onto a side street or into a parking area.

\subsubsection{Estimating Capacity Reduction}

Capacity reductions were estimated using a methodology similar to the one used for crashes.

\subsubsection{Estimating Delay}

Delay was estimated using a methodology similar to the one used for crashes.

\subsection{RESULTS}

This study estimates that, in 1999, over 21 million vehicle breakdowns occurred on freeways and principal arterials, reducing capacity by nearly 5.9 billion vehicles and causing over 217 million vehiclehours of delay (Table 4). By comparison, crashes caused an estimated 773 million vehicle-hours of delay, about three and a half times as much.

This study estimates that breakdowns typically caused only 10.2 vehicle-hours of delay per incident, while crashes caused 369.8. This is over thirty times more delay per occurrence. This is primarily because drivers are usually able to get disabled vehicles off the highway onto the shoulder, a parking area, or a side street with less traffic. Though estimates vary somewhat, studies in the literature and statistics from data sets indicate that approximately 80 percent of vehicle breakdowns do not block highway lanes. This reduces the amount of bottleneck delay significantly although some slowdown from rubbernecking or a vehicle's proximity to traffic lanes can be expected. According to our estimates, only 8.8 percent of breakdowns caused bottleneck delays, while 62.4 percent of crashes resulted in bottlenecks. 
Table 14. Total estimated capacity reductions and delay due to breakdowns on freeways and principal arterials, 1999

\begin{tabular}{|c|c|c|c|c|c|c|c|}
\hline Breakdown type & \multicolumn{2}{|c|}{$\begin{array}{l}\text { Number of } \\
\text { breakdowns }\end{array}$} & \multicolumn{2}{|c|}{$\begin{array}{c}\text { Capacity lost } \\
\text { (million vehicles) }\end{array}$} & \multicolumn{2}{|c|}{$\begin{array}{c}\text { Delay } \\
\text { (million vehicle-hours) }\end{array}$} & $\begin{array}{c}\text { Delay per } \\
\text { breakdown } \\
\text { (vehicle-hours) }\end{array}$ \\
\hline \multicolumn{8}{|l|}{ Freeway breakdowns } \\
\hline Total breakdowns & $7,086,694$ & $100.00 \%$ & $4,864.7$ & $100.00 \%$ & 119.7 & $100.00 \%$ & 16.9 \\
\hline $\begin{array}{l}\text { NOT causing } \\
\text { bottleneck delay }\end{array}$ & $6,530,290$ & $92.20 \%$ & $4,388.1$ & $90.20 \%$ & 3.5 & $2.90 \%$ & 0.5 \\
\hline $\begin{array}{l}\text { Causing bottleneck } \\
\text { delay }\end{array}$ & 556,403 & $7.90 \%$ & 476.6 & $9.80 \%$ & 116.2 & $97.10 \%$ & 208.8 \\
\hline \multicolumn{8}{|c|}{ Principal arterial breakdowns } \\
\hline Total breakdowns & $14,264,554$ & $100.00 \%$ & $1,074,338,672$ & $100.00 \%$ & $97,449,491$ & $100.00 \%$ & 6.8 \\
\hline $\begin{array}{l}\text { NOT causing } \\
\text { bottleneck delay }\end{array}$ & $12,946,634$ & $90.80 \%$ & $468,192,920$ & $43.60 \%$ & 334,528 & $0.30 \%$ & 0.0 \\
\hline $\begin{array}{l}\text { Causing bottleneck } \\
\text { delay }\end{array}$ & $1,317,920$ & $9.20 \%$ & $606,145,753$ & $56.40 \%$ & $97,114,963$ & $99.70 \%$ & 73.7 \\
\hline \multicolumn{8}{|c|}{ Freeway \& principal arterial breakdowns } \\
\hline Total breakdowns & $21,351,248$ & $100.00 \%$ & $5,939,069,409$ & $100.00 \%$ & $217,133,400$ & $100.00 \%$ & 10.2 \\
\hline $\begin{array}{l}\text { NOT causing } \\
\text { bottleneck delay }\end{array}$ & $19,476,924$ & $91.20 \%$ & $4,856,313,612$ & $81.77 \%$ & $3,844,543$ & $1.80 \%$ & 0.2 \\
\hline $\begin{array}{l}\text { Causing bottleneck } \\
\text { delay }\end{array}$ & $1,874,324$ & $8.80 \%$ & $1,082,755,797$ & $18.23 \%$ & $213,288,857$ & $98.20 \%$ & 113.8 \\
\hline
\end{tabular}




\section{WORK ZONES}

\subsection{METHODOLOGY}

The method used to estimate delays due to work zones was similar to the one used for crashes since both types of events produce localized bottlenecks. The relevant variables defining a work zone are its location (urban or rural), the total number of lanes, the number of lanes closed, the length of the work zone, and the duration of the work. Due to the lack of complete information on work zones on principal arterials, capacity loss and delay were estimated only for freeways. In addition, since 1999 data was not available, the work zone estimates in the study are for May 2001 through May 2002.

The basic process for estimating the delay from work zones includes the following:

$\underline{\text { Step } 1 .}$ An inventory of work zones and their attributes was obtained from the Rand McNally website.

Step 2. Capacity loss was estimated based on the number of lanes normally open and the number of lanes closed due to the work zone, along with the length of time the lanes were closed.

Step 3. Delay was estimated based on capacity reduction, vehicle demand on the segment, and the duration of the work zone.

These steps are described in more detail in the paragraphs below.

\subsubsection{Identifying Work Zones}

Identifying the location and time span of work zones was problematic. There are currently two nationallevel data sets that identify work zones: the Rand McNally website and FHWA's FMIS. However, each has significant limitations.

\section{Rand McNally Construction Information Data}

Rand McNally Construction Information for North America is an Internet-based searchable highway construction information system. It allows the users to find highway construction information by road types, by signed routes, by beginning and ending dates, and by States. The Rand McNally database is compiled to inform drivers of work zone activities. Thus, it includes location, beginning and ending dates, and, in some cases, lane closures for existing and scheduled work zones. However, any data regarding work zones that are no longer active are purged from their database. In addition, data on scheduled work zones are typically only accurate to about 4 months into the future. Finally, this data is collected from state and local agencies by a team of Rand McNally employees. Thus, time and resource considerations can affect the amount of data that is gathered. ORNL downloaded work zone data for May 2001 through May 2002.

\section{Fiscal Management Information System (FMIS)}

The FHWA maintains the FMIS database. FMIS is a database that tracks the allocation of funding obligated to states for federally funded highway projects. According to FHWA, the database includes information on highway and bridge construction and maintenance projects, their locations, the type of activity funded, and other data. The FMIS data for calendar year 1999 was acquired from FHWA and examined. It was determined that the FMIS data could be used to establish a more complete inventory of work zones than the Rand McNally database. However, it would take significant time and effort to 
process the data into a form usable by the TLC study. Therefore, the time and effort constraints of the TLC project made it infeasible to use the FMIS data for generating the initial TLC estimates. Using the FMIS data to produce a more complete estimate of capacity loss and delay should be considered for the future.

\subsubsection{Estimating Loss of Capacity}

Work zones produce a loss of capacity on the freeway that depends on the total number of lanes normally available and the number of lanes closed. The "end-of-transition" and "activity-area" capacities of work zones' open lanes as a function of the available lanes and the environment (rural or urban) of the facility were determined using data from the Highway Capacity Manual, Special Report 209 and studies performed by Dixon. Table 15 shows the end-of-transition and activity-area capacities of work zones' open lanes as a function of the available lanes and the environment (rural or urban) of the facility. The table was obtained by combining information from Table 2 and Table 3.

Table 15. Capacities of open lanes at work zone

\begin{tabular}{|c|c|c|c|c|}
\hline \multicolumn{2}{|c|}{ Number of lanes } & \multirow{2}{*}{$\begin{array}{l}\text { Rural or } \\
\text { urban }\end{array}$} & \multicolumn{2}{|c|}{ Capacity (vehicles per hour per lane) } \\
\hline Normal & Closed & & End of transition & Activity area \\
\hline 2 & 1 & Rural & 1,300 & 1,210 \\
\hline 2 & 2 & Rural & $1,300^{*}$ & $1,210^{*}$ \\
\hline 2 & 1 & Urban & 1,690 & 1,515 \\
\hline 3 & 1 & Rural & 1,490 & 1,490 \\
\hline 3 & 2 & Rural & 1,170 & 1,170 \\
\hline 3 & 1 & Urban & 1,490 & 1,490 \\
\hline 3 & 2 & Urban & 1,640 & 1,440 \\
\hline 4 & 1 & Urban & 1,520 & 1,520 \\
\hline 4 & 2 & Urban & 1,480 & 1,480 \\
\hline 4 & 3 & Urban & 1,170 & 1,170 \\
\hline 5 & 1 & Urban & 1,520 & 1,520 \\
\hline 5 & 2 & Urban & 1,480 & 1,480 \\
\hline 5 & 3 & Urban & 1,370 & 1,370 \\
\hline 5 & 4 & Urban & 1,170 & 1,170 \\
\hline
\end{tabular}

* Crossover work zone, both ways operate with one lane. This case has not been considered in this study

Information from Table 3 was given priority in creating Table 15 above. Where information was missing, data provided in Table 2 was used. For some combinations (e.g., 5 available lanes and 3 lanes closed), the closest data from Table 15 that provided the same number of open lanes was used (i.e., for the previous example, 1,480 vphpl which corresponds to 4 lanes available and 2 open lanes). When the information was derived from Table 2, the same values were adopted for the end-of-transition and activity-area capacities.

To determine the capacity of open lanes in a work zone, it was necessary to know the total number of available lanes and the number of lanes closed. The total number of lanes on the highway segment being analyzed was obtained from HPMS. If the work zone database contained the number of lanes closed, that information was used. For cases where this data was not available, data from the Highway Capacity

Manual, Special Report 209 was used to determine the number of lanes closed due to the construction/maintenance work (Table 16). 
Table 16. Probability distribution of the number of lanes closed in work zone areas

\begin{tabular}{llccc}
\hline $\begin{array}{l}\text { Number of } \\
\text { available lanes }\end{array}$ & Type of work & $\begin{array}{c}\text { 1 Lane } \\
\text { closed }\end{array}$ & $\begin{array}{c}\text { 2 Lanes } \\
\text { closed }\end{array}$ & $\begin{array}{c}\text { 3+ Lanes } \\
\text { closed }\end{array}$ \\
\hline 2 Lanes & New construction or road widening & 1.000 & 0.000 & 0.000 \\
& Other type of work & 1.000 & 0.000 & 0.000 \\
3 Lanes & New construction or road widening & 1.000 & 0.000 & 0.000 \\
& Other type of work & 0.000 & 1.000 & 0.000 \\
More than 3 lanes & New construction or road widening & 1.000 & 0.000 & 0.000 \\
& Other type of work & 0.000 & 1.000 & 0.000 \\
\hline
\end{tabular}

Finally, to compute the travel time delays at work zones, it was necessary to know the physical length of the work zone. This information was obtained from the Rand McNally database, where available. If this data was missing, a work zone length of 0.5 miles was assumed for bridgework, or a length of 1.0 mile was assumed for other work.

\subsubsection{Delays Due to Work Zones}

Work zone delay was estimated using a method similar to the one used for crashes, since both events produce localized bottlenecks. Delay estimates were based on (1) the capacity of the open lanes at the work zone (determined as from Table 15), (2) the traffic demand as a function of time of day and day of week, and (3) and the location of the work zone (determined using the same procedure as in the case of crashes). Delays were computed for each hour of each day during the entire duration of the work (using the corresponding demand) and then added to determine the total delays due to the work zone.

To estimate the queues that would form upstream of the work zones and to calculate the delays produced, the "end-of-transition" capacities were used (see Table 15), while the "activity area" capacities were used to compute the travel time delays. One difference, however, between crashes and work zones is that travelers can often adjust their travel behavior (e.g., trip re-routing, trip re-scheduling, and trip canceling) during the duration of the construction period. When this is a feasible alternative to drivers, the demand will be reduced. This effect was not considered in the present study.

\subsection{RESULTS}

Capacity losses due to 585 work zones reported by Rand McNally to be active on Interstates and other expressways during 2001 amount to an estimated 3.1 billion vehicles per year (Table 17). The impacts are more complicated to measure since drivers often have prior knowledge of work zones and can reroute, reschedule, or cancel trips accordingly. We have estimated total delay, at 400-600 million vehicle-hours (Table 17). Our estimate does not include delays from work zones on principal arterials, nor does it include any construction not found in the Rand McNally database. Based on Rand McNally data, Interstate highways account for just over 40 percent of the mileage of all reported work zones). Finally, our estimates are based on the assumption that no rerouting, rescheduling or reduced mobility occurred.

FHWA's FMIS data was obtained and evaluated as an alternate or complimentary source of information on work zone characteristics. Initial review of the data suggests that it is a more comprehensive inventory of work zones and their general characteristics. However, the effort that would have been required to use this data made it impractical, given the time and effort constraints of the TLC study. Future research should use this data set to produce more-accurate estimates of work zone delay. 
Table 17. Capacity loss and delay due to work zones*

\begin{tabular}{lrr}
\hline Impact & Quantity & Percent \\
\hline Delay (million vehicle-hours) & 482.1 & $100 \%$ \\
$\quad$ At Transition Area & 435.4 & $90 \%$ \\
At Activity Area & 46.6 & $10 \%$ \\
Capacity Lost (million vehicles) & $3,124.5$ & \\
Delay per Work Zone (million vehicle-hours) & 0.8 & \\
Capacity Lost per Work Zone (million & 5.3 \\
vehicles) & 0.15 \\
$\begin{array}{l}\text { Delay per Unit of Capacity Lost (vehicle- } \\
\text { hours) }\end{array}$ & \\
*585 work zones, 1 year of data
\end{tabular}

Table 18. Comparison of work zone and fatal crash impacts

\begin{tabular}{lccrc}
\hline Event & $\begin{array}{c}\text { Delay per } \\
\text { Event } \\
\text { (vehicle-hours) }\end{array}$ & $\begin{array}{c}\text { Ratio of } \\
\text { Work Zone } \\
\text { Delay to } \\
\text { Crash Delay }\end{array}$ & $\begin{array}{c}\text { Capacity } \\
\text { Lost per } \\
\text { Event } \\
\text { (vehicles) }\end{array}$ & $\begin{array}{c}\text { Ratio of Work } \\
\text { Zone Cap. } \\
\text { Loss to Crash } \\
\text { Cap. Loss }\end{array}$ \\
\hline Work Zone & 824,023 & & $5,341,068$ & \\
Fatal Crash (all types) & 497 & 1659 & 1,599 & 3,339 \\
Fatal Crash Causing Bottleneck & 857 & 961 & 1,421 & 3,758 \\
$\begin{array}{l}\text { Delays } \\
\text { Fatal Crash Involving Truck(s) } \\
\& \text { Causing Bottleneck Delays }\end{array}$ & 1,599 & 515 & 2,307 & 2,315 \\
\hline
\end{tabular}

Table 19. Work zone mileage and bridgework by highway type

\begin{tabular}{|c|c|c|c|c|c|}
\hline Activity & Interstate & US Highways & State Routes & Others & Total \\
\hline & \multicolumn{5}{|c|}{ Work Zone Mileage } \\
\hline Reconstruction & 1,509 & 911 & 654 & 99 & 3,173 \\
\hline Resurfacing & 894 & 1,007 & 739 & 49 & 2,689 \\
\hline Widening & 291 & 411 & 221 & 44 & 967 \\
\hline Rehabilitation & 512 & 209 & 134 & 3 & 858 \\
\hline Total & 3,206 & 2,537 & 1,749 & 195 & 7,687 \\
\hline \multirow[t]{2}{*}{ Percent of Total } & 41.7 & 33.0 & 22.8 & 2.5 & 100.0 \\
\hline & \multicolumn{5}{|c|}{ Number of Bridges } \\
\hline Bridgework & 121 & 102 & 96 & 27 & 346 \\
\hline
\end{tabular}




\section{WEATHER}

\subsection{METHODOLOGY}

The TLC study estimated the capacity losses and delays due to three kinds of weather that affect highway travel: fog, snow, and ice. All three of these weather conditions are similar in that they reduce visibility and/or vehicle traction, causing drivers to reduce speeds and increase following distances. Due to time and resource limitations, capacity losses and delays due to rain were not included in the study. The study also did not consider any trip re-scheduling or canceling behavior due to adverse weather in its delay estimates.

The process for estimating delay for adverse weather consisted of the following tasks:

$\underline{\text { Step } 1 .}$ Identify all fog-, snow-, and ice-related weather events in the "Storm Data and Unusual Weather Phenomena" database, along with the temporal and location characteristics of each event. Location was defined in terms of public forecast zones.

Step 2. Map the weather events to the highway network system. Public forecast zones usually follow county boundaries. This was convenient, since HPMS data is county-based. However, for those zones that are not county-based, a GIS-based computer model was used to map the public forecast data to the National Highway Performance Network (NHPN). This allowed the study to determine the percentage of highway mileage (by highway type) in each part of a county that partially belonged to a forecast zone. This percentage was used to adjust delay estimates for counties that are only partially included in a zone that experiences a weather event.

Step 3. Estimate capacity losses on highways in impacted counties. Capacity losses due to weather were based on data in the Highway Capacity Manual 2000 and on studies in the literature (Transportation Research Board, 2000).

Step 4. Estimate the normal delay (congestion delay without adverse weather condition) for roadways in each county during the time of the event.

Step 5. Estimate the delay with adverse weather conditions for roadways in each county during the time of the event. This was accomplished by repeating the same delay estimation step with the appropriate capacity reduction for the weather type. If link average speed was greater than the typical travel speed for that event, the delay was calculated based on the difference between those two speeds. Otherwise, the delay was not adjusted.

Step 6. Calculate the delay induced by adverse weather conditions for each county as the difference in the estimated delay with the adverse weather condition and the estimated delay without the adverse weather condition.

Step 7. Calculate the delay induced by adverse weather conditions for each public forecast zone as the sum of the delay for all involved counties multiplied by the percentage of each county's major arterial mileage lying within the public forecast zone.

\subsubsection{Identifying Adverse Weather Conditions}

The first step in the assessing the effect of adverse weather conditions on travel was to identify events with the potential to reduce capacities and cause delays. These events were identified using the "Storm Data and Unusual Weather Phenomena," published by the National Climatic Data Center. The Storm 
Data database contains a chronological listing, by state, of events such as hurricanes, tornadoes, thunderstorms, hail, floods, drought conditions, lightning, high winds, snow, temperature extremes, and other weather phenomena. In principle, the database only includes storms and other important climatological events having sufficient intensity to cause injuries, loss of life, and/or significant property damage. "Significant" events, for the purposes of inclusion in the database, include those causing losses of at least \$1,000. Within the National Weather Service Weather Services Operation Manual (Chapter F42, Storm Data and Related Reports), quantitative measures and procedures are provided to identify severe and/or significant weather and weather-related events. However, much of the data is compiled by NWS personnel based on their judgment in ascertaining the severity of a meteorological event.

In the Storm Data database, the location and impacted area for an event is described in terms of (1) the county name and nearby town, or by mileage and direction from one town or between two towns, or (2) public forecast zones. Public forecast zones are geographical areas within a state designated by the Weather Service Forecast Offices (WSFO) and Next Generation Radar (NEXRAD) Weather Service Forecast Offices (NWSFO) with consent of the Regional Headquarters. Ideally, a forecast zone is an area with sufficient climatological and meteorological homogeneity to allow a single forecast to serve as the local forecast for the communities within the area. Each WSFO's area of responsibility is divided into forecast zones. The only exceptions are a few mountainous or largely unpopulated areas of the far western United States, certain wilderness areas in Alaska, island areas of the Pacific Region, and Isle Royale in Lake Superior.

Zone boundaries are typically determined by considering:

- Homogeneity of climate and usual weather features

- Population distribution

- Local communications and dissemination capabilities

In practice, most public forecast zones follow county boundaries, although some counties might be split into multiple public forecast zones and some forecast zones may consist of multiple counties. For example, public forecast zone boundaries in Alabama typically coincide with county boundaries. This is true for all counties except Baldwin and Mobile counties, which border the Gulf of Mexico. The local WSFO further divides these two counties into four public forecast zones. However, in some states, public forecast zone boundaries do not follow county boundaries. For example, public forecast zones in Utah and Colorado typically span several counties. Each public forecast zone is assigned a Universal Generic Code. This allows local offices to create their own "regional" areas.

Capacity losses and delay resulting from three broad weather categories were estimated: fog, snow, and ice. However, the database contains more specific types of event categories than these three broad categories. Therefore, each of the appropriate NWS event categories was assigned to one of the broad event categories as listed in Table 20.

Table 20. National weather service weather event categories used in the study

\begin{tabular}{l|lll|ll}
\hline Fog-Related & \multicolumn{3}{|c|}{ Snow-Related } & \multicolumn{2}{c}{ Ice-Related } \\
\hline Fog & Blizzard & Light Snow & Snow Squalls & Freezing Fog & Ice Storm \\
& Early & Moderate & Winter Mix & Freezing Rain & Icy Roads \\
& Snowfall & Snowfall & Winter Storm & Freezing & Light Freezing Rain \\
& Excessive & Monthly & Wintry Mix & Rain/Sleet & Light \\
& Snow & Snowfall & & Glaze & Snow/Freezing \\
& Heavy Snow & Snow & & Ice & Precip \\
& Lake Effect & Snow \& Sleet & & Ice Roads & Snow \& Ice \\
& Snow & & & & \\
\hline
\end{tabular}




\subsubsection{Mapping Adverse Weather Conditions to Highway Segments}

FHWA's HPMS was used to help estimate weather impacts in terms of traffic capacity losses and delays. HPMS provides traffic operation information by highway functional class, county, and state. Since the locations of unusual weather events are described using public forecast zones, additional effort is needed to map public forecast zones to counties. In order to efficiently calculate the storm impacts, information such as the counties affected and the percentage of each county's major arterial mileage impacted within a given public forecast zone were determined for each public forecast zone.

Because the HPMS does not include GIS information, an additional database was used to help map the GIS-based public forecast zone locations to highway segments. FHWA's National Highway Planning Network (NHPN) Ver. 2.2 was used to establish linkage between public forecast zones and counties (U.S. DOT/FHWA, c). The NHPN, which has been under development since the mid 1980s, was originally assimilated from a variety of sources at a nominal scale of 1:2 million and contains a set of data attributes that are suited to analytical modeling of large-scale transportation activities. The accuracy of the Version 2 database has changed from a scale of 1: 2 million to a scale of 1:100,000 (an accuracy of about 80 meters rather than 1,500$)$.

The method for mapping highway links to public forecast zones consisted of the following steps:

1. "Cut" All NHPN Links at Public Forecast Zone Boundaries All NHPN links (roadway segments) data are already "cut" at county boundaries. In order words, each NHPN link lies entirely within a county boundary. In order to establish linkage with a public forecast zone, all NHPN major arterial links were "cut" at public forecast zone boundaries.

2. Aggregate All NHPN Major Arterial Links by Public Forecast Zone Thus, aggregated mileages can be calculated for each public forecast zone based on the NHPN major arterial link's public forecast zone subdivision.

3. Determine Counties in Public Forecast Zones and Percentage of Major Arterial Mileage Involved

Based on the information obtained from the previous step, the number of counties, county identification, and the percentage of each county's major arterial mileage within a given public forecast zone were determined for each public forecast zone.

\subsubsection{Estimating Capacity Losses}

Adverse weather affects capacity and reduces operating speeds significantly. However, each type of weather can affect highway travel differently. Thus, the capacity losses resulting from fog, snow, and ice were estimated using different parameters. There have been several research studies on the impacts of rain, snow, and fog. The following sections discuss the effects of each of these weather conditions and address the issue of when and how to consider these effects in applying the methodology. Due to a lack of information on ice, heavy snow impacts were used as a surrogate. Assumptions regarding fog impacts were guided by values for rain and snow.

\section{Rain}

Research has shown that speeds are not particularly affected by wet pavement until visibility is also affected (Lamm et al., 1990). This result suggests that light rain does not have much effect on speeds (and presumably not on capacities) unless it is of such extended duration that there is considerable water 
on the pavement. Heavy rain, on the other hand, affects visibility immediately and can have a noticeable impact on traffic flow.

This expectation is borne out by studies of freeway traffic. Ibrahim and Hall (1994) found minimal reductions in maximum observed flows for light rain, but significant reductions for heavy rain. Likewise, they found a small effect on operating speeds for light rain, and larger effects for heavy rain. These changes to operating speeds are important because they have a direct impact on traffic performance.

For light rain, Lamm observed a reduction in free-flow speeds of $2 \mathrm{~km} / \mathrm{h}$. At a flow rate of 2,400 pcphpl, the effect of light rain reduced speeds to about $82 \mathrm{~km} / \mathrm{h}$, compared to speeds of $89-95 \mathrm{~km} / \mathrm{h}$ under clear and dry conditions. Under light rain conditions, little if any effect was observed on flow or capacity.

Heavy rain decreased free-flow speeds by $5-7 \mathrm{~km} / \mathrm{h}$. At a flow rate of $2,400 \mathrm{pcphpl}$, it reduced speeds from $89 \mathrm{~km} / \mathrm{h}$ down to $76 \mathrm{~km} / \mathrm{h}$ and from $95 \mathrm{~km} / \mathrm{h}$ down to $79 \mathrm{~km} / \mathrm{h}$, reductions of 13 and $16 \mathrm{~km} / \mathrm{h}$, respectively. Maximum flow rates can also be impacted and might be 14 to 5 percent lower than those observed under clear and dry conditions.

\section{Snow}

The impact of snow differed based on the quantity or rate of snowfall, with light snow having minimal effects, and heavy snow having potentially very large effects (Ibrahim and Hall, 1994). One aspect of heavy snowfall is that, when snow-clearing operations cannot keep the road relatively clear, the snow accumulation on the highway obscures lane markings. Observation suggests that, under these circumstances, drivers often seek not only longer headways, but also greater lateral clearance. As a result, a three-lane freeway segment is used as if it had only two widely separated lanes. This alone will have a considerable effect on capacity.

Light snow was found to be associated with a statistically significant drop of $1 \mathrm{~km} / \mathrm{h}$ in free-flow speeds. The effect on maximum observed flows was midway between the effects of light and heavy rain or somewhere between a 5 and 10 percent reduction.

Heavy snow significantly influences the speed-flow curve. Free-flow speeds were reduced by $37 \mathrm{~km} / \mathrm{h}$ at one station and $42 \mathrm{~km} / \mathrm{h}$ at the other from what they were under clear and dry conditions (102 and 106 $\mathrm{km} / \mathrm{h}$, respectively). Maximum observed flows dropped from 2,160 to 1,200 pcphpl at the station upstream in the queue. At the station that might be a bottleneck itself for part of the peak period, the maximum observed flows dropped from 2,400 to 1,680 pcphpl. This suggests a 30 percent drop in capacity due to heavy snow in an urban area where traffic will generally keep moving to some extent.

\section{Ice Storms}

There is currently no data on the capacity or delay effects of ice storms. However, it was assumed that these events are similar to heavy snow in the way they affect highway travel and in severity. Thus, for ice storms a capacity reduction of 30 percent was assumed.

\section{Fog}

Although there have not been any studies that have quantified the effects of fog on capacity, a few European studies have focused on fog warning systems that use variable speed limit signs to reduce speeds during foggy conditions. Those studies examined the effectiveness of the speed warning signs in reducing mean speeds, rather than measuring the reduction due to fog alone. For example, they report that fog-warning devices reduce speeds by $8-10 \mathrm{~km} / \mathrm{h}$, but provide no information on capacity effects (Hogema et al., 1994; Aron et al., 1994). 
Because the results cited above deal with effects on both speeds and capacity, the analyst can simply use a speed-flow curve for a lower free-flow speed (FFS) in order to model the effects of inclement weather. Neither of the studies reported a method that would equate to a free-flow speed reduction, but their results can be reasonably well approximated that way (Ibrahim and Hall, 1994; Brilon and Ponzlet, 1995). For light rain or snow for example, there is a drop of $7-13 \mathrm{~km} / \mathrm{h}$ in speeds at capacity, which can be approximated by a reduction of $10 \mathrm{~km} / \mathrm{h}$ in free-flow speed. For heavy rain, the approximation would be a free-flow speed reduction of $15 \mathrm{~km} / \mathrm{h}$. For heavy snow, the reduction would be $50 \mathrm{~km} / \mathrm{h}$. Fig. 10 shows the approximate curves for these conditions, using a constant density to determine the capacity for each curve.

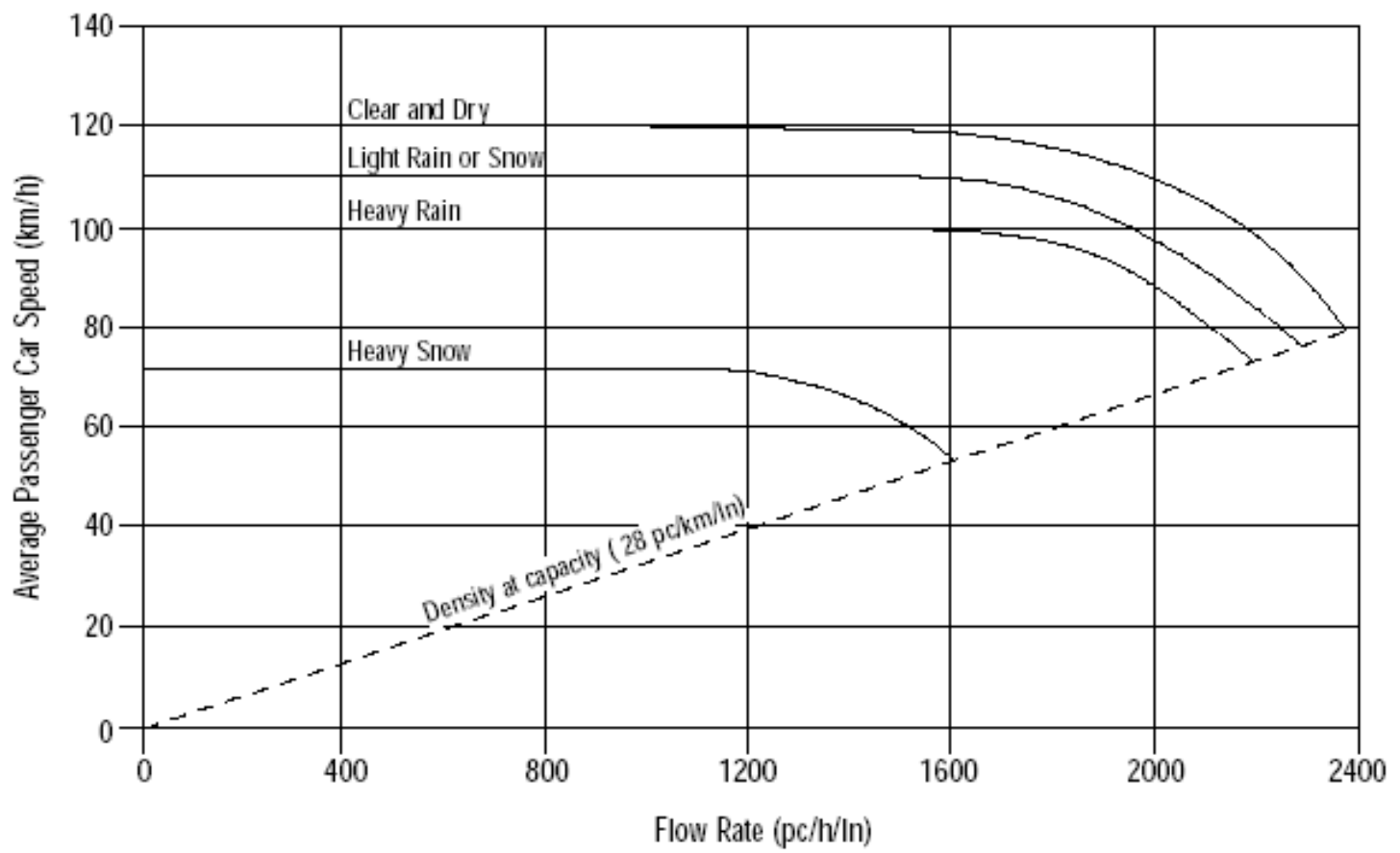

Fig. 10. Speed-flow relationships for various adverse weather conditions

Due to a lack of information on the effect of fog on capacity, assumptions on the impact of fog were guided by information on rain and snow impacts. It was assumed that dense fog would reduce the capacity of a transportation roadway facility by 20 percent. This study also assumed the safe operating speed under dense fog would be $50 \mathrm{mph}$.

\subsubsection{Estimating Delay}

All methodologies used to estimate delays are based on procedures outlined in Highway Capacity Manual 2000. These are described in the sections below.

\section{Rural/Urban Interstates and Urban Other Expressways}

One of the major traffic operation parameters required for calculating traffic delay is average speed. The average speed information can be determined by the speed-volume relationship. The traffic volume by hour of the day and day of the week can be estimated based on the AADT and the k-factor (peak hour traffic volume factor) from HPMS.

Traffic flow on a freeway segment can be categorized into three flow types: under-saturated flow, queue discharge flow, and over-saturated flow (Fig. 11). Each flow type is defined within general speed-flow-density ranges, and each represents different conditions on the freeway. 
- Under-saturated flow represents traffic flow which is unaffected by upstream or downstream conditions. This flow regime is generally defined within a speed range of 90 to $120 \mathrm{~km} / \mathrm{h}$ at low to moderate flows and between 70 and $100 \mathrm{~km} / \mathrm{h}$ at high flow rates.

- Queue discharge flow represents traffic flow that has just passed through a bottleneck and is accelerating back up to the free-flow speed of the freeway. Queue discharge flow is characterized by relatively stable flow as long as the effects of another bottleneck downstream are not present. This flow type is generally defined within a narrow range of flows, 2,000-2,300 pcphpl, with speeds typically ranging from $55 \mathrm{~km} / \mathrm{h}$ up to the free-flow speed of the freeway segment. Lower speeds are typically observed just downstream of the bottleneck. Depending upon horizontal and vertical alignments, queue discharge flow usually accelerates back up to the free-flow speed of the facility within 1 to 2 kilometers downstream from the bottleneck. Studies suggest that the queue discharge flow rate from the bottleneck is lower than the maximum flows observed prior to breakdown. A typical value for this drop in flow rate is approximately 5 percent.

- Over-saturated flow represents traffic flow that is influenced by the effects of a downstream bottleneck. Traffic flow in the congested regime can vary over a broad range of flows and speeds depending upon the severity of the bottleneck. Queues may extend several kilometers upstream from the bottleneck. Freeway queues differ from queues at intersections in that they are not static, or standing. On freeways, vehicles move slowly through a queue, with periods of both stopping and movement.

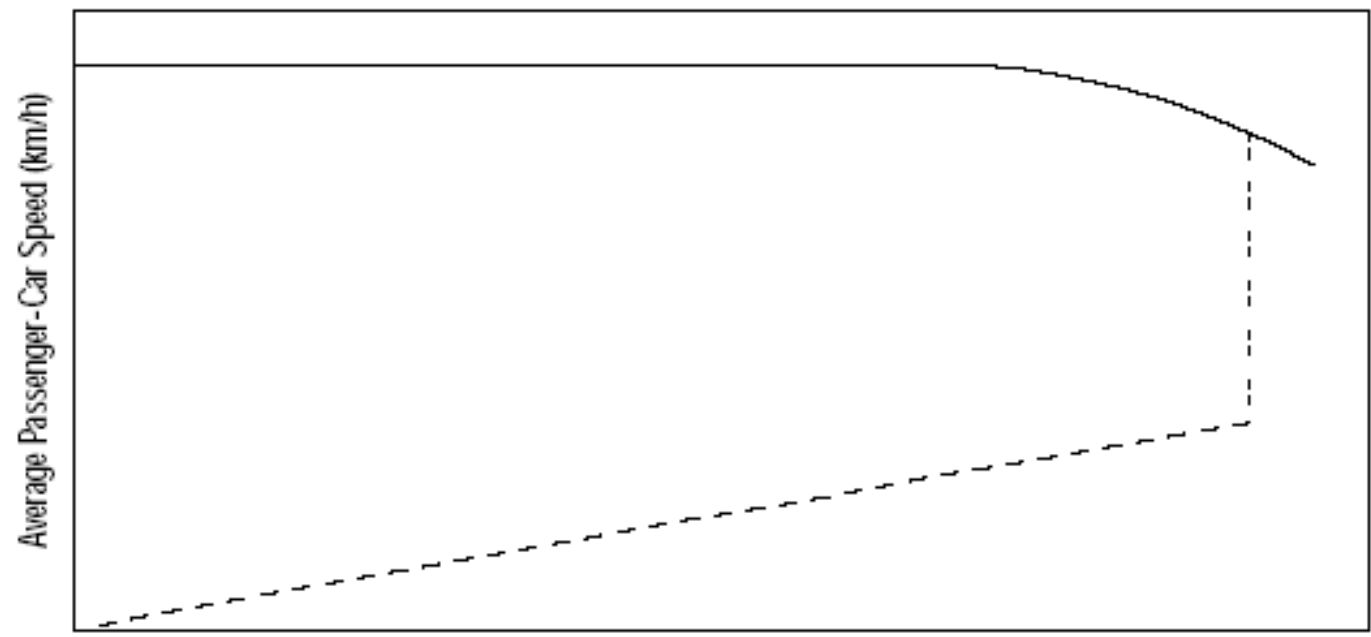

Flow Rate (pc/h/ln)

Regime 1 (undersaturated)

Regime 2 (queue discharge)

Regime 3 (oversaturated)

Fig. 11. Freeway traffic flow types

Speed-flow and density-flow relationships for a typical basic freeway segment under either base or non-base conditions in which free-flow speed is known are shown in Fig. 12. 


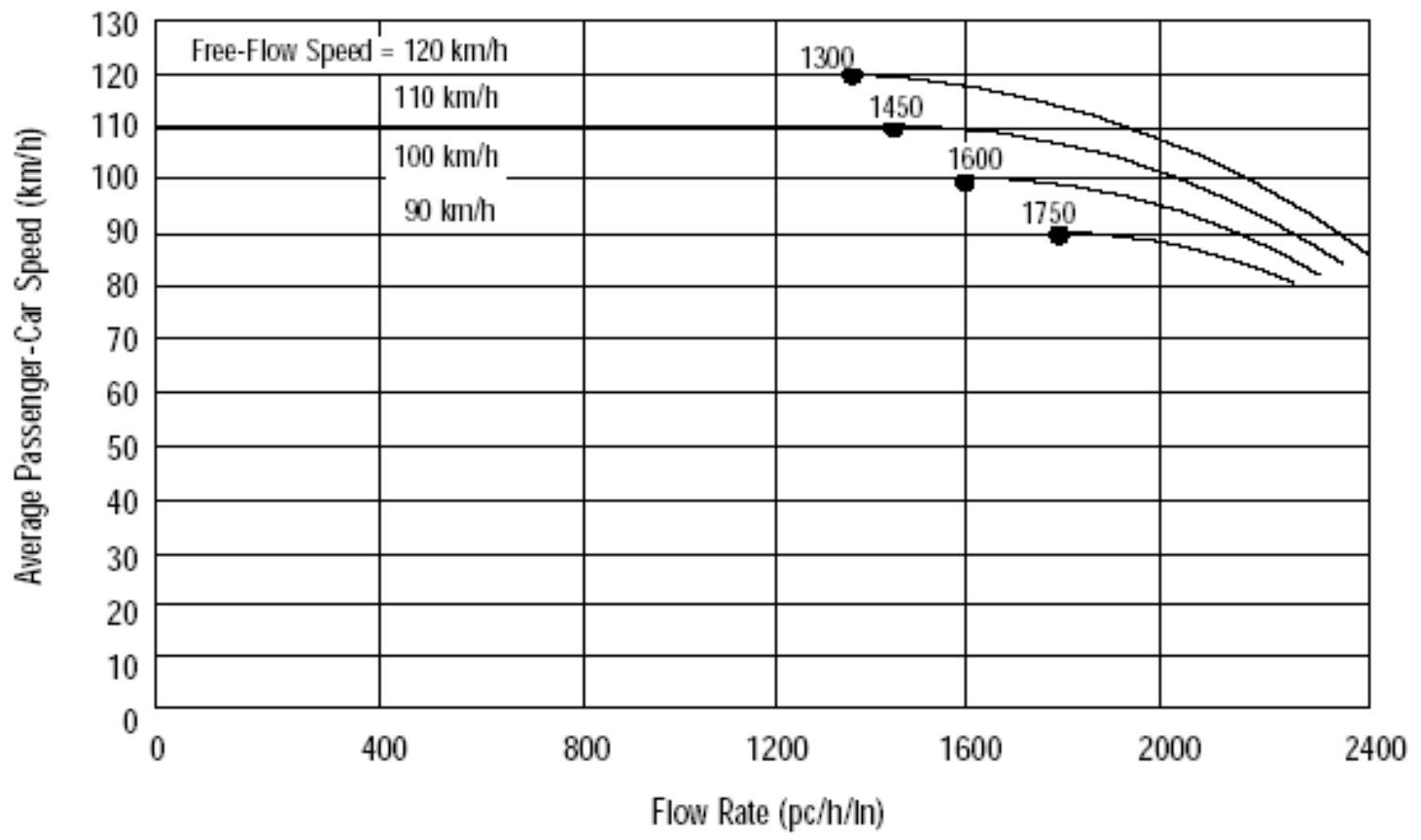

Fig. 12. Speed-flow relationships for a typical basic freeway segment

Recent freeway studies indicate that speed on freeways is insensitive to flow in the low to moderate range. This is reflected in Fig. 12, which shows speed to be constant for flows up to 1,300 pcphpl for a $120 \mathrm{~km} / \mathrm{h}$ free-flow speed. For lower free-flow speeds, the region over which speed is insensitive to flow extends to even higher flow rates.

Under base traffic and geometric conditions, freeways will operate with capacities as high as 2,400 pcphpl. This capacity is typically achieved on freeways with free-flow speeds of $120 \mathrm{~km} / \mathrm{h}$ or greater. As the free-flow speed decreases, there is a slight decrease in capacity. For example, capacity of a basic freeway segment with a free-flow speed of $90 \mathrm{~km} / \mathrm{h}$ is expected to be approximately $2,250 \mathrm{pcphpl}$.

As indicated in Fig. 12, the point at which an increase in flow rate begins to impact the average passenger car speed varies from 1,300 to 1,750 pcphpl. Speed will be reduced beginning at 1,300 pcphpl for freeway segments with a free-flow speed of $120 \mathrm{~km} / \mathrm{h}$. For facilities with lower free-flow speeds, the average speed begins to diminish at higher flow rates.

The relationships in Fig. 12 were digitized and transformed into speed volume-to-capacity ratio relationships. Polynomial equations to the fourth order were used and "fitted" to these curves (Equations 14-17 and Fig. 13). These equations made it possible to use a computer program to calculate average speeds based on volume-to-capacity ratio.

Based on the speed limit (used as free flow speed), AADT, peak-hour factor, directional flow split (applied to morning and afternoon peak-hours) and peak-hour capacity information from HPMS, the average speed was estimated based on these equations. If the volume-to-capacity ratio was larger than 1 , the queue was tracked, and queue length and queue delay were calculated. The total travel time was calculated as the travel time (based on average speed estimated by one of the abovementioned equations) plus the queue delay. 


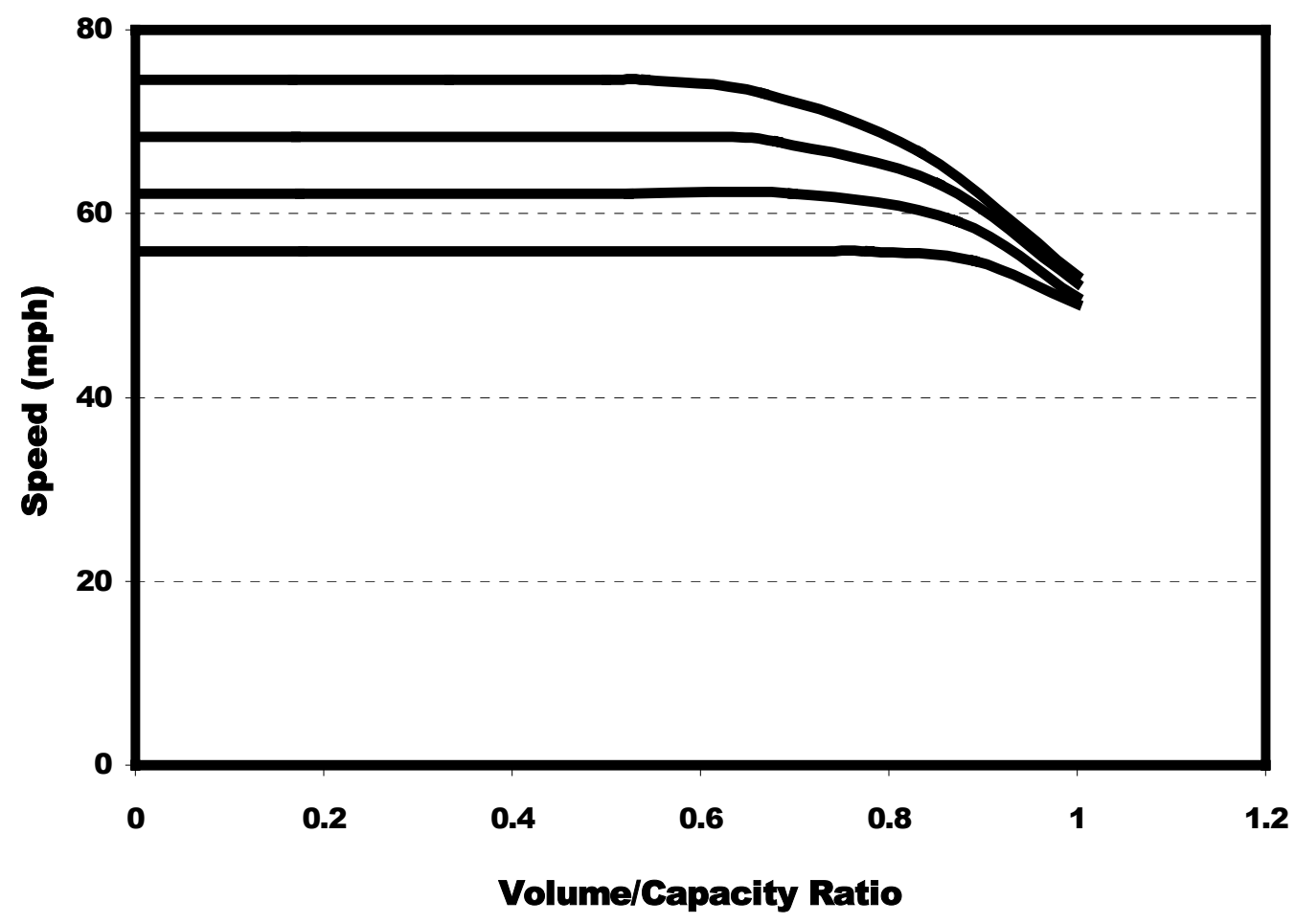

Fig. 13. Speed relationship to volume/capacity ratio for basic freeway segment

Avg Speed $(m p h)_{F F S \approx 75 m p h}=-46.97\left(\frac{v}{c}\right)^{4}+22.72\left(\frac{v}{c}\right)^{3}+5.0909\left(\frac{v}{c}\right)^{2}-2.1844\left(\frac{v}{c}\right)+74.6$

Avg Speed $(m p h)_{F F S \approx 68 m p h}=-87.69\left(\frac{v}{c}\right)^{4}+107.92\left(\frac{v}{c}\right)^{3}-40.719\left(\frac{v}{c}\right)^{2}+4.5651\left(\frac{v}{c}\right)+68.345$

Avg Speed $(m p h)_{F F S \approx 60 m p h}=-111.01\left(\frac{v}{c}\right)^{4}+164.11\left(\frac{v}{c}\right)^{3}-74.212\left(\frac{v}{c}\right)^{2}-9.9859\left(\frac{v}{c}\right)+60.091$

Avg Speed $(m p h)_{F F S \approx 55 m p h}=-79.645\left(\frac{v}{c}\right)^{4}+127.36\left(\frac{v}{c}\right)^{3}-62.256\left(\frac{v}{c}\right)^{2}-9.0488\left(\frac{v}{c}\right)+55.87$

\section{Rural/Urban Other Major Principal Arterials}

Intersections without Signals or Stop Signs: The speed-flow relationships for a typical uninterrupted-flow segment on a multilane highway under either base or non-base conditions in which free-flow speed is known are shown in Fig. 14. The operating characteristics for a multilane highway may be slightly lower than for a freeway because drivers on multilane highways allow for potential conflicts with turning traffic, even when there are no access points in the immediate vicinity.

As indicated in Fig. 14, the speed of traffic on a multilane highway is insensitive to traffic volume up to a flow rate of $1,400 \mathrm{pcphpl}$. The exhibit shows that the capacity of a multilane highway under base conditions is $2,200 \mathrm{pcphpl}$ for highways with a $100-\mathrm{km} /$ hour free-flow speed. For flow rates from 1,400 to $2,200 \mathrm{pcphpl}$, the speed on a multilane highway with a $100-\mathrm{km} / \mathrm{h}$ free-flow speed drops $12 \mathrm{~km} / \mathrm{h}$. 


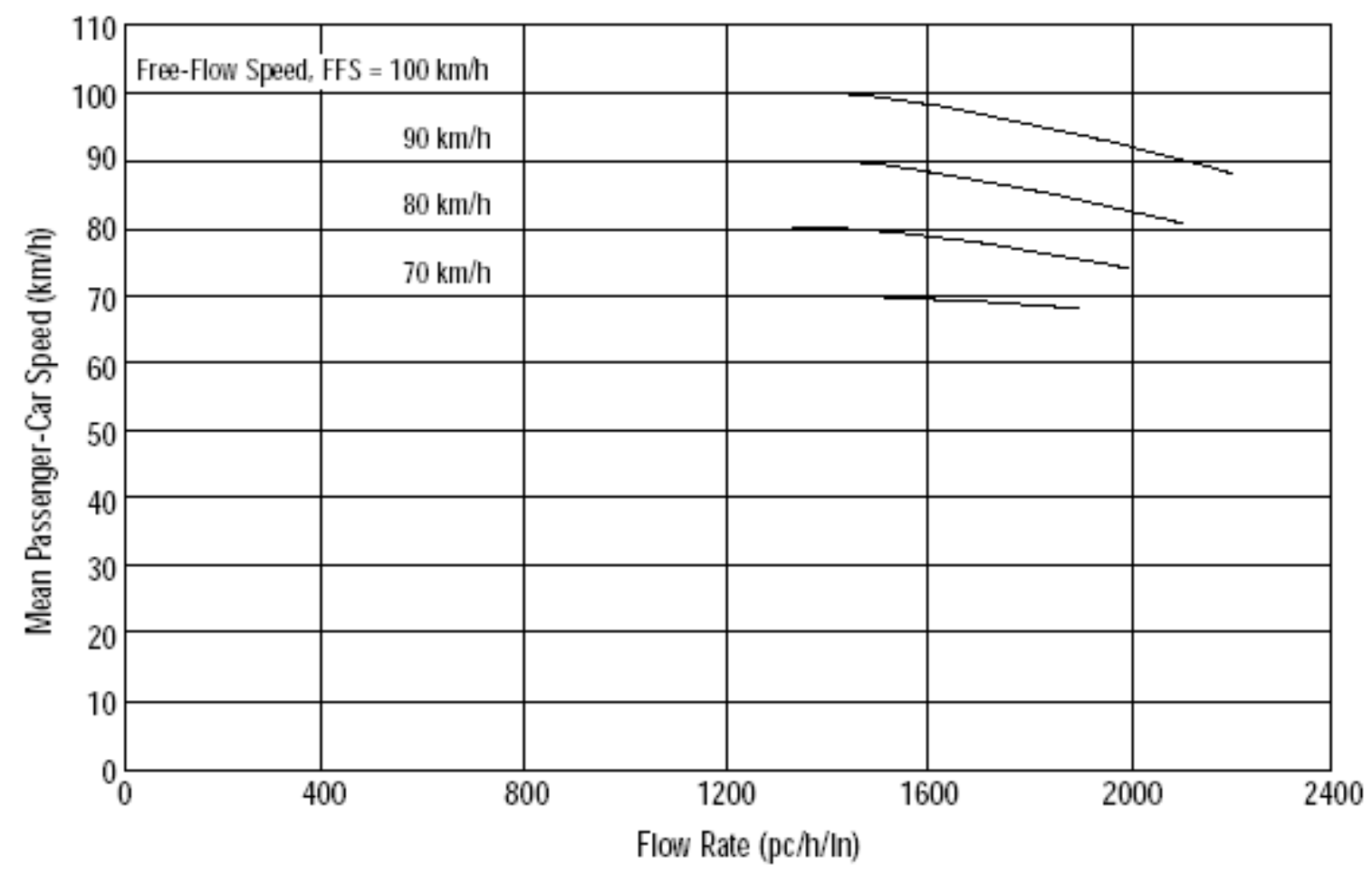

Fig. 14. Speed-flow relationships on multi-lane freeways

The capacity value of 2,200 pcphpl is representative of the maximum 15-minute flow rate that can be accommodated under base conditions for highways with a free-flow speed of $100 \mathrm{~km} / \mathrm{h}$. Actual capacities on specific multilane highway sections may vary from this value.

The relationships presented in Fig. 14 were digitized, polynomial equations to the fourth order were "fitted" to the displayed curves (Equations 18-21 and Fig. 15). These equations made it possible to use a computer program to calculate average speeds based on volume-to-capacity ratio.

$$
\begin{aligned}
& \operatorname{Avg~Speed~}(\mathrm{mph})_{\mathrm{FFS}=62 \mathrm{mph}}=-2.2238\left(\frac{v}{c}\right)^{4}-23.011\left(\frac{v}{c}\right)^{3}+21.701\left(\frac{v}{c}\right)^{2}-4.3551\left(\frac{v}{c}\right)+62.184 \\
& \operatorname{Avg} \operatorname{Speed}(\mathrm{mph})_{\mathrm{FFS}=55 \mathrm{mph}}=-6.4985\left(\frac{v}{c}\right)^{4}-10.795\left(\frac{v}{c}\right)^{3}+14.347\left(\frac{v}{c}\right)^{2}-3.226\left(\frac{v}{c}\right)+55.962 \\
& \operatorname{Avg} \operatorname{Speed}(\mathrm{mph})_{\mathrm{FFS}=50 \mathrm{mph}}=0.246\left(\frac{v}{c}\right)^{4}-14.159\left(\frac{v}{c}\right)^{3}+12.523\left(\frac{v}{c}\right)^{2}-2.4503\left(\frac{v}{c}\right)+49.729 \\
& \operatorname{Avg} \operatorname{Speed}(\mathrm{mph})_{\mathrm{FFS}=44 \mathrm{mph}}=-13.636\left(\frac{v}{c}\right)^{4}+20.225\left(\frac{v}{c}\right)^{3}-9.1272\left(\frac{v}{c}\right)^{2}+1.2136\left(\frac{v}{c}\right)+43.496
\end{aligned}
$$

Similar to the method used for freeways, the average speed was estimated using these equations based on the speed limit (used as free flow speed), AADT, peak-hour factor, directional flow split (applied to morning and afternoon peak-hours) and peak-hour capacity information from HPMS. If the volume-tocapacity ratio was larger than 1, the queue was tracked, and queue length and queue delay were calculated. The total travel time was calculated as the travel time (based on average speed estimated by one of the abovementioned equations) plus the queue delay. 


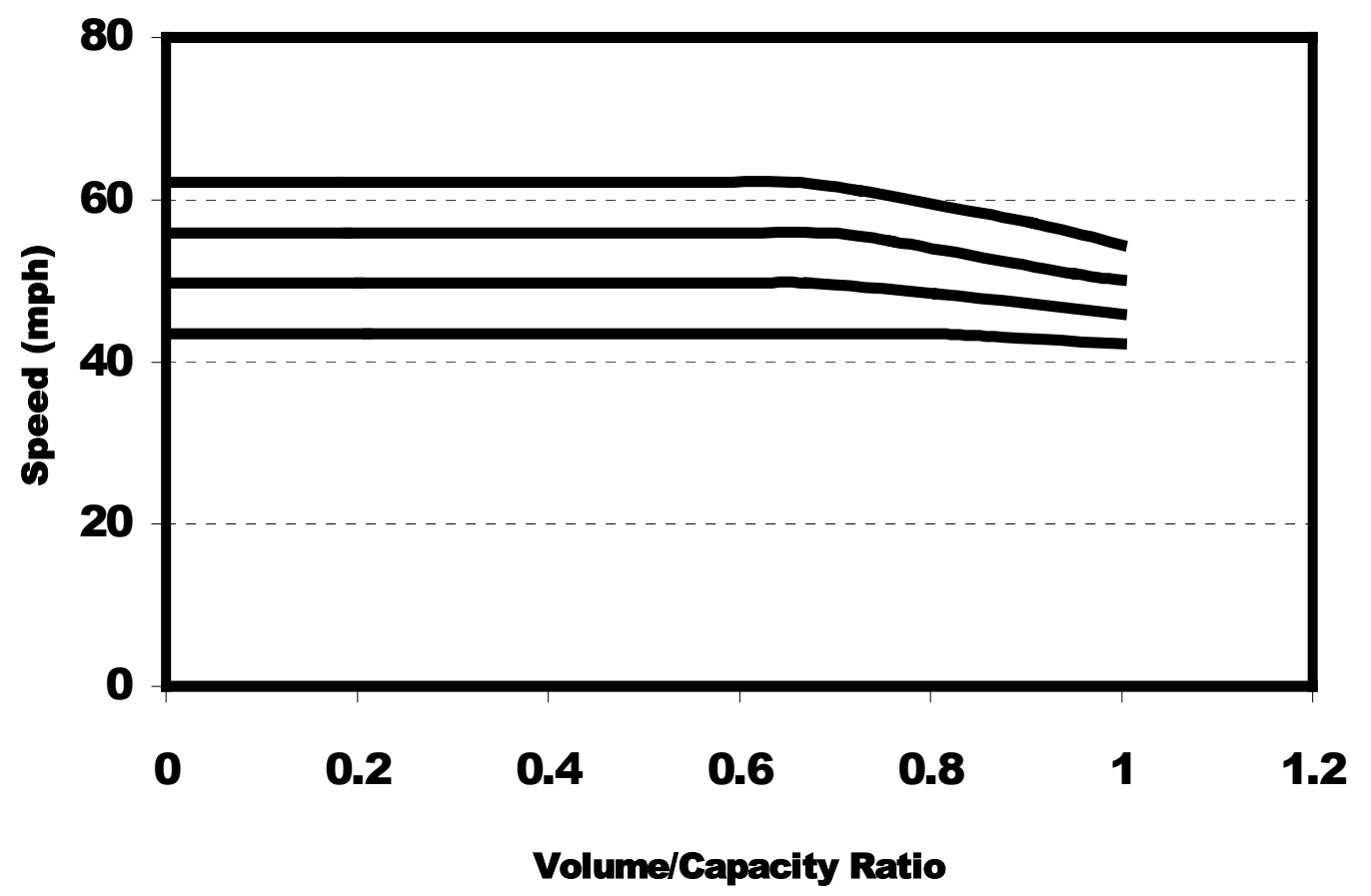

Fig. 15. Speed relationship to volume/capacity ratio for multi-lane freeways

Signal-Controlled Intersections: For principal arterials with signal-controlled intersections, the capacity for the arterial segment was calculated as the capacity at the signal-controlled intersections. Thus, average speed was dominated by the delay time at these signal-controlled intersections.

The methodology described in Section 7.1.2 "Estimating Total Delay for Signal-Controlled Intersections" was used to estimate total delay time at signal-controlled intersections during adverse weather conditions. If the volume-to-capacity ratio was larger than 1, queue was tracked and queue length and queue delay were calculated. The total travel time was calculated as the sum of the travel time (based on free flow speed), signal-controlled intersection delay time, and queue delay.

Stop-Sign-Controlled Intersections: For principal arterials with stop-sign-controlled intersections, the capacity for the arterial segment was calculated as the capacity of the stop-sign-controlled intersections. Thus, average speed was dominated by the delay time at these intersections.

The delay experienced by a motorist is made up of a number of factors that relate to control, geometry, traffic, and incidents. Total delay is the difference between the travel time actually experienced and the reference travel time that would result during ideal conditions, in the absence of incident, control, traffic, or geometric delay. This study quantifies only that portion of total delay attributed to traffic control measures (i.e., either traffic signals or stop signs). This delay is called control delay. Control delay includes initial deceleration delay, queue move-up time, stopped delay, and final acceleration delay. With respect to field measurements, control delay is defined as the total elapsed time from when a vehicle stops at the end of the queue until the vehicle departs from the stop line. This total elapsed time includes the time required for the vehicle to travel from the last-in-queue position to the first-in-queue position, including deceleration of vehicles from free-flow speed to the speed of vehicles in queue.

Average control delay for any particular minor movement is a function of the capacity of the approach and the degree of saturation. The analytical model used to estimate control delay (Equation 22) assumes that the demand is less than capacity for the period of analysis. In situations where the degree of saturation is greater than about 0.9 , average control delay is significantly affected by the length of the 
analysis period. In most cases, the recommended analysis period is 15 minutes. If demand exceeds capacity during a 15-minute period, the delay results calculated by the procedure may not be accurate. In this case, the period of analysis should be lengthened to include the period of over-saturation.

The constant value of 5 seconds/vehicle is included in Equation 22 to account for the deceleration of vehicles from free-flow speed to the speed of vehicles in queue and the acceleration of vehicles from the stop line to free-flow speed.

$$
d=\frac{3600}{c_{m, x}}+900 T\left[\frac{v_{x}}{c_{m, x}}-1+\sqrt{\left(\frac{v_{x}}{c_{m, x}}-1\right)^{2}+\frac{\left(\frac{3600}{c_{m, x}}\right)\left(\frac{v_{x}}{c_{m, x}}\right)}{450 T}}\right]+5
$$

where

$$
\begin{aligned}
d & =\text { stop sign control delay in } \frac{\text { secs }}{\text { veh }} \\
v_{x} & =\text { flow rate for movement } x \text { in } \frac{\text { vehs }}{\text { hour }} \\
c_{m, x} & =\text { capacity of movement } x \text { in } \frac{\text { vehs }}{\text { hour }} \\
T & =\text { analysis time period in hours }(T=0.25 \text { for a } 15 \text { - minute period })
\end{aligned}
$$

If the volume-to-capacity ratio was larger than 1, the queue was tracked, and queue length and queue delay were calculated. The total travel time was calculated as the travel time based on free flow speed, stop sign controlled intersection delay time, plus the queue delay.

To estimate the delay due to adverse weather conditions, the normal delay (congestion delay without the adverse weather condition) for roadways in each county during the time of the event was estimated. The delay with adverse weather conditions for roadways in each county during the time of the event was then estimated. This was accomplished by repeating the same delay estimation step with the appropriate capacity reduction for the event type. If the link average speed was greater than the typical travel speed for that event, the delay was calculated at that speed. Otherwise, the delay was not adjusted. The delay induced by adverse weather conditions for each county was calculated as the difference in the estimated delay with the adverse weather condition and the estimated delay without the adverse weather condition. The delay induced by adverse weather conditions was then calculated for each public forecast zone as the sum of the delay for all involved counties multiplied by the percentage of each county's major arterial mileage lying within the public forecast zone. These estimates were summed to produce a national total.

\subsection{RESULTS}

Capacity losses and delays due to three kinds of weather that affect highway travel were estimated: fog, snow, and ice. All three of these weather conditions are similar in the fact that they reduce visibility and/or vehicle traction, causing drivers to reduce speeds and increase following distances. Due to time and funding limitations, capacity losses and delays due to rain were not included in the study. The study also does not consider any trip re-scheduling or canceling behavior in its delay estimates. 
The TLC study estimated that, in 1999, fog, snow, and icy conditions reduced capacity on freeways and principal arterials by approximately 24 billion vehicles. This resulted in an estimated 543.9 million vehicle-hours of delay. Most of this estimated delay (90 percent) was due to snow in urban areas. Icy conditions accounted for 7 percent of the estimated delay from these weather conditions, and fog accounted for about 3 percent.

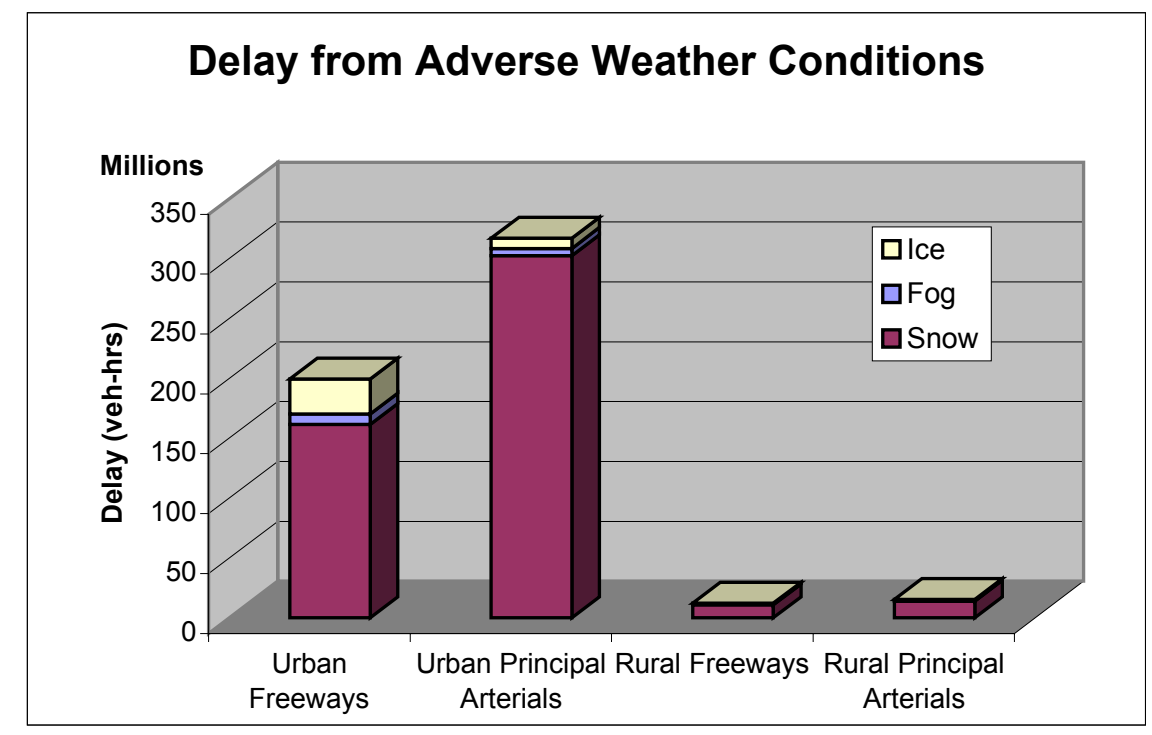

Fig. 16. Most delay from adverse weather conditions was experienced in urban areas

Table 21. Capacity loss $\&$ delay due to adverse weather conditions

\begin{tabular}{lrrrr}
\hline Impact/Highway Type & \multicolumn{1}{c}{ Fog } & \multicolumn{1}{c}{ Snow } & \multicolumn{1}{c}{ Ice } & \multicolumn{1}{c}{ All } \\
\hline No. of Events & 76 & 1,326 & 100 & 1,502 \\
Licensed Drivers Impacted & $24,048,405$ & $106,942,050$ & $26,107,731$ & $157,098,187$ \\
\hline Capacity Reduction (million & & & & \\
vehicles) & & & & \\
Urban Freeways & 247.8 & $3,226.2$ & 246.0 & $3,720.1$ \\
Urban Principal Arterials & 622.1 & $7,406.3$ & 453.4 & $8,481.8$ \\
Rural Freeways & 151.1 & $3,698.3$ & 250.5 & $4,100.0$ \\
Rural Principal Arterials & 372.3 & $6,915.0$ & 370.5 & $7,657.7$ \\
Total Capacity Reduction & $1,393.4$ & $21,245.8$ & $1,320.4$ & $23,960.0$ \\
\hline Delay (million vehicle-miles) & & & & \\
Urban Freeways & 8.8 & 161.5 & 29.3 & 199.5 \\
Urban Principal Arterials & 6.1 & 302.4 & 8.6 & 317.1 \\
Rural Freeways & 0.5 & 10.9 & 0.7 & 12.1 \\
Rural Principal Arterials & 0.5 & 14.0 & 0.7 & 15.2 \\
Total Delay & 15.8 & 488.7 & 39.4 & 543.9 \\
Delay per Impacted Driver (hrs) & 0.66 & 4.57 & 1.51 & 3.46 \\
\hline
\end{tabular}

\subsubsection{Capacity Losses \& Delay Due to Fog}

It is estimated that, in 1999, fog caused a loss of capacity of about 1.4 billion vehicles on freeways and principal arterials. These losses in capacity resulted in an estimated total of 15.8 million hours of vehicle delay on freeways and principal arterials. Most of this estimated delay (94 percent) was experienced in urban areas, and most was in the form of queue delay. 
Table 22. Capacity losses and delay due to fog

\begin{tabular}{lccrrr}
\hline & Urban & Urban Principal & Rural & Rural \\
Principal & \\
Impact & Freeways & Arterials & Freeways & Arterials & \multicolumn{1}{c}{ All } \\
\hline Delay (million vehicle-hrs) & 0.9 & 0.2 & 0.5 & 0.5 & 2.1 \\
Queue Delay (vehicle-hrs) & 7.9 & 5.8 & 0.0002 & 0 & 13.8 \\
Total Delay (vehicle-hrs) & 8.8 & 6.1 & 0.5 & 0.5 & 15.8 \\
\hline Total Capacity Loss (veh) & 247.8 & 622.1 & 151.1 & 372.3 & $1,393.4$ \\
\hline
\end{tabular}

\subsubsection{Capacity Losses \& Delay Due to Snow}

It is estimated that, in 1999, snowy conditions caused a loss of capacity of about 21.2 billion vehicles on freeways and principal arterials. These losses in capacity resulted in an estimated total of 488.7 million hours of vehicle delay on freeways and principal arterials. Most of this estimated delay (95 percent) was experienced in urban areas, and most was in the form of queue delay.

Table 23. Capacity losses and delay due to snow

\begin{tabular}{lcrrrr}
\hline & Urban & Urban Principal & Rural & Rural Principal & \\
Impact & Freeways & Arterials & Freeways & Arterials & \multicolumn{1}{c}{ All } \\
\hline Delay (million vehicle-hours) & 14.6 & 3.5 & 1.0 & 13.2 & 41.2 \\
Queue Delay (million vehicle-hours) & 147.0 & 298.9 & 0.9 & 0.8 & 447.5 \\
Total Delay (million vehicle-hours) & 161.5 & 302.4 & 10.9 & 13.9 & 488.7 \\
\hline Total Capacity Loss (million & $3,226.2$ & $7,406.3$ & $3,698.3$ & $6,915.0$ & $21,245.8$ \\
vehicles) & & & & & \\
\hline
\end{tabular}

\subsubsection{Capacity Losses \& Delay Due to Ice}

It is estimated that, in 1999, icy conditions caused a loss of capacity of about 1.3 billion vehicles on freeways and principal arterials. These losses in capacity resulted in an estimated total of 39.4 million hours of vehicle delay on freeways and principal arterials. Most of this estimated delay (96 percent) was experienced in urban areas, most of which was in the form of queue delay.

Table 24. Capacity losses and delay due to ice

\begin{tabular}{lccccr}
\hline & Urban & Urban Principal & Rural & Rural Principal & \\
Impacts & Freeways & Arterials & Freeways & Arterials & \multicolumn{1}{c}{ All } \\
\hline Delay (million vehicle-hours) & 1.1 & 0.4 & 0.6 & 0.6 & 2.7 \\
Queue Delay (million vehicle-hours) & 28.2 & 8.2 & 0.1 & 0.1 & 36.7 \\
Total Delay (million vehicle-hours) & 29.3 & 8.7 & 0.7 & 0.7 & 39.4 \\
\hline Total Capacity Loss (million & & & & & \\
vehicles) & 246.0 & 453.4 & 250.5 & 370.5 & $1,320.4$ \\
\hline
\end{tabular}




\section{SUB-OPTIMAL SIGNAL TIMING}

\subsection{METHODOLOGY}

Capacity reduction and delay on principal arterials due to sub-optimal signal control were estimated using a three-step process. The first step was to determine the number and type of signals on principal arterials. The next step was to estimate the total vehicle delay at these intersections, since traffic signals cause delay in comparison to free-flowing traffic. However, most of this delay is un-avoidable. The third step was to estimate the avoidable delay due to sub-optimal signal timing. Delay due to sub-optimal signal timing was estimated as a percent of the total delay based on evidence from the literature. Capacity reduction was calculated in a similar manner. However, since HPMS provides capacity estimates, it was not necessary to estimate intersection capacities.

The primary data source for estimating signal control delay was the HPMS Sample Database. The HPMS Sample Database contains the following information used to calculate traffic signal delays:

- Annual Average Daily Traffic (AADT)

- Directional Factor

- Prevailing Type of Signalization

- Typical Peak Percent Green Time

- Number and Type of At-Grade Signal-Controlled Intersections

- Peak Capacity

- Volume/Service Flow Ratio (V/SF)

Other data sources used in this part of the study are noted in the methodology descriptions that follow.

\subsubsection{Identifying Signal-Controlled Intersections on Principal Arterials}

The HPMS Sample Database provides a count of the number of intersections and traffic controls on the nation's roadways. These include at-grade intersections at entrances to shopping centers, industrial parks, and other large traffic-generating enterprises. The database also provides information on the type of signal control used at each intersection. Expansion factors were applied to the totals from the Sample Database to estimate the number of signal-controlled intersections on principal arterials (see Table 25 in Section 7.2.1).

\subsubsection{Estimating Total Delay for Signal-Controlled Intersections}

Delay at signal-controlled intersections on principal arterials was estimated based on a methodology outlined in the Highway Capacity Manual 2000. According to Chapter 16 in the manual, the average delay per vehicle for a lane group at a controlled intersection is given by the following equation:

$$
d=d_{1} \times P F+d_{2}+d_{3}
$$

where

$\mathrm{d}=\quad$ control delay per vehicle (seconds/vehicle)

$\mathrm{d}_{1}=$ uniform control delay, assuming uniform arrivals (seconds/vehicle)

$\mathrm{PF}=$ uniform delay progression adjustment factor that accounts for the effects of signal progression

$\mathrm{d}_{2}=$ incremental delay to account for the effect of random and over-saturation queues, adjusted for the duration of the analysis period and the type of signal control (seconds/vehicle). This delay component assumes that there is no residual demand for the lane group at the start of the analysis period. 
$\mathrm{d}_{3}=\quad$ supplemental delay to account for over-saturation queues that may have existed prior to the analysis period (seconds/vehicle)

Thus, the total control delay per vehicle was the sum of the uniform control delay, the incremental delay, and the supplemental delay. Each of these was estimated on an hourly basis, using time-of-day

distributions for a week. Daily average delay was calculated and multiplied by 365 to calculate the delay for an entire year. The methods used to estimate each type of delay are described in the following sections.

\section{Uniform Delay}

The next equation gives an estimate of delay, assuming uniform arrivals, stable flow, and no initial queue. It is based on the first term of the delay formulation suggested in the Highway Capacity Manual 2000 and is widely accepted as an accurate depiction of delay for the idealized case of uniform arrivals.

$$
d_{1}=\frac{0.50 C(1-g / C)^{2}}{1-[\min (1, X) g / C]}
$$

where

$\mathrm{d}_{1}=$ uniform control delay, assuming uniform arrivals (seconds/vehicle)

$\mathrm{C}=\quad$ cycle length (seconds). Cycle length is used for pre-timed signal control; average cycle length is used for estimating actuated control parameters.

$\mathrm{g}=\quad$ effective green time for a lane group (seconds). Green time is used for pre-timed signal control; average lane group effective green time is used for actuated control.

$\mathrm{X}=\quad$ volume/capacity ratio or degree of saturation for a lane group

Effective green time and capacity were obtained from HPMS Sample Data. The volume data used in the volume/capacity ratio was calculated by applying a time-of-day distribution to the AADT data given in HPMS. For urban intersections, this distribution was based on a study of four cities: San Antonio, Texas; Milwaukee, Wisconsin; San Diego, California; and Seattle, Washington (see footnote 4 on page 17). For rural intersections, the distribution was based on hourly traffic counts in the state of Tennessee (T.DOT, ????). Cycle length was calculated based on a methodology described in Revised Monograph on Traffic Flow Theory (U.S. DOT/FHWA, 1997).

As shown in equation 23, uniform delay $\left(\mathrm{d}_{1}\right)$ is adjusted using a uniform delay progression adjustment factor (PF) that accounts for the effects of signal progression. A suggestion of the Highway Capacity Manual 2000 was followed in using a progression adjustment factor based of Arrival Type 3 (AT-3) for uncoordinated lane groups and Arrival Type 4 (AT-4) for coordinated lane groups. These guidelines are provided for planning situations where the arrival characteristics cannot be directly observed. Thus, they should be suitable for our purposes.

\section{Incremental Delay}

The next equation was used to estimate the incremental delay due to non-uniform arrivals and temporary cycle failures (random delay), as well as delay caused by sustained periods of over-saturation (oversaturation delay). Such delay is sensitive to the degree of saturation of the lane group (X), the duration of the analysis period (T), the capacity of the lane group (c), and the type of signal control, as reflected by the control parameter $(\mathrm{k})$. The equation assumes that there is no unmet demand that causes residual queues at the start of the analysis period $(\mathrm{T})$. 


$$
d_{2}=900 T\left[(X-1)+\sqrt{(X-1)^{2}+\frac{8 k l X}{c T}}\right]
$$

where

$\mathrm{d}_{2}=$ incremental delay to account for the effect of random and over-saturation queues, adjusted for the duration of the analysis period and the type of signal control (seconds/vehicle). This delay component assumes that there is no residual demand for the lane group at the beginning of the analysis period.

$\mathrm{T}=\quad$ duration of analysis period (hours)

$\mathrm{k}=$ incremental delay factor that is dependent on controller settings

$1=$ upstream filtering/metering adjustment factor

c $\quad=\quad$ lane group capacity (vehicles/hour)

$\mathrm{X}=\quad$ lane group volume/capacity ratio or degree of saturation

Since delay was calculated on an hourly basis in this study, $T$ was equal to 1 . The upstream filtering/metering adjustment factor (1) was also set to 1 , because there is no information that would allow it to be calculated. The incremental delay factor $(\mathrm{k})$ was set to 0.5 for pre-timed control, the value suggested by the Highway Capacity Manual 2000. The incremental delay factor for actuated control was based on the extension value and the degree of saturation and ranged from 0.04 to 0.5 . The degree of saturation was taken from HPMS. Since timing plans for each signal are not available, an extension of 3 seconds was assumed for actuated controls. This yielded $\mathrm{k}$ values ranging from 0.11 to 0.50 .

\section{Supplemental Delay}

When a residual demand from a previous time period causes a residual queue to occur at the start of the analysis period $(\mathrm{T})$, additional delay is experienced since the residual queues must clear the intersection first. A procedure to determine this supplemental delay is described in detail in Appendix $\mathrm{F}$ of the Highway Capacity Manual 2000. This procedure is also extended to analyze delay over multiple time periods where a residual demand may be carried from one time period to the next. Due to the lack of information on queue formation, a value of zero was used for supplemental delay $\left(\mathrm{d}_{3}\right)$.

\subsubsection{Typical Delay Associated with Inadequate Signal Timing}

According to the Institute of Transportation Engineers (ITE), there are about 300,000 traffic signals in the United States. Over 75 percent of these signals could easily be improved by updating equipment or by simply adjusting their timing. The total number of signal-controlled intersections specified in this ITS study is consistent with the total number of signal-controlled intersections estimated based on HPMS Sample Database.

According to FHWA's Arterial Management Benefits database, approximately 15-20 percent delay reductions can be achieved by signal-timing updates and/or improvements. Up to 40 percent delay reduction can be achieved by implementing automated signal control. This study based its estimates of delay due to sub-optimal signal timing on the percentage of delay reduction that can be realized from improving signal timing.

In order to be conservative in estimating delays, the TLC study assumed signal timing to be inadequate at 50 percent of signals, rather than the 75 percent estimated by ITE. Furthermore, it was assumed that a 15 
percent reduction in delay could be achieved by correcting these signals. This is at the lower end of the range estimated by the FHWA Arterial Management Benefits database.

\subsubsection{Typical Capacity Loss Associated with Inadequate Signal Timing}

According to the ITS Deployment Analysis System (IDAS) User's Manual (Cambridge Systematics, Inc., 2001), updated and improved signal timing can increase capacity at signal-controlled intersections by about 8-23 percent. The amount of improvement depends on traffic condition, time since the last signaltiming update, and intersection densities. This study assumed that signal control could be improved on 50 percent of the signals and that a 10 percent increase of intersection capacity could be achieved. Again, the assumptions were intended to be conservative.

\subsection{RESULTS}

\subsubsection{Delay Due to Sub-optimal Signal Control}

Based on HPMS data, this study estimates that, in 1999, the nation's highway system employed signalized control at 306,177 intersections, 106,859 of which were utilized on principal arterials (Table 25). The delay from sub-optimal signal controls on principal arterial intersections is estimated at 296.4 million vehicle-hours (Table 26). As expected, the lion's share of this delay (over 97 percent) occurs on urban principal arterials since urban streets contain more signalized intersections.

Table 25. Number of signals on principal arterials nation-wide, 1999

\begin{tabular}{lcrrrr}
\hline \multirow{2}{*}{ Highway Type } & \multicolumn{5}{c}{ Signal Type } \\
\cline { 2 - 6 } & Fixed Time & Actuated & Coordinated & Unknown & \multicolumn{1}{c}{ Total } \\
\hline Rural Principal Arterials & 466 & 688 & 79 & 3,004 & 4,237 \\
Urban Principal Arterials & 29,345 & 46,433 & 26,841 & 3 & 102,622 \\
All Principal Arterials & 29,811 & 47,121 & 26,920 & 3,007 & 106,859 \\
All Roads & 99,614 & 133,423 & 61,649 & 111,491 & 306,177 \\
\hline
\end{tabular}

Table 26. Delay associated with sub-optimal signal control, 1999 (million vehicle-hours)

\begin{tabular}{lccccr}
\hline \multirow{2}{*}{ Arterial Type } & \multicolumn{5}{c}{ Signal Control Type } \\
\cline { 2 - 6 } & Fixed Time & Actuated & Coordinated & Unknown & Total \\
\hline Rural Principal Arterials & 0.7 & 0.9 & 0.1 & 6.5 & 8.2 \\
Urban Principal Arterials & 87.5 & 139.6 & 61.2 & 0.0006 & 288.2 \\
All Principal Arterials & 88.1 & 140.4 & 61.3 & 6.6 & 296.4 \\
\hline
\end{tabular}

\subsubsection{Capacity Losses Due to Sub-optimal Signal Control}

The TLC study estimates capacity loss on principal arterials due to sub-optimal signal control was about 173 billion vehicles in 1999 (Table 27). Again, about 96 percent of this reduction occurs on urban principal arterials. Capacity losses estimated for signal timing are much larger than capacity losses associated with crashes and vehicle breakdowns. This is because capacity losses at signal-controlled intersections occur 24 hours a day 365 days a year, regardless of demand. Therefore, these reductions occur but have little actual impact. The durations for the capacity losses associated with crashes and vehicle breakdowns, on the other hand, are much shorter, and they often coincide with high traffic volumes. 
Table 27. Capacity loss on principal arterials due to sub-optimal signal control, 1999 (million vehicles)

\begin{tabular}{lrrrrr}
\hline \multirow{2}{*}{ Arterial Type } & \multicolumn{5}{c}{ Signal Control Type } \\
\cline { 2 - 6 } & Fixed Time & Actuated & Coordinated & Unknown & \multicolumn{1}{c}{ Total } \\
\hline Rural Principal Arterials & 675 & 1,071 & 104 & 4,857 & 6,706 \\
Urban Principal Arterials & 39,978 & 77,296 & 48,873 & 5 & 166,150 \\
All Principal Arterials & 40,653 & 78,367 & 48,977 & 4,861 & 172,856 \\
\hline
\end{tabular}




\section{RESULTS SUMMARY}

\subsection{RESULTS}

Temporary capacity losses due to work zones, crashes, breakdowns, adverse weather, and sub-optimal signal timing resulted in an estimated 2.3 billion vehicle-hours of delay on U.S. freeways and principal arterials in 1999 (Fig. 17, Table 28). Assuming an average vehicle occupancy of 1.6 persons, this translates into 3.7 billion person-hours of delay. Assuming an average value of time of $\$ 15$ per hour for each person impacted, temporary capacity losses produced $\$ 55$ billion in lost time alone in 1999 . Because conservative assumptions have been used throughout this analysis, and because several significant sources of delay have not been included, these estimates are believed to be a lower bound on the actual impacts of TLC.

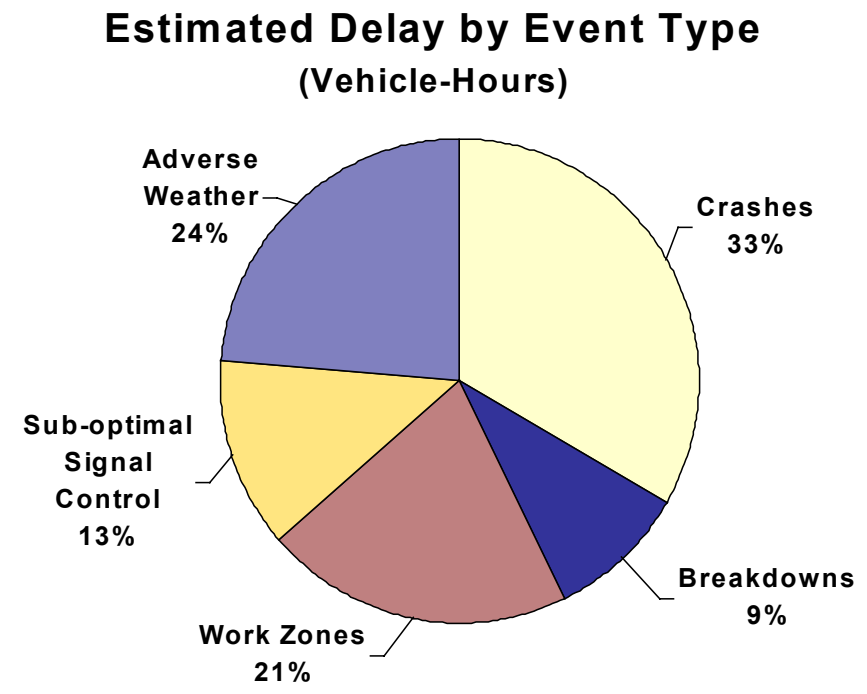

Fig. 17. Estimated delay by event type

Table 28. Summary of capacity loss and delay estimates for freeways and principal arterials*

\begin{tabular}{lcccr}
\hline Event & $\begin{array}{c}\text { Total Capacity } \\
\text { (billion vehicles) }\end{array}$ & $\begin{array}{c}\text { Total Delay } \\
\text { (million veh-hours) }\end{array}$ & $\begin{array}{c}\text { Delay/Driver } \\
\text { (hours) }\end{array}$ & $\begin{array}{c}\text { Delay/Event } \\
\text { (hours) }\end{array}$ \\
\hline Crashes & 1.9 & 772.6 & 4.1 & 289.5 \\
Breakdowns & 5.9 & 217.1 & 1.2 & 10.2 \\
Work Zones ${ }^{*}$ & 3.1 & 482.1 & 2.6 & $824,023.2$ \\
Adverse Weather & 24.0 & 543.9 & 2.9 & $362,117.2$ \\
Signal Timing & 172.9 & 296.4 & 1.6 & $2,773.7$ \\
Total & 207.8 & $2,312.1$ & 12.4 & 95.8 \\
Non-recurring Delay & 34.9 & $2,015.7$ & 10.8 & 83.9 \\
\hline
\end{tabular}

* Work zone estimates only include capacity loss and delay on freeways; they do not include delay on principal arterials.

Crashes were estimated to be the event causing the most delay, followed by adverse weather. Because work zone delay has been underestimated, it is possible that it was responsible for more delay than weather and even crashes. However, a more complete set of data on work zones would be needed to improve this estimate. 


\subsection{COMPARING TLC RESULTS TO OTHERS}

This study has broken new ground in developing the first "bottom-up," nationwide estimates of temporary losses of highway capacity and resulting delay. In the course of the research, much has been learned about both data sources and methodologies that can be applied to improve and expand information about TLC impacts.

The next phase of research will estimate additional sources of delay that time and resources precluded from this first phase of research. These sources include highway work zones not included in the first phase, tollbooth operations, at-grade railroad crossings, weather events such as rain and flooding, nearroad utility work zones, and trucks loading/unloading in commercial districts. Also, for crashes at intersections, delay on transversal roadway segments will be estimated.

The TLC estimates of delay per licensed driver were also compared to similar estimates derived from TTI study results. TTI estimated an annual total delay of 3.6 billion vehicle-hours for the 68 cities in its study for 1999. Of this total, 1.7 billion vehicle-hours were estimated as recurring delay and 1.9 billion vehiclehours were estimated to be non-recurring delay (The 2001 Urban Mobility Report, Table A-6). Since the population total for these cities is 124.4 million, this averages to 36 hours of delay per person.

Assuming the percent of licensed drivers in the study is the same as for the U.S. population, these estimates can be used to calculate the delay per licensed driver. The U.S. Census estimates the population at 272.7 million as of July 1999, and FHWA estimates that there were 187.2 million licensed drivers in the United States that year. This would indicate that there were roughly 85.4 million drivers for the 68 cities in the TTI study (Fig. 18). Using this estimate, the TTI study indicates an annual average of 42 hours of delay per driver, 19.4 hours of recurring delay and 22.7 hours of non-recurring delay. The TLC study estimates that events within the scope of the study resulted in 12.4 hours of delay per licensed driver. Since all events other than signal timing can be considered non-recurring, delay per licensed driver for non-recurring delays was estimated as 10.8 hours. One would expect average delay per driver to be higher in the larger cities than for the nation as a whole. Thus, these indicators also suggest that the results of the TLC study are roughly consistent with TTI's data.

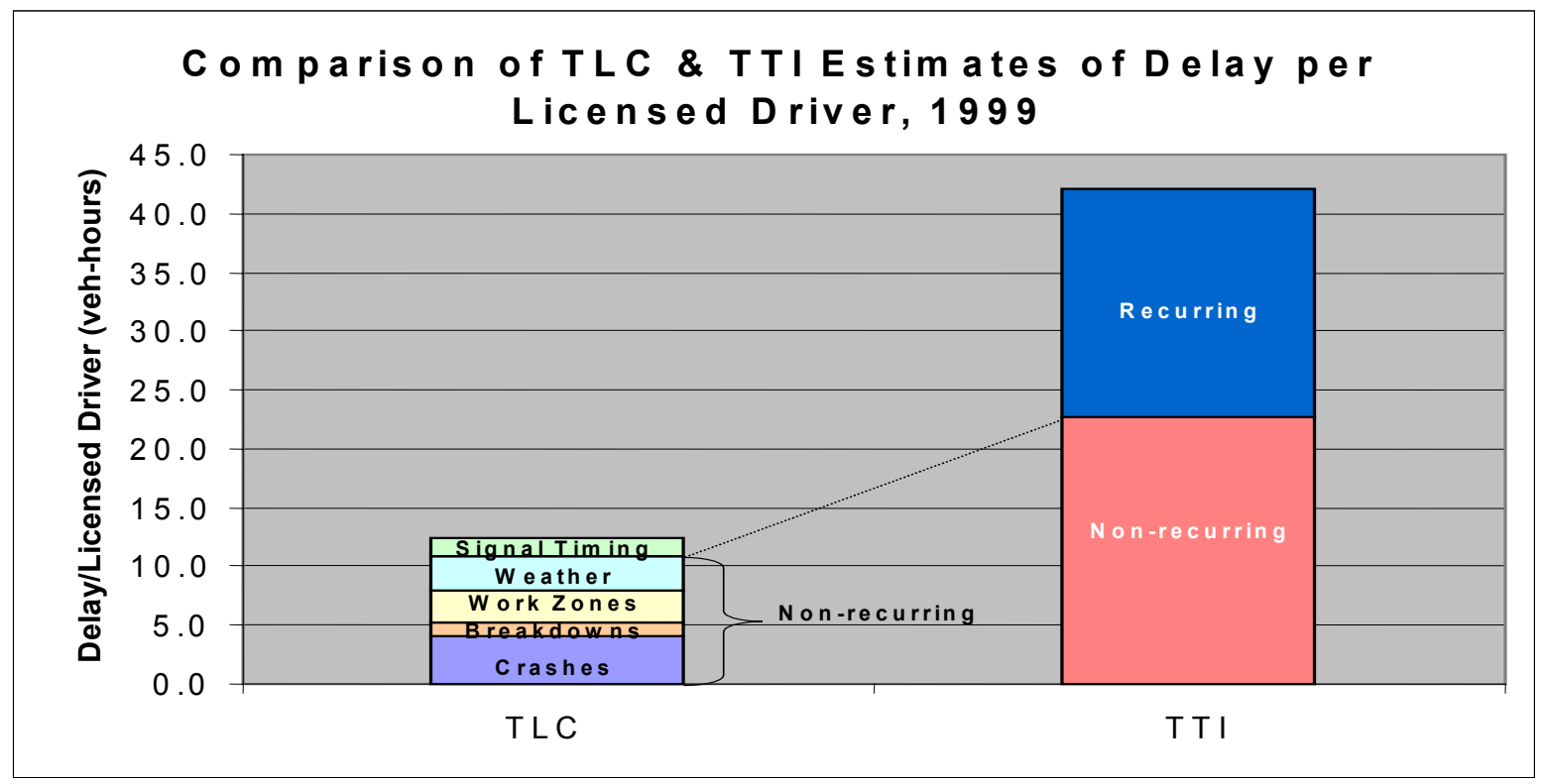

Fig. 18. TLC estimates of delay per licensed driver compared to TTI estimates 


\section{NEXT STEPS}

The TLC study represents an initial attempt to estimate the loss of capacity and delay due to short-term events. Due to the scope of the study, time and effort constraints, and limitations in available data, there are areas in which TLC delay estimates can be significantly improved or expanded. This chapter discusses further activities that would improve the initial estimates.

\subsection{IMPROVE WORK ZONE ESTIMATES}

Currently, the estimates of delay due to work zones are incomplete. During the study, significant limitations were discovered in the Rand McNally construction zone data that was used to estimate work zone delay. The Rand McNally database is a "rolling" database, and it is not archived. Thus, historical data is deleted. Resource limitations also affect the thoroughness of the data. In particular, the database does not always capture short-term work zones or the majority of work zones on highway types other than freeways. Also, data for work zones that are scheduled to begin more than 3-4 months in the future are far less complete.

FHWA's FMIS data was obtained and evaluated as an alternate or complimentary source of information on work zone characteristics. Initial review of the data suggests that it is a more comprehensive inventory of work zones and their general characteristics. Future research should use this data set to produce more compete estimates of work zone delay.

\subsection{EXPAND WEATHER ESTIMATES}

Due to time and resource constraints, it was not possible to estimate the impacts of some adverse weather events, such as rain and flooding. It would be useful to estimate the delay from these events so that the estimates of weather-induced delays would be more complete.

\subsection{ADDITIONAL SOURCES OF DELAY}

The next phase of research will estimate additional sources of delay that time and resources precluded from this first phase of research. These sources include highway work zones not included in the first phase, tollbooth operations, at-grade railroad crossings, near-road utility work zones, and trucks loading/unloading in commercial districts. Also, for crashes at intersections, delay on transversal roadway segments will be estimated.

\subsection{DELPHI SURVEY}

A number of assumptions were made in the TLC study, some of which affected the methodologies and some of which affected equation parameters. Because of uncertainties about many of the key parameters of this analysis, it would be useful to conduct a Delphi survey of traffic engineers and other experts regarding the values they believe are correct. In addition to improving assumptions for key variables in the current methodology, the results of the Delphi survey could be used to determine distributions of values for sensitivity analysis. 


\subsection{SENSITIVITY ANALYSES}

The national-level scope of the TLC study and its novelty made it necessary to make a large number of assumptions regarding key parameters. Confidence in the resulting estimates could be greatly increased by performing a sensitivity analysis to determine which variables most affect capacity loss and delay estimates.

\subsection{METHODS FOR ESTIMATING THE 4 RS}

As stated often in this report, the TLC study did not attempt to assess impacts of re-routing, rescheduling, reduced mobility, and reduced reliability on delay. Analytical methods for estimating rerouting, rescheduling, reduced mobility, and reduced reliability should be developed to give a more complete and accurate analysis of TLC impacts.

\subsection{ASSESS POLICY AND TECHNOLOGY IMPACTS}

At present, the TLC study attempts to estimate only the quantity or magnitude of delay from temporary losses of capacity. Of greater significance for policy decision-making would be estimates of the potential benefits of various policy and technology alternatives, such as work zone management strategies, electronic toll technologies, and other alternatives, that may reduce capacity losses and their impacts.

\subsection{METHODOLOGY IMPROVEMENTS}

During the TLC study, several areas in which the initial methodologies could be improved were identified:

- Using probability distributions to assign incident duration instead of using mean duration

- Obtaining more information about crashes on arterials and adjust the methodology to compute delays accordingly

- For crashes at intersections, estimating the impacts on transversal roadway segments

- Including the effects of crossover work zones, where the capacity of lanes in the other direction are affected by the construction

- Improving the delay estimation methodology by considering demand reductions downstream of a capacity-reducing event

- Developing methodologies for estimating delay and capacity losses from tollbooths and at-grade railroad crossings.

- Using stochastic network simulation models to validate the deterministic delay calculation

\subsection{DATA IMPROVEMENTS}

The completeness and reliability of TLC estimates could be improved by using, compiling, and/or collecting additional data. 


\subsubsection{Improvements in Current Data}

- Use FMIS to estimate delay and capacity loss due to highway work zones

- Refine data for demand distribution multipliers for freeways and generate demand distribution multipliers for arterials instead of using freeway distributions as a surrogate.

- Several other data sources for crashes and breakdowns on freeways were used as a surrogate for arterials. These data need to be validated for arterials or new data sources need be identified.

- Collect more data on delay and capacity loss estimation due to vehicle breakdowns. This could also lead to methodology improvements.

- Use fatal crash data from FARs for crashes on principal arterials rather than using the GES data. (GES crashes are currently assigned to locations using Monte Carlo simulation techniques and must be extrapolated.)

- Further study of the Monte Carlo simulations used with GES data to estimate delay and capacity loss due to non-fatal crashes should be performed.

\subsubsection{Expand Data Scope}

- Collect data necessary to estimate delay and capacity reduction due to toll booth operations

- Collect data necessary to estimate delay and capacity reduction due to at-grade railroad crossings

\subsection{CONSIDER PUBLISHING TLC STUDY AS AN ANNUAL REPORT}

The TLC study methodology could be used to produce an annual report on delays due to temporary capacity losses. A historical time series of nation-wide delay due to TLC could also be estimated. 


\section{REFERENCES}

American Trucking Association and Cambridge Systematics, Inc. 1991. Incident Management: Challenges, Strategies, and Solutions for Advancing Safety and Roadway Efficiency.

Aron, M., M. Ellenerg, and P. Veyre 1994. "Weather Related Traffic Management," Towards an Intelligent Transport System, Vol. 3, Proceedings of the First World Congress on Applications of Transport Telematics and Intelligent Vehicle-Highway Systems, Paris, November 30-December 3, pp. 1089-1096.

Blumentritt, C.W., D.W. Ross, J. Glazer, C. Pinnell, and W.R. McCasland 1981. Guidelines for Selection of Ramp Control Systems (NCHRP Report 232), Transportation Research Board, National Research Council, Washington DC., May.

Brilon, W., and M. Ponzlet. 1995. Auswirkungen on Zeitlich Veraenderlichen Leistungsfaehigkeiten, Schlussbericht. Lehrstuhl fur Verkeshrswesen, Ruhr Universitat Bochum.

Cambridge Systematics, Inc. 2001. ITS Deployment Analysis System (IDAS) - User's Manual. Oakland, California, November, (http://idas.camsys.com/documentation.htm).

Chin, S.M., A. A. Gibson, D. L. Greene, and H. L. Hwang 2000. "Real-time Indicators of Vehicle Kilometers of Travel And Congestion: One Year of Experience." Transportation Research Record No. 1719: Transportation Data, Statistics, and Information Technology, Transportation Research Board, National Research Council, Washington DC.

Chin, S. M., D. L. Greene, J. Hopson, H. L. Hwang, and B. Thompson 1999. “Toward National Indicators of Vehicle Travel And Traffic Congestion Based on Real-time Traffic Data," Transportation Research Record No. 1660, Part 2: Improving Transportation Data, Transportation Research Board, National Research Council, Washington DC.

Dixon, K.K., J.E. Hummer, and A.R. Lorscheider 1996. "Capacity for North Carolina Freeway Work Zones," Transportation Research Record 1529, Transportation Research Board, National Research Council, Washington DC, pp. 27-34.

Giuliano, G. 1989. "Incident Characteristics, Frequency, and Duration on a High Volume Urban Freeway," Transportation Research Part A: General 23(5), Transportation Research Board, National Research Council, Washington DC, pp 387-96.

Hogema, J.H., ARA Vanderhorst, and P.J. Bakker 1994. Evaluation of the 16 Fog-Signaling System with Respect to Driving Behaviour (Evaluatie Van Het a 16 Mistsignaleringssysteem in Termen Van Het Rijgedrag). Report TNO-TM 1994 C-48. TNO Technische Menskunde, Soesterberg, Netherlands.

Ibrahim, A., and F.L. Hall 1994. "Effect of Adverse Weather Conditions on Speed-Flow-Occupancy Relationships," Transportation Research Record 1457, Transportation Research Board, National Research Council, Washington DC, pp. 184-191.

Lamm, R., E.M. Choueiri, and T. Mailaender 1990. "Comparison of Operating Speeds on Dry and Wet Pavements of Two-Lane Rural Highways," Transportation Research Record 1280, Transportation Research Board, National Research Council, Washington DC, pp. 199-207. 
Shrank, D., and T. Lomax 2001. The 2001 Urban Mobility Study. Texas Transportation Institute (TTI), Texas A\&M University, College Station, Texas, May.

Skabardonis, A., T. Chira-Chavala, and D. Rydzewski 1998. The I-880 Field Experiment: Effectiveness of Incident Detection Using Cellular Phones, California PATH Research Report UCB-ITS-PRR-98-1 Report for MOU 119, January.

(T.DOT) Tennessee Department of Transportation. Average Daily Traffic data. Nashville, Tennessee.

Transportation Research Board 2000. Highway Capacity Manual. National Research Council, Washington DC.

Transportation Research Board 1985. Highway Capacity Manual, Special Report 209, National Research Council, Washington DC.

(U.S. DOT/FHWA) U.S. Department of Transportation, Federal Highway Administration 1997. Revised Monograph on Traffic Flow Theory. Ed. N. Gartner, C. Messer, and A. Rathi. Washington, DC,

November. Data taken from Chapter 9, Traffic Flow At Signalized Intersections, by N. Rouphail, A. Tarko, and J. Li.

(U.S. DOT/FHWA) U.S. Department of Transportation, Federal Highway Administration, a. Highway Performance Monitoring System (HPMS). (http://www.fhwa.dot.gov/ohim/hpmspage.htm).

(U.S. DOT/FHWA) U.S. Department of Transportation, Federal Highway Administration, b. Highway Statistics 2000 (http://www.fhwa.dot.gov/ohim/hs00/index.htm)

(U.S. DOT/FHWA) U.S. Department of Transportation, Federal Highway Administration, c. National Highway Planning Network (NHPN) Version 2.2. (http://www.fhwa.dot.gov/hep10/data/nhpntoc.html).

(U.S. DOT/NHTSA) U.S. Department of Transportation, National Highway Traffic Safety Administration 19XX. Fatality Analysis Reporting System (FARS) database, (http://wwwfars.nhtsa.dot.gov/main.cfm). 